\title{
Evaluation of heavy-duty engine exhaust hydrocarbon and non- methane hydrocarbon analysis methods
}

\author{
Abishek Muralidharan \\ West Virginia University
}

Follow this and additional works at: https://researchrepository.wvu.edu/etd

\section{Recommended Citation}

Muralidharan, Abishek, "Evaluation of heavy-duty engine exhaust hydrocarbon and non-methane hydrocarbon analysis methods" (2007). Graduate Theses, Dissertations, and Problem Reports. 1861. https://researchrepository.wvu.edu/etd/1861

This Thesis is protected by copyright and/or related rights. It has been brought to you by the The Research Repository @ WVU with permission from the rights-holder(s). You are free to use this Thesis in any way that is permitted by the copyright and related rights legislation that applies to your use. For other uses you must obtain permission from the rights-holder(s) directly, unless additional rights are indicated by a Creative Commons license in the record and/ or on the work itself. This Thesis has been accepted for inclusion in WVU Graduate Theses, Dissertations, and Problem Reports collection by an authorized administrator of The Research Repository @ WVU. For more information, please contact researchrepository@mail.wvu.edu. 


\title{
Evaluation of Heavy-Duty Engine Exhaust Hydrocarbon and Non-Methane Hydrocarbon Analysis Methods
}

\author{
Abishek Muralidharan \\ Thesis submitted to the \\ College of Engineering and Mineral Resources \\ at West Virginia University \\ in partial fulfillment of the requirements for the degree of \\ Master of Science
in
Mechanical Engineering \\ Gregory J. Thompson, Ph. D., Chair \\ Mridul Gautam, Ph. D. \\ Nigel N. Clark, Ph. D. \\ Department of Mechanical and Aerospace Engineering \\ Morgantown, West Virginia \\ 2007
}

Keywords: Hydrocarbon Analysis, Gas Chromatography 


\section{ABSTRACT \\ Evaluation of Heavy-Duty Engine Exhaust Hydrocarbon and Non-Methane Hydrocarbon Analysis Methods}

\section{Abishek Muralidharan}

The harmful environmental and health effects of automobile exhaust constituents have necessitated their regulation in many countries. The constituents of concern from diesel fueled engines are oxides of nitrogen $\left(\mathrm{NO}_{\mathrm{x}}\right)$, hydrocarbons (HC), carbon monoxide (CO) and particulate matter. Hydrocarbons combine with the oxides of nitrogen in a photochemical reaction, aided by sunlight, to form ozone which is a major constituent of smog. However methane does not aid in smog formation and is excluded from the present United States on-road hydrocarbon regulation.

Flame ionization detectors (FID) are the preferred detectors for hydrocarbon measurement from compression ignition internal combustion engines. Regulatory requirement for nonmethane hydrocarbon measurement involve the determination of total hydrocarbon using a FID-based analyzer and methane measurement using gas chromatographs (GC) and subtraction of these two values. New regulatory standards allow the use of non-methane cutter equipped analyzers for on-line determination of exhaust methane content.

The SAE J1151 standard GC method and an in-house GC method, incorporated at West Virginia University (WVU), were compared for correlation in methane measurements. The total hydrocarbon measurements from the WVU method were compared with bench analyzer results. A non-methane cutter equipped California Analytical Instruments (CAI) heated FID hydrocarbon analyzer capable of continuous methane measurements was evaluated for correlation with the SAE J1151 GC method. Day-to-day repeatability of the analyzer and SAE J1151 GC method was studied.

Good correlation was observed in the methane measurements by the two GC methods. The SAE J1151 GC methane measurements with natural gas samples were $5 \%$ lower than the WVU GC method results. A projection factor was determined to estimate THC concentration from methane concentration. The methane results from the two GC methods showed poor correlation for diesel-based fuel samples but the range of concentration in the values were within the drift limits of the detectors to make any inferences. The total hydrocarbon measurements from the WVU GC method had poor correlation with the analyzer results. The CAI HFID analyzer results agreed well with the results of the SAE J1151 GC method indicating its capabilities in methane measurement. The SAE J1151 GC method showed greater variability with transient exhaust emission test dilute bag samples but the results were within the allowable precision in the standard. The CAI analyzer showed good repeatability when tested with tunnel background samples. The Horiba total hydrocarbon analyzer showed increasing variations in day-to-day measurement in the repeatability tests. Due to the very small magnitude of brake specific methane values associated with diesel-based fuels the final brake specific NMHC concentration reported is not affected significantly by the method of methane analysis. 


\section{ACKNOWLEDGEMENTS}

First and foremost I would like to thank Dr. Gregory Thompson for being my research advisor and providing me with the opportunity to gain experience and knowledge in the field of engine emission testing, which will play a vital role in shaping my career. His guidance throughout my stint as a graduate research assistant has been invaluable and enlightening. I would also like to thank Dr. Mridul Gautam and Dr. Nigel Clark for being on my committee and their valuable inputs.

My special salutations go to Tom Spencer and David Estep for the support they've provided during my initial learning phase and during hard times at the laboratory. I am extremely thankful and grateful to Bradley Ralston for his help with my thesis research. John Nuzkowski's useful advices over the course of my research are worth mentioning. I also appreciate the help of the staff at ERC, friends and colleagues for any help, however small it may be, they have given me. Without these people this thesis would not be complete.

I salute my mom for her courage and willpower during testing times she faced in her life and her single-handed effort in shaping me into what I am today. I dedicate all my success to her. I thank my good friend Arvind Thruvengadam for all the support and good times from college to this day. Last but not the least I thank god for making my life so wonderful and memorable. 


\section{TABLE OF CONTENTS}

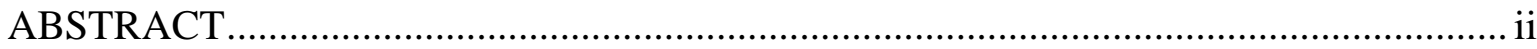

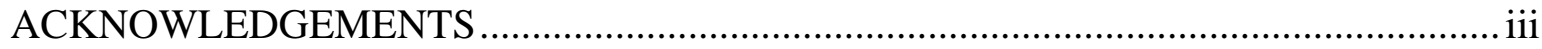

TABLE OF CONTENTS.......................................................................................... iv

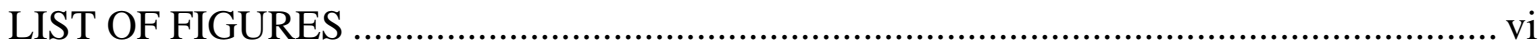

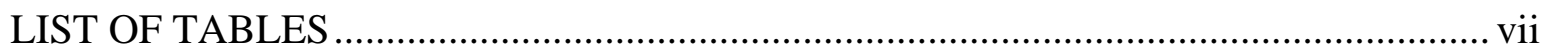

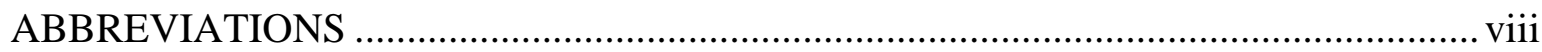

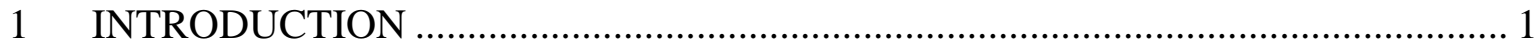

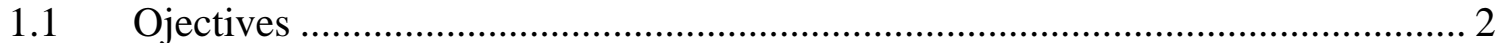

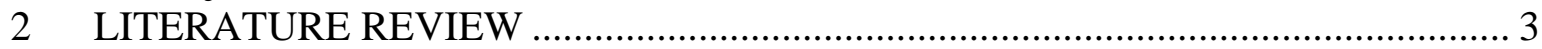

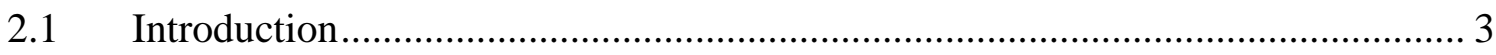

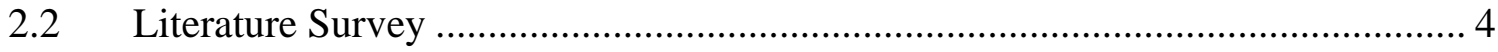

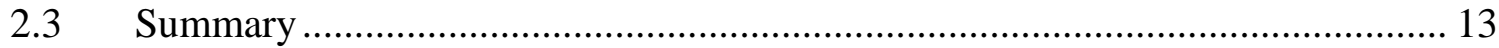

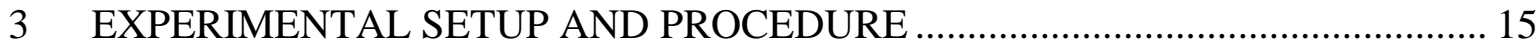

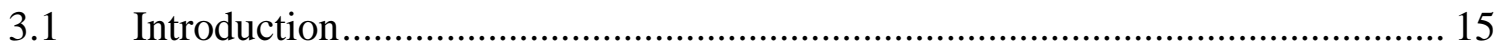

3.2 Engine Dynamometer Test Cell............................................................... 15

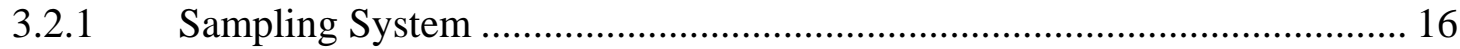

3.2.2 Engine and Dynamometer.......................................................................... 16

3.2.3 Data Acquisition and Handling................................................................. 18

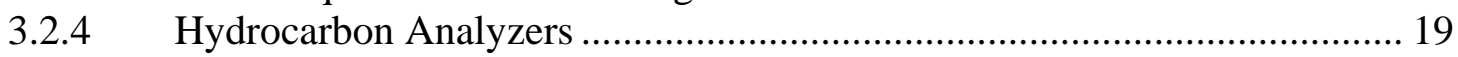

3.2.5 Oxides of Nitrogen Analyzers ………………….................................... 20

3.2.6 Carbon Dioxide and Carbon Monoxide Analyzers....................................... 20

3.2.7 Calibration of Hydrocarbon Analyzers ....................................................... 20

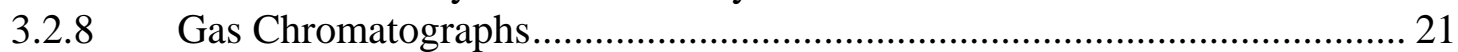

3.2.9 Federal Test Procedure (FTP) Transient HD Cycle..................................... 22

3.3 Gas Chromatography ………………………............................................. 24

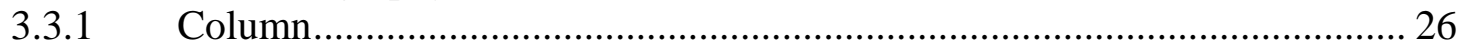

3.3.2 Adsorbents for Gas-Solid Chromatography................................................. 27

3.3.3 Stationary Phase for Gas Liquid Chromatography .................................... 28

3.3.4 Solid Supports for Gas Liquid Chromatography ………………………....... 29

3.3.5 Capillary Cages .......................................................................................... 29

3.4 Detectors in Gas Chromatography ……………............................................. 30

3.4.1 Flame Ionization Detector (FID) …………….......................................... 30

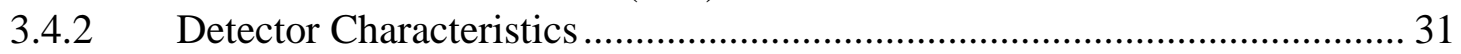

3.5 SAE J1151 Standard for Exhaust Methane Measurement ...................................... 31

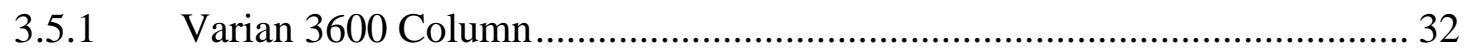

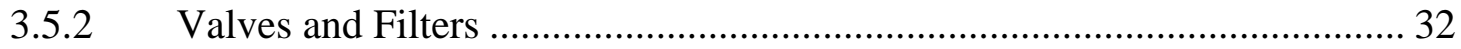

3.5.3 Pressure Regulators and Pressure Gauges (PR1-PR3, PG1-PG3) ................ 33

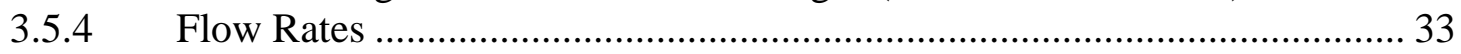

3.5.5 Detector Linearity …………………………....................................... 34

3.5.6 Detector Noise .................................................................................. 34

3.5.7 Precision and Column Resolution............................................................. 34

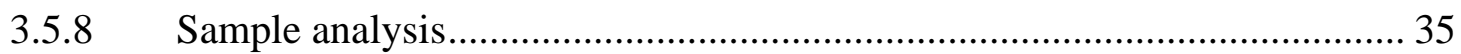

4 TEST PROGRAMS AND DATA ANALYSIS ……….......................................... 36

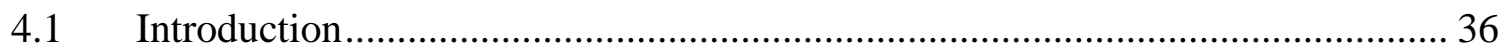




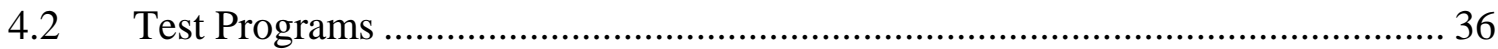

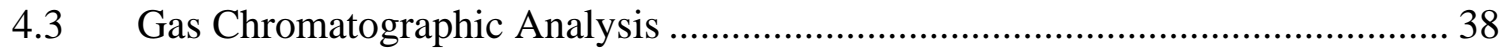

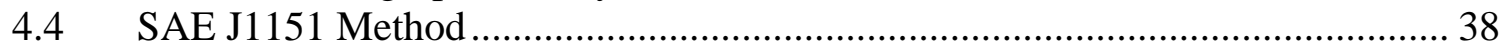

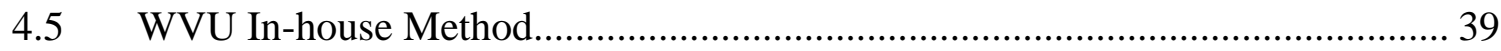

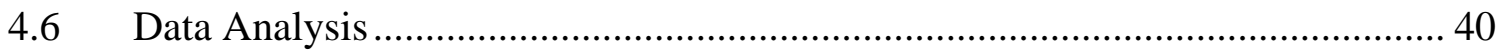

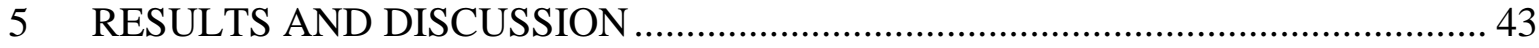

5.1 Comparison Between SAE J1151 and WVU GC Methods ................................ 43

5.2 Natural Gas Sample THC Determination from SAE J1151 Methane Results..... 51

5.3 Comparison of SAE J1151 Method with CAI Model 600 HFID ........................ 54

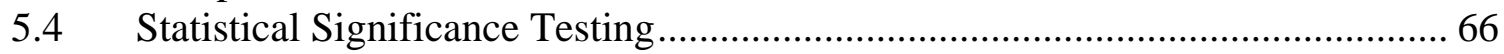

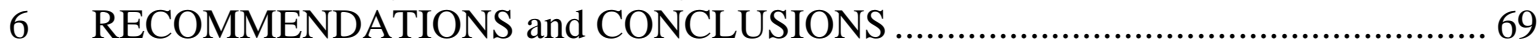

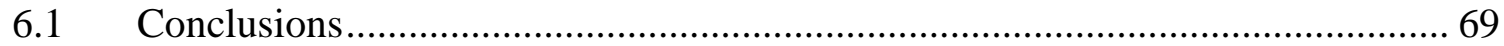

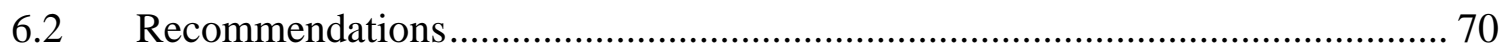

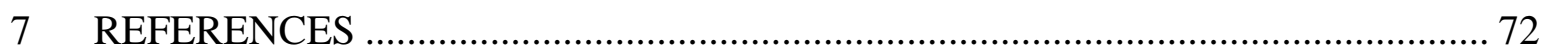

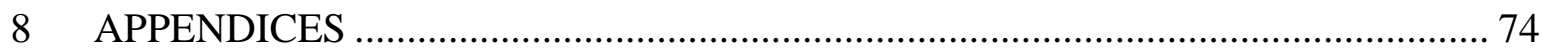




\section{LIST OF FIGURES}

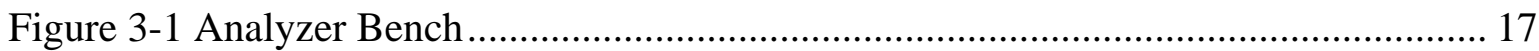

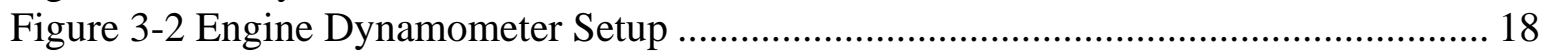

Figure 3-3 Data Acquisition Hardware..................................................................... 19

Figure 3-4 Varian 3600 Gas Chromatograph............................................................ 22

Figure 3-5 FTP Transient Heavy Duty Cycle Speed Set Points ...................................... 23

Figure 3-6 FTP Transient Heavy Duty Cycle Torque Set Points .................................... 24

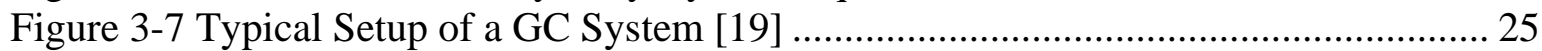

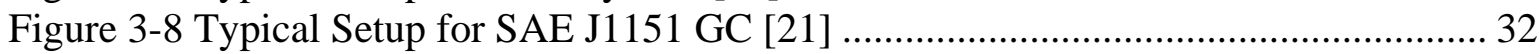

Figure 4-1 WVU Method Column Temperature Profile.................................................. 40

Figure 4-2 Typical Chromatogram from SAE J1151 GC Method ................................... 41

Figure 4-3 Typical Chromatogram from WVU GC Method ........................................... 41 Figure 5-1 Comparison of Dilute Bag Methane between SAE J1151 and WVU Method for

Tunnel Background Samples ................................................................................. 44

Figure 5-2 Comparison of Dilute and Background Bag THC from Horiba Analyzer and

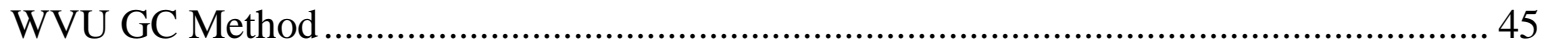

Figure 5-3 Comparison of Dilute and Background Bag THC from CAI HFID and Horiba 45 Figure 5-4 Dilute Bag THC Results for Tunnel Background Samples ........................... 46

Figure 5-5 Dilute Bag THC Results for Diesel-Based Exhaust Samples .......................... 47

Figure 5-6 Comparison of Dilute Natural Gas Sample Methane from SAE J1151 and WVU

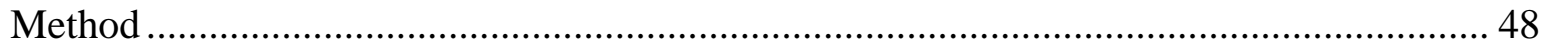

Figure 5-7 Comparison of Transportable Laboratory Background Bag Methane from SAE

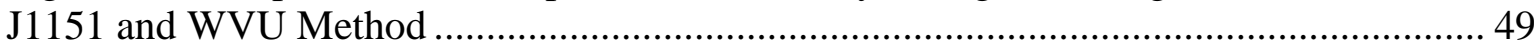

Figure 5-8 Comparison of Bio-Diesel Sample Dilute Bag Methane from SAE J1151 and WVU Method................................................................................................ 50

Figure 5-9 Comparison of Bio-Diesel Sample Background Bag Methane from SAE J1151

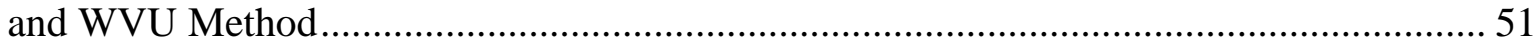
Figure 5-10 Comparison of WVU GC THC and Methane results for Natural Gas Samples

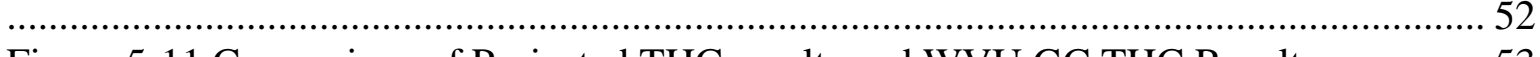

Figure 5-11 Comparison of Projected THC results and WVU GC THC Results............... 53

Figure 5-12 Comparison of Dilute Bag Methane from SAE J1151 and CAI HFID........... 55 Figure 5-13 Comparison of Background Bag Methane from SAE J1151 and CAI HFID.. 56 Figure 5-14 Comparison of Brake Specific Methane from SAE J1151 and CAI HFID ..... 57 Figure 5-15 Comparison of Brake Specific NMHC from SAE J1151 and CAI HFID ....... 58 Figure 5-16 Comparison of Dilute Bag Methane from SAE J1151 and CAI HFID........... 59 Figure 5-17 Comparison of Background Bag Methane from SAE J1151 and CAI HFID.. 59 Figure 5-18 Comparison of Brake Specific Methane from SAE J1151 and CAI HFID .... 60 Figure 5-19 Comparison of Brake Specific NMHC from SAE J1151 and CAI HFID ....... 61 Figure 5-20 Percentage Difference in SAE J1151 Dilute Bag Methane Concentration from Initial Analysis ................................................................................................... 62 Figure 5-21 Percentage Difference in SAE J1151 Background Bag Methane Concentration

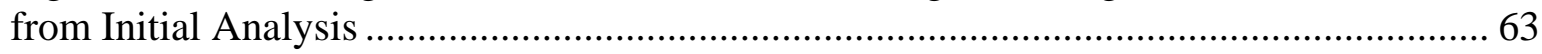
Figure 5-22 Day-to-Day Variation in Background Bag Measurements by CAI HFID....... 64 Figure 5-23 Day-to-Day Variation in Bag Measurements by Horiba THC Analyzer......... 65 


\section{LIST OF TABLES}

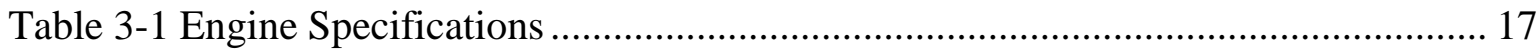

Table 5-1 Results of Statistical Significance Testing ................................................... 68

Table 8-1 Tunnel Background Sample Results from SAE J1151 and WVU GC Methods. 74

Table 8-2 THC Results from Horiba HC Analyzer and WVU GC .................................. 74

Table 8-3 THC Results from Horiba and CAI HFID Analyzers ...................................... 75

Table 8-4 Transportable Chassis Laboratory Background Sample Methane Results from SAE J1151 and WVU GC Method ............................................................................. 75

Table 8-5 Natural Gas Sample Dilute Bag Methane Results from SAE J1151 and WVU GC

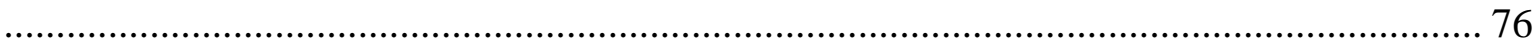

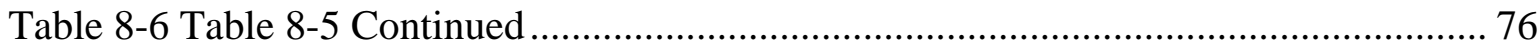

Table 8-7 Natural Gas Samples THC and Methane Results from WVU GC................... 77

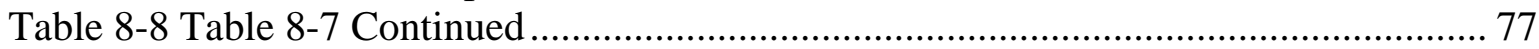

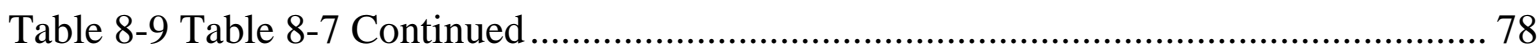

Table 8-10 Comparison of Projected Natural Gas THC and THC from WVU GC Method79

Table 8-11 Table 8-10 Continued 80

Table 8-12 Bio-Diesel Sample Methane Results from SAE J1151 and WVU GC Methods

Table 8-13 Diesel Blend FTP Exhaust Sample Results from SAE J1151 GC and CAI HFID

Analyzer. 82

Table 8-14 Diesel Blend FTP Exhaust Sample Brake Specific Methane and NMHC from SAE J1151 GC and CAI HFID Analyzer 83

Table 8-15 Diesel Blend FTP Exhaust Sample (Test 2) Results from SAE J1151 GC and CAI HFID Analyzer.

Table 8-16 Diesel Blend FTP Exhaust Sample (Test 2) Brake Specific Methane and NMHC from SAE J1151 and CAI HFID Analyzer ................................................................. 85 Table 8-17 Day to Day Variation in Methane Results from SAE J1151 GC for Diesel Blend FTP Exhaust Sample..... 86

Table 8-18 Day to Day Variation in Bag Integrated Concentrations from Horiba THC Analyzer for Tunnel Background Samples. 86

Table 8-19 Day to Day Variation in Bag Integrated Methane Results from CAI HFID Analyzer for Tunnel Background Samples.... 


\section{ABBREVIATIONS}

\begin{tabular}{|c|c|c|}
\hline CAFEE & - & Center for Alternative Fuels, Engines and Emissions \\
\hline CARB & - & California Air Resources Board \\
\hline CFR & - & Code of Federal Regulations \\
\hline CNG & - & Compressed Natural Gas \\
\hline EPA & - & Environment Protection Agency \\
\hline FID & - & Flame Ionization Detector \\
\hline GC & - & Gas Chromatograph \\
\hline GMC & - & General Motor Corporation \\
\hline LEV & - & Low Emission Vehicle \\
\hline NDIR & - & Non-Dispersive Infrared \\
\hline NMHC & - & Non-Methane Hydrocarbon \\
\hline NOX & - & Oxides of Nitrogen \\
\hline PLOT & - & Porous Layer Open Tubular \\
\hline SAE & - & Society of Automotive Engineers \\
\hline SOF & - & Soluble Organic Fraction \\
\hline SULEV & - & Super Ultra Low Emission Vehicle \\
\hline THC & - & Total Hydrocarbon \\
\hline WVU & - & West Virginia University \\
\hline
\end{tabular}




\section{INTRODUCTION}

Hydrocarbons emitted from combustion sources have been found to aid in ozone formation which is the primary constituent of smog. Unburned fuel and lubricating oil are the sources of hydrocarbon emissions from automobiles. The hydrocarbons content in automobile exhaust is a complex mixture of diverse species whose concentrations vary with many parameters such as engine operating engine speed, load, wear, type of fuel used, and combustion mechanism. Hydrocarbons in diesel exhaust exist as either volatile organic compounds (VOC) (gas phase) or soluble organic fractions (SOF) (particulate phase) [1]. Volatile hydrocarbons are determined using flame ionization detector (FID)-based analyzers while SOFs are a part of particulate measurements. Due to their ozone forming capabilities, hydrocarbons are also one of the many constituents of automobile exhaust which are being regulated since the enforcement of heavy duty mobile source emission regulations by the Environment Protection Agency (EPA) in 1988. From 1988 until 2004 (actually, October 2002) the regulation on total hydrocarbon (THC) emission from heavy-duty diesel engines was $1.3 \mathrm{~g} / \mathrm{bhp}-\mathrm{hr}$. Determination of the fact that methane does not aid in smog formation led to the formation of non-methane hydrocarbon (NMHC) regulation by CARB in 1991 subsequently adopted by the EPA for 2004 and later year engines. Engine manufacturers are given two options to certify 2004 and later year engines. Engine manufacturers can either certify their 2004 and later year heavy duty engines based on $\mathrm{NMHC}+\mathrm{NO}_{\mathrm{x}}$ emission of $2.5 \mathrm{~g} / \mathrm{bhp}-\mathrm{hr}$ or a NMHC emission of $0.5 \mathrm{~g} / \mathrm{bhp}-\mathrm{hr}$ and $\mathrm{NO}_{\mathrm{x}}$ emission of $2.4 \mathrm{~g} / \mathrm{bhp}-\mathrm{hr}$. The latest emission standards for 2007 and later year model regulates the NMHC emissions to $0.14 \mathrm{~g} / \mathrm{bhp}-\mathrm{hr}$.

The development of NMHC regulations necessitated the measurement of methane in addition to total hydrocarbons in the exhaust. The recommended method for methane measurement in the 
Code of Federal Regulations (CFR) is the SAE J1151 standard or a value of 2\% of the THC measurement [2]. The SAE J1151 method incorporates a gas chromatograph (GC) equipped with a FID for methane measurement from bag samples. The transportable chassis dynamometer laboratory at the Center for Alternative Fuel, Engines and Emissions (CAFEE) at West Virginia University (WVU) incorporates a thirty five minute GC-FID based method, henceforth referred to as the WVU method, capable of determining methane as well as THC content in exhaust bag samples. The WVU GC setup is used to determine THC content in compressed natural gas (CNG) vehicle exhaust samples which has a large content of methane. Since this method is not based on any established standard, samples analyzed with this method were also analyzed with the SAE J1151 method and the methane results compared through correlations. Also, the SAE J1151 method applicability to measure CNG sample methane and the possibility of subsequent estimation of the THC concentration is examined. A recent addition to the CAFEE laboratory is a CAI model 600 heated FID (HFID) analyzer capable of measuring THC or methane concentration in the sample. If proved reliable the need for the GC determination of methane could be eliminated, thus saving time and money.

\subsection{Ojectives}

The main objective of this study was to study the existing hydrocarbon measurements systems at the Engines Emissions Research Laboratory (EERL) at WVU. This included the examination of the SAE J1151 GC setup for methane and THC measurements and the scope for online NMHC measurement using a bench analyzer. 


\section{LITERATURE REVIEW}

\subsection{Introduction}

In the early years of automobile exhaust analysis non-dispersive infrared (NDIR) analyzers were used for the quantification of exhaust hydrocarbons. Inability to detect all hydrocarbons and decreased sensitivity to low concentrations were some of the shortcomings recognized by NDIRs [3]. Hence, the 1972 regulations called for the use of FID analyzers for exhaust hydrocarbon analysis. With the realization that methane did not contribute to smog formation, the CARB developed regulations for NMHC regulations in the 1980s which were later added to the 1990 federal emission standards through the Clean Air Act Amendments [4]. NMHC concentrations can be determined by subtracting the THC concentration value from an emissions test by the methane concentration value obtained by GC analysis.

Though the type of column used in the gas chromatographic qualification varied from instrument to instrument based on the type of constituents being qualified, quantification is predominantly done using FID detectors. The reason for preference of FIDs over other detectors is its selective response to hydrocarbons. Its response is linear over a wide range of hydrocarbon concentrations. Over the years many different configurations of FID-equipped gas chromatographic systems have been developed to aid in the analysis of diverse classes of hydrocarbons. Though there hasn't been much work been done towards comparison of different GC systems developed for analysis of hydrocarbons, there is considerable amount of literature on the use of FIDs for exhaust hydrocarbon analysis. This section in general reviews relevant literature on automobile exhaust hydrocarbon analysis which includes literature on GC-based hydrocarbon analysis systems and on FIDs for hydrocarbon quantification. 


\subsection{Literature Survey}

The use of FIDs and infrared analyzers for the determination of hydrocarbon in automobile exhaust were compared as early as in 1961 [5]. Jackson investigated the response of the infrared analyzer to various hydrocarbons in automobile exhaust and compared exhaust hydrocarbon concentration results from the two analyzers. He found that the when the infrared analyzer was operated in its linear concentration range the responses of a mixture of various hydrocarbons were additive. It was known that infrared analyzers equipped with n-hexane detectors had interference from the carbon monoxide, carbon dioxide and water in the sample. However, he found that carbon monoxide caused very little interference while carbon dioxide and water caused significant interference. The relative responses of two FIDs, a Beckman model 109 and a Perkin-Elmer model 213, were examined using the same hydrocarbon blends used for the relative response test of the infrared analyzer. The relative responses were found to be very close for the various hydrocarbons. Study of oxygen interference in the FIDs showed that it increased with increasing oxygen concentration. Elsewhere, Sternberg reported that oxygen increased the measured HC under some conditions and decreased it under other conditions while Andreatch noted that oxygen had little effect [6,7]. The error due to oxygen also varied considerably with the operating conditions of the analyzer. Studying the results of the FID and infrared analyzer for automobile exhaust with different fuels showed that FID results were higher than the infrared analyzer results. A similar study performed by McKee and Mills also showed that the FID results were higher than the infrared analyzer results and the ratios observed were 0.9-2.4 [8]. Similar studies by Jones and Jackson also agreed with the results of this study [9]. It was concluded that FID measured hydrocarbons was approximately the THC content but it needs 
to be operated at conditions that result in uniform hydrocarbon response and minimal oxygen interference.

The traditional difference method for the determination of NMHC was considered unreliable due to the errors associated when applied for low emission vehicle (LEV) and CNG vehicle exhaust. In order to improve the technique of NMHC measurement a workgroup consisting of Environment Research Consortium (ERC) (Chrysler, Ford, and General Motors Corporation), USEPA, and CARB was formed in 1993 which came to be known as American Industry/Government Emissions Research (AIGER) consortium [10]. The objective of AIGER was to develop/identify a direct method for determination of NMHC concentration. AIGER identified the FID as the preferred detector for hydrocarbon quantification due to its sensitivity, response characteristics and linearity. CARB, GMC, and USEPA individually evaluated a then available direct NMHC instrument/technique chosen by them while performing a round robin study of six cylinder gas mixtures and FTP-75 exhaust samples from a cross check. The GM evaluated technique developed by Prostak was identified as the most prospective one for further development.

Of the instrument prototypes submitted by Horiba Instruments, Thermedics Detection Inc, and Thermo Environmental Instruments (TEI), the TEI instrument was found to be accurate for direct NMHC measurement. A more advanced version of the TEI instrument, later available in the market as the TEI 55C, was tested by CARB, GMC, and Daimler Chrysler. It was based on the AIGER developed method of using a GC column for separation of methane from NMHC and measuring each quantity independently. The measurement time was only 70 seconds and could measure concentrations as low as 0.5 ppmc of methane and NMHC using hydrogen instead of hydrogen-helium blend as FID fuel. The methane measurement complied with the requirements 
of the SAE J1151 standard for measuring methane specified by USEPA. The values were within $\pm 2 \%$ for wide range of fuels and vehicle types. The possibility of interference errors due to the presence of water and oxygen were eliminated due to their separation from the compounds of interest. After extensive testing the AIGER group concluded that the direct reading methodology was suitable for vehicle certification. Additional testing to confirm applicability for super ultra low emission vehicles (SULEV) and diesel engine certification were recommended for future development.

As per the 40 CFR part 86 subpart N, methane measurement for NMHC determination has to be done using a proportional bag sampling system and a GC/FID based on SAE J1151. The standards in part 40 CFR part1065, which will become mandatory starting 2010, specifies that methane could also be measured using a non-methane cutter and FID analyzer. NMHC, in both these cases, is determined by subtraction from the THC value. Another option provided in 40 CFR parts 1065 is assuming 2\% of THC is methane [11]. CARB allows the use of direct GC speciation for CNG vehicle exhaust samples. A study of the subtraction method of determination of NMHC concentration was done by Weaver to evaluate the reliability of this method for various fuels producing a wide range of methane content in the exhaust [4]. Six CNG and six gasoline vehicles were tested extensively. The test program for each vehicle comprised of the light-duty FTP-75 cycle, supplemental FTP test cycle proposed by the EPA in 1995, federal cold CO emission testing cycle (cold FTP), and a wide open throttle (WOT) acceleration cycle. Fuel for CNG vehicle was a gas mixture of CARB and EPA certification standard fuel while reformulated and non-reformulated gasoline fuels were used for the gasoline vehicles. For bench determination of NMHC a Beckman 400 FID hydrocarbon analyzer and a Horiba model GFA220 GC based methane analyzer were used. All the samples were collected in Tedlar bags. Three 
identically equipped Varian 3600 GCs were used for individual VOC speciation of the sample bags as per CARB regulations in addition to the bench NMHC values.

A scatter plot of the NMHC values obtained for each bag from the bench and individual GC speciation showed poor correlation with a correlation coefficient of 0.296 . This was considered to be as expected due to the subtraction of a large THC concentration value from a large methane concentration value. The methane concentrations for CNG vehicles were typically $80-90 \%$ of the THC concentrations. On the other hand the scatter plot for the gasoline vehicle results showed very good correlation. For the non-reformulated RF-A gasoline the correlation coefficient was 0.999 while that for reformulated gasoline was 0.990 . The slightly reduced correlation for reformulated gasoline was believed to have been due to the presence of oxygenated compounds in it to which the response of the FID is significantly less. In order to bring equality in comparison only the NMHC values which were less than $0.3 \mathrm{~g} /$ mile for the gasoline vehicles were used to examine correlation. This was done because the NMHC results for the CNG vehicles were past full scale value at $0.23 \mathrm{~g} /$ mile while that of the gasoline vehicles was as high as $4 \mathrm{~g} /$ mile. Reducing the range of values did not change the correlation by much with near perfect correlation for non-reformulated gasoline and slight offset for reformulated gasoline. Hence it was concluded that the subtraction method of NMHC determination was highly unreliable when used with CNG vehicles.

Since FIDs have been used for automobile exhaust hydrocarbon analysis, investigations on FID performance based on operating parameters date back to as early as 1970. Teague at Chrysler Corporation conducted an investigation to determine the optimum sampling and operating parameters for FIDs used for continuous analysis of hydrocarbons in automotive exhaust [3]. It was found that increasing the sample flow rate increased instrument sensitivity, response time, 
and reduced hang-up. However an increase in the oxygen interference effect was observed. A sample flow of $6 \mathrm{~cm}^{3} /$ min showed good exhibited good response speed and sensitivity. Oxygen was believed to be causing interference by reducing flow by changing viscosity and by inhibiting ionization.

At a diffusion air flow rate of $120 \mathrm{~cm}^{3} / \mathrm{min}$, zero oxygen interference was observed for a wide range of oxygen content in the sample. The use of $40 \%$ hydrogen and $60 \%$ helium fuel showed less dependence of oxygen interference on air flow rate. As the fuel flow increased, zero oxygen interference air flow value also increased. The response of the FID varied with the molecular structure of the hydrocarbon. After making a careful compromise between zero oxygen synergism and deviation from equi-response for various hydrocarbons the FID operating parameters recommended were fuel flow rate of $122 \mathrm{~cm}^{3} / \mathrm{min}$, diffusion air flow rate of 220 $\mathrm{cm}^{3} / \mathrm{min}$ and sample flow rate of $6 \mathrm{~cm}^{3} / \mathrm{min}$. Under these operating conditions the oxygen synergism observed for an oxygen concentration range of 0 - $24 \%$ was $\pm 1 \%$.

Reschke conducted an investigation of instrument to instrument correlation and operating parameters on relative response characteristics using four identical Beckman Model 400 FIDs at GMC [12]. It was found that two analyzers with different flow settings can measure hydrocarbons differently even if they measure the calibration propane gas alike. The relative response to various hydrocarbons remained non-linear at high sample flow rates. As the sample flow was decreased the relative response to methane, ethane, ethylene and propylene converged to 1 . Benzene and toluene were insensitive to sample flow rate while acetylene response remained fairly high at all sample flow rates. In a fuel flow rate range of $60-100 \mathrm{~cm}^{3} / \mathrm{min}$ the relative responses were uniform at the higher flow rates. Drastic reduction in analyzer sensitivity was observed for air flow rates under $250 \mathrm{~cm}^{3} / \mathrm{min}$ and above it there was not much change in 
response or sensitivity. The use of hydrogen/helium fuel showed similar trends with slightly better relative responses.

Measurement of dilute exhaust bag samples showed that low sample rate and/or hydrogen/helium fuel yielded higher values while higher sample flow rates with hydrogen/nitrogen fuel yielded $12 \%$ lower results. The effect of fuel composition on response was greater at higher sample flow rates than at low sample flow rates. Based on these studies the parameters recommended were sample flow rate of $5 \mathrm{~cm}^{3} / \mathrm{min}$, hydrogen/helium fuel, fuel flow rate of $100-120 \mathrm{~cm}^{3} / \mathrm{min}$ and air flow rate four times the fuel flow rate. Comparison with response characteristics of other analyzers led to the conclusion that all FID's have similar relative response characteristics and can therefore be optimized using the parameters developed for the Beckman Model 400 FID.

Baronick and Kroneisen performed a study to highlight the problems involved with hydrocarbon measurements using FIDs [13]. Ten FIDs from different manufacturers were calibrated with the same propane/air mixture and then calibration gases were checked on each of them. It was seen that hydrocarbons such as methane, propylene, and acetylene cannot be accurately measured with FIDs calibrated on propane. Twenty one chassis dynamometer samples were analyzed using each of the ten FIDs and it was found that errors were primarily due to instrument errors.

Changes in composition of the HC samples along with the changes in concentration of other emissions constituents like oxygen, carbon monoxide, carbon dioxide, water vapour, hydrogen, nitric oxide, and nitrogen were found to cause errors in the results with exhaust oxygen causing the most notable influence. The use of helium as make up gas was expected to cause higher diffusion rates of hydrogen and oxygen. [6]. Helium had a positive influence on the error. 
Premixing of the hydrogen fuel with oxygen caused an increase in the structural and oxygen error. Investigation of the combustion air flow rate showed that at flow rates between 200 and $250 \mathrm{ml} / \mathrm{min}$ there was a reduction in measuring error for saturated HCs, minimal errors for unsaturated HCs and small oxygen errors. The structural error was found to decrease with an increase in the fuel flow rate. Turbulent mixing of fuel and air in the reaction zone of the flame showed an improvement in the measurement accuracy but caused an increase in the oxygen error. However laminar flow of air to the flame always gave good measuring accuracy. The flow of air to the flame depended on the angle of the conical jet. Keeping the jet angle as small as possible helped to control the oxygen error. It was also found that jet material had no effect on the sensitivity of the FID but had significant effects on the error. Vacuum operation of FID was not considered as a feasible improvement option as it would cause an increase in the oxygen error similar to the increase caused by the addition of makeup gas. The conclusion was reached that precision of the instrument can be achieved by optimization of the burner assembly, gas flow rates, and polarization voltages.

Schofield examined the problems with FIDs for automotive exhaust hydrocarbon quantification [14]. Tests were conducted to study the differences in correlation among various instruments with respect to operating condition and exhaust type, the magnitude of oxygen interference on various FIDs and the instrument response times for various sample lines. The inter-model variations were studied by measuring relative carbon sensitivities for certain hydrocarbons with three FIDs manufactured by Beckman. Variations of the order of $25 \%$ for methane, $21 \%$ ethylene, $24 \%$ for acetylene and $17 \%$ for toluene were observed. It was seen that the relative response to methane and acetylene were higher with hydrogen/nitrogen fuel compared to hydrogen/helium fuel. Reduction in sample flow decreased relative response to methane and 
acetylene and increased that of ethylene. For various mixtures, typifying different exhaust, analyzed using the FIDs showed variations of 5\%, 12.1\%, 15.4\% and 7\% in relative responses. The various constituents in the mixture contribute differently to each of these mixtures.

Oxygen interference was examined by comparing the response of the FIDs to mixtures prepared with same quantities of propane in nitrogen and in air. The effect was significant when hydrogen/nitrogen fuel was used. Sample flow changes produced random changes. It was found that addition of a small amount of air to the fuel and sample prior to combustion drastically reduced the oxygen effect irrespective of the balance gas in the sample. The effect of sampling lines in the measurement of exhaust hydrocarbons were studied by measuring the response time of the FID for lines of different materials and diameters. Stainless steel performed equally well under cold and heated conditions. Teflon performed well at high temperatures. Slight variations in response were noted with changing length of stainless steel lines while cold Teflon lines showed definite line length dependence. Quarter inch heated Teflon and stainless steel lines performed similarly.

Tsurumi et al. developed a method for optimizing FIDs and correcting for oxygen quench effects. In this method the fuel and air flow rate was optimized for propane in air with $20.8 \%$ oxygen such that the propane reads the same as propane in nitrogen at zero percent oxygen. This method reduced the effect of the balancing air in the span gas on the span propane reading [15]. Following this optimization a zero correction had to be applied. It was found that without the use of these methods the average NMHC of three CVS emission tests were underreported by $1.7 \%$ while bag mini diluter results were underreported by $7.8 \%$ which was considered to be significant. 
Sherman et al. suggested a process for improving oxygen quench correction by studying the source of variation in oxygen concentration and the interaction between oxygen and hydrocarbons [16]. The effect of oxygen variation in burner air, zero air, span/calibration balance gas and exhaust samples were investigated. The oxygen effect of zero gas was determined by varying the oxygen concentration of the zero gas using a gas divider and measuring the instrument response. A second order fit was obtained for the response with oxygen content. Similar fits were obtained for the span gas at full scale reading by varying the oxygen content of the span gas. Using these fits the offset in the FID with oxygen content were calculated. Studying the effect of sample oxygen content on oxygen quench showed that the effect became more as the hydrocarbon content increased.

Sherman et.al. also conducted an investigation to study the effect of sample composition on FID responses by using blended cylinders of 3ppmC propane in air with oxygen content ranging from $17.5 \%$ to $21 \%$ by volume [17]. The objective was to study the effect of oxygen content variation on sample concentration measurement at a single propane concentration of 3ppmC. The cylinders were analyzed using various models of FIDs and it was seen that the response dropped as the oxygen content approached $18 \%$ below which there was an increase in response up to $17.5 \%$ oxygen which was the lower limit of the test oxygen concentration. All of the FIDs, except a Horiba -220A, showed similar responses. The discrepancy in the Horiba analyzer was believed to be due to the catalytic material in it which was used to address the issue of variable response to different hydrocarbons. Tests were conducted to test the oxygen quench compensation method developed by Horiba. This method involved the calculation of the error in measurement from the zero gas by generating a bias calibration curve for zero gas with varying oxygen content. By measuring the sample oxygen content the appropriate correction could be 
applied to the HC measurement. Bag samples from the same blended cylinders were analyzed with the various FIDs and simultaneously the oxygen content were measured. Applying the bias correction reduced the oxygen quench from $7 \%$ to $2 \%$ in the range of oxygen concentrations found in dilute emission testing. At an oxygen concentration of $18 \%$, where most sample measurements fall, the error was reduced from $6 \%$ to $1 \%$.

Analysis of six exhaust samples on Horiba and Rosemount FIDs showed that the two instruments had good agreement between them but the Rosemount analyzer had a 6\% bias over the Horiba. Relative response test of a Horiba FIA-726 LE was conducted at four operating points, two fuel and two air flow rates. Comparing the relative response of methane measured by the Horiba analyzer with the data from a previous study by Reschke, summarized earlier, showed good agreement. The relative response converged towards one as the fuel and air flow rates were increased. Another independent investigation by Horiba showed that relative response decreased with decreasing sample flow rate. Noise and linearity increased on the other hand [18]. Optimization of the FID was also found to influence oxygen interference. Decreasing sample pressure improved oxygen quench.

\subsection{Summary}

From the literature survey it was evident that extensive work has been done for over forty years towards the application of FIDs for hydrocarbon measurement in automobile exhaust. Though the operating principle of a FID is the same across various manufacturers, studies have shown that there are differences in hydrocarbon measurement from FID based analyzers from different manufacturers. The tight regulations also necessitate analyzers that can measure hydrocarbons at very low concentration levels. This has led to new innovations in FID designs. Apart from the FID designs it has been established that the flow of fuel, burner air, and sample gas play a critical 
role in the measurement. Numerous studies have been performed to examine the variations in these flows on the response characteristics of the FID. Other factors like the concentration of oxygen in the gases flowing through the FID have been found to effect response. Studies on determination of optimized values of fuel, sample, and burner air flows indicate that no universal values can be obtained for the flows and that the flows have to be optimized for each instrument. All these factors combined together make hydrocarbons measurement using FID more of an art than a science. 


\section{EXPERIMENTAL SETUP AND PROCEDURE}

\subsection{Introduction}

This section explains the setup of the equipments used and the procedures followed for the collection and analysis of the gaseous samples. The samples collected were from engines exercised in an engine dynamometer test cell based on the federal testing procedure (FTP) at the Engine Emissions Research Laboratory (EERL) at WVU. Samples were also collected from chassis dynamometer testing of CNG vehicles. The engine laboratory conforms to the regulations set forth in of CFR 40, Part 86, Subpart N. The transportable chassis laboratory at WVU, mentioned elsewhere, also follows CFR40, Part 86, Subpart N, where applicable.

\subsection{Engine Dynamometer Test Cell}

The test cell consisted of a heavy duty diesel engine coupled to a dynamometer. The dynamometer was used to load the engine to the set points specified in the CFR. The exhaust from the engine was sent to a dilution tunnel where it was diluted with conditioned ambient air. A blower placed downstream of the dilution tunnel drew the gas mixture through critical flow venturis which maintain constant flow volume in the tunnel. The diluted exhaust sample was fed continuously to the analyzer bench which housed the analyzers which measured the concentration of the exhaust constituents on a real time basis, albeit delayed by the transport, diffusion and dispersion affects. The analog signal from the analyzers were converted to digital signals with the aid of analog-to-digital coverter (ADC) modules and finally stored in engineering units by the data acquisition software. The various components of the test cell are explained below. 


\subsubsection{Sampling System}

The sampling system at EERL consisted of an 18 inch diameter stainless steel dilution tunnel which was about 20 feet in length. A mixing orifice was placed upstream of the tunnel where the engine exhaust pipe culminates to enable mixing of the exhaust gas with the ambient air. A 75 HP blower pulled the gaseous mixture through any combination of the four critical flow venturisthree of $1000 \mathrm{scfm}$ flow capacity and one of $400 \mathrm{scfm}$ flow capacity. The sampling plane was located 10 diameters downstream of the orifice where the heated sampling probes were arranged radially. There were four probes in total, one each for the $\mathrm{HC}, \mathrm{HC} 2, \mathrm{NOx}, \mathrm{NOx} 2$, and $\mathrm{CO} / \mathrm{CO}_{2}$ analyzers. It is notable that redundant $\mathrm{HC}$ and $\mathrm{NO}_{\mathrm{x}}$ analyzers are used in the laboratory. The sample was pumped by heated pumps through heated stainless steel sample lines and filters to the analyzers. The temperatures of the sample lines for the NOx and $\mathrm{CO} / \mathrm{CO}_{2}$ analyzers were maintained at $235 \pm 20^{\circ} \mathrm{F}$ while those of the $\mathrm{HC}$ analyzers were maintained at a higher temperature of $375 \pm 20^{\circ} \mathrm{F}$ to prevent condensation of heavier hydrocarbons. Figure 3- 1 shows the analyzer bench housing the analyzers for the various exhaust constituents. The exhaust and dilution air samples were simultaneously filled into two 80 liter tedlar bags during the test cycle. The dilute bag was filled from a probe in the sampling plane while the background bag was filled with the dilution air prior to mixing with the exhaust. Analysis of these bags by the analyzers yielded integrated bag values in addition to the continuous traces. Three liter tedlar bags were filled with samples from these bags to perform GC analysis.

\subsubsection{Engine and Dynamometer}

The engine predominantly used for sample collection was a 1992 DDC S60 series heavy-duty diesel engine built by Detroit Diesel Corporation. Table 3-1 shows the specifications of the test engine. This engine was exercised using a 550 HP GE DYC 243 direct current dynamometer. 
The two were coupled using a Vulkan coupling and drive shaft. An encoder on the dynamometer was used for engine speed measurement. Calibration of the dynamometer was done as specified in CFR 40, Part 86 Subpart N using standard weights traceable to NIST standards. The engine dynamometer setup is shown in Figure 3-2.

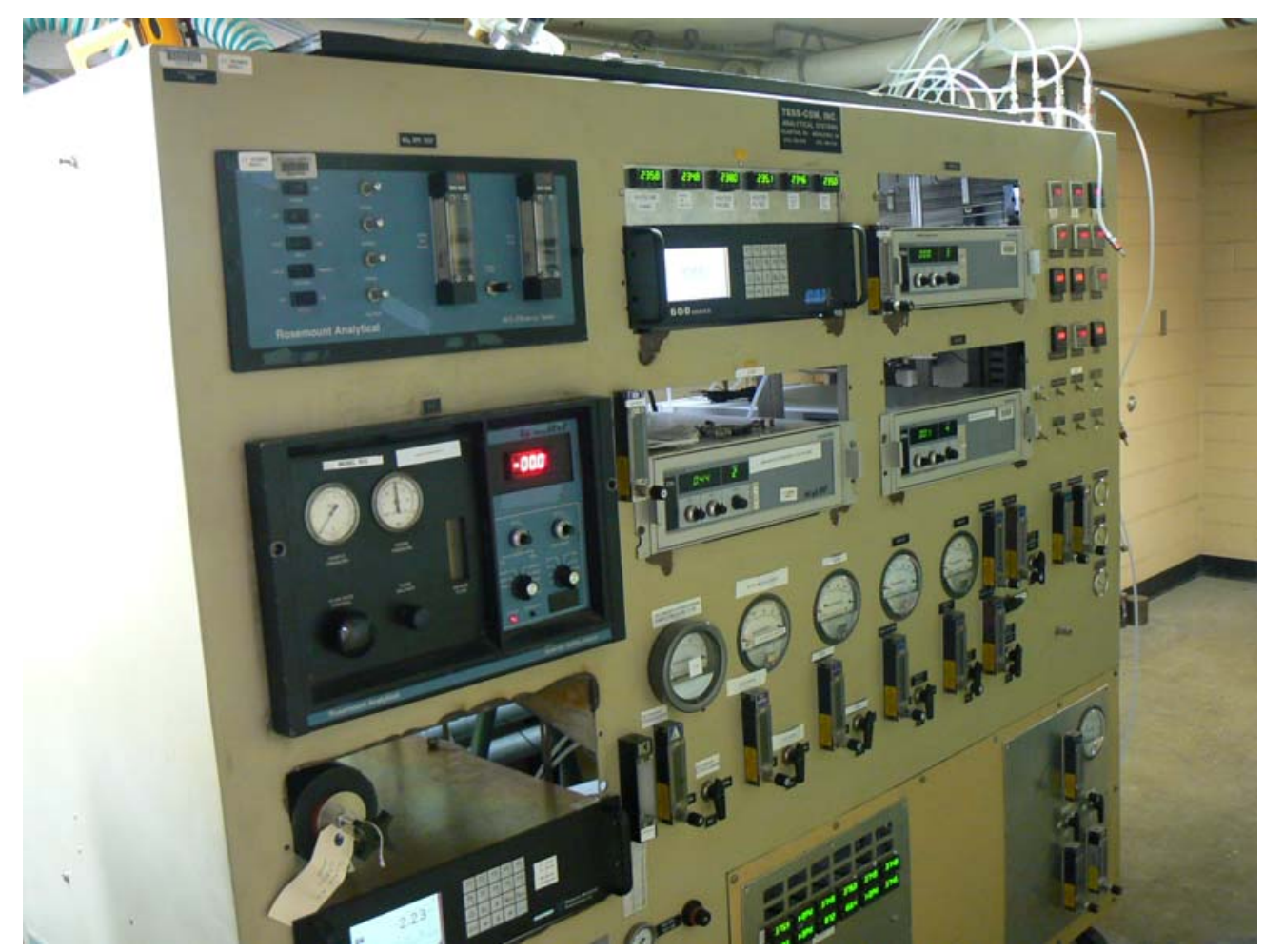

Figure 3-1 Analyzer Bench

Table 3-1 Engine Specifications

\begin{tabular}{|c|c|}
\hline Engine & 1992 DDC S60 \\
\hline Year & 1992 \\
\hline Displacement & 12.7 \\
\hline Cylinder & Inline 6 \\
\hline Rated power (bhp) & 360 \\
\hline Rated torque (ft-lb) & 1450@1200 rpm \\
\hline Aspiration & Turbocharged After-cooled \\
\hline Injection & Direct \\
\hline Compression ratio & $15: 1$ \\
\hline
\end{tabular}




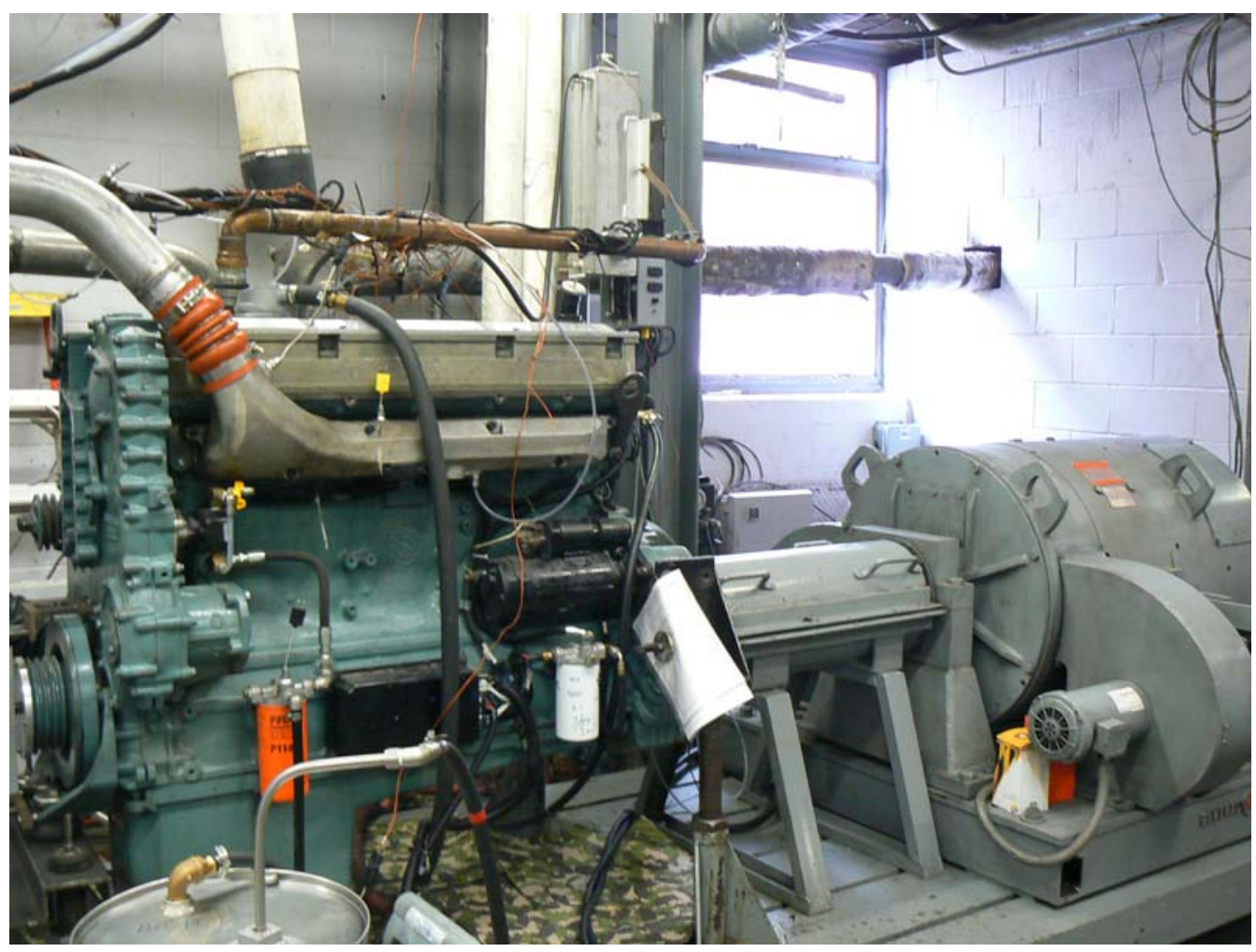

Figure 3-2 Engine Dynamometer Setup

\subsubsection{Data Acquisition and Handling}

The signals from the analyzers were acquired and handled using hardware shown in Figure 3-3 and software developed in-house at WVU. Raw analog signals from various sources like analyzers, temperature sensors, and pressure sensors were fed to Analog Devices 3B series backplanes which amplified, isolated and linearized the signals as standard analog inputs to ADC boards installed in the data acquisition computer. The digital codes were then converted to engineering units by post processing software. 


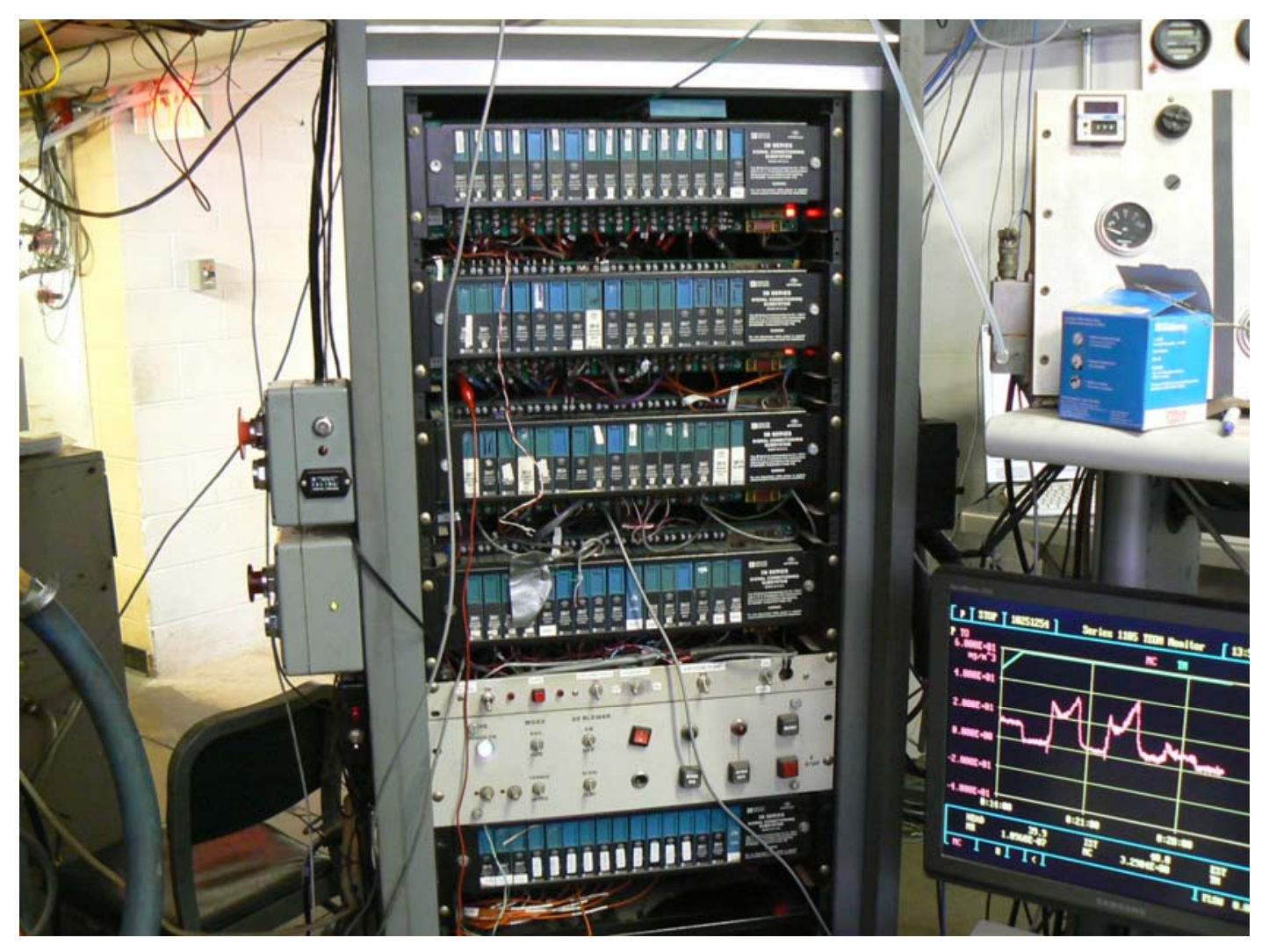

Figure 3-3 Data Acquisition Hardware

\subsubsection{Hydrocarbon Analyzers}

Over the period of sample collection, three different types of hydrocarbon analyzers were used to determine THC and methane concentration. They were a Rosemount model 402 heated FID analyzer, a CAI 600 heated FID analyzer capable of measuring THC or methane only, and a Horiba FID analyzer. For any given test there were two $\mathrm{HC}$ analyzers in the bench measuring the hydrocarbon concentrations of the sample. During operation each of these analyzers detectors were fueled by $40 \%$ hydrogen and $60 \%$ helium gas bottles. The Rosemount analyzer had a measurement range of 1 to 5000 ppm while that of the CAI was 0 to $3 \%$. The span gas bottles used for the analyzers were generally $10 \mathrm{ppm}$ propane in air. When the CAI analyzer was set in methane measurement mode $4.5 \mathrm{ppm}$ methane in air gas bottle was used as the span. These span gas concentrations were selected to cover the full range of THC and methane concentrations encountered in the dilution tunnel during an FTP emission test of a heavy-duty diesel engine. 


\subsubsection{Oxides of Nitrogen Analyzers}

Two analyzers were installed in the analyzer bench for the measurement of $\mathrm{NO}_{\mathrm{x}}$. One of them was a Rosemount model 955 heated chemiluminescence analyzer. The analyzer converts any $\mathrm{NO}_{2}$ in the sample to $\mathrm{NO}$ using a $\mathrm{NO}_{2}$ to $\mathrm{NO}$ converter and then measured the total $\mathrm{NO}$ to yield a $\mathrm{NO}_{\mathrm{x}}$ measurement. It is capable of measuring $\mathrm{NO}_{\mathrm{x}}$ from 10 to 10000 ppm. A Beckman $\mathrm{NO}_{\mathrm{x}}$ efficiency tester was used to test the efficiency of the converter periodically as a quality control measure. An Ecophysics or CAI $\mathrm{NO}_{\mathrm{x}}$ analyzer was used in tandem with the Rosemount analyzer.

\subsubsection{Carbon Dioxide and Carbon Monoxide Analyzers}

Three Horiba AIA-210 model non-dispersive infrared (NDIR) analyzers were used to measure high $\mathrm{CO}$, low $\mathrm{CO}$ and $\mathrm{CO}_{2}$. The infrared absorption characteristics of gases are made use of in NDIR analyzers to measure gas concentrations. An infrared beam is passed through a sample cell containing the gas to be quantified. Depending on the concentration of the gas energy is absorbed the beam emerges attenuated. The remaining beam is passed serially through two cavities of an infrared detector and mass flow sensor containing the same gas that is being measured. Any change in the intensity of the beam changes the pressure differential in the two cavities which leads to an imbalance in the electrical bridge circuit. Electronics convert this imbalance into an electrical signal proportional to the concentration of the gas.

\subsubsection{Calibration of Hydrocarbon Analyzers}

During initial induction into service and annually thereafter as required by the CFR, the FID of the analyzers was optimized for hydrocarbon response. This was done by starting with the fuel and air flow specified by the manufacturer. A 100 ppm propane span gas (the recommended span gas concentration is $350 \pm 75 \mathrm{ppm}$ ) was introduced into the analyzer and the response was 
noted as the difference between the span response and zero response. The fuel flow rate was varied on either side of the initial flow rate and the response was noted in each case. A plot of the response versus fuel flow determined the flow rates of optimum response. The richest fuel flow rate was selected and this is the new initial flow rate setting.

The next step was optimization for oxygen interference. The analyzer was zeroed. A span gas containing $21 \%$ oxygen was used to span the analyzer. Zero was checked again. If it had drifted more than $0.5 \%$ it was zeroed and spanned again. After that the $5 \%$ and $10 \%$ oxygen check gases were introduced and the analyzer response was noted. The percentage of oxygen interference was calculated using the appropriate formula. If it was above $\pm 3 \%$ the air flow was adjusted incrementally and the test was performed again. In case of failing of the test after the air flow adjustment the fuel flow was adjusted followed by the sample flow until the test passes.

Calibration was done by introducing blends of span and zero gas starting from 100\% span gas down to $0 \%$ span gas blend with $10 \%$ decrements. At each point the analyzer response was noted in terms of the ADC codes and a linear least square regression was performed on the data. If the difference in the percentage of full scale response from the analyzer, calculated from the regression plot, was within $\pm 2 \%$ of the actual concentration percentage at each point the calibration was accepted.

\subsubsection{Gas Chromatographs}

Two Varian 3600 series dual FID GC’s as seen in Figure 3-4 were used to measure the methane concentration in the sample bags. One of the GC's was configured as per the SAEJ1151 standard for measurement of methane in the automobile exhaust while the other GC was setup based on the WVU in-house standard to measure methane in the exhaust samples collected by 
the transportable laboratory at EERL. Each of the two GC's was equipped with two 10 port Valco valves with air actuators for sample routing.

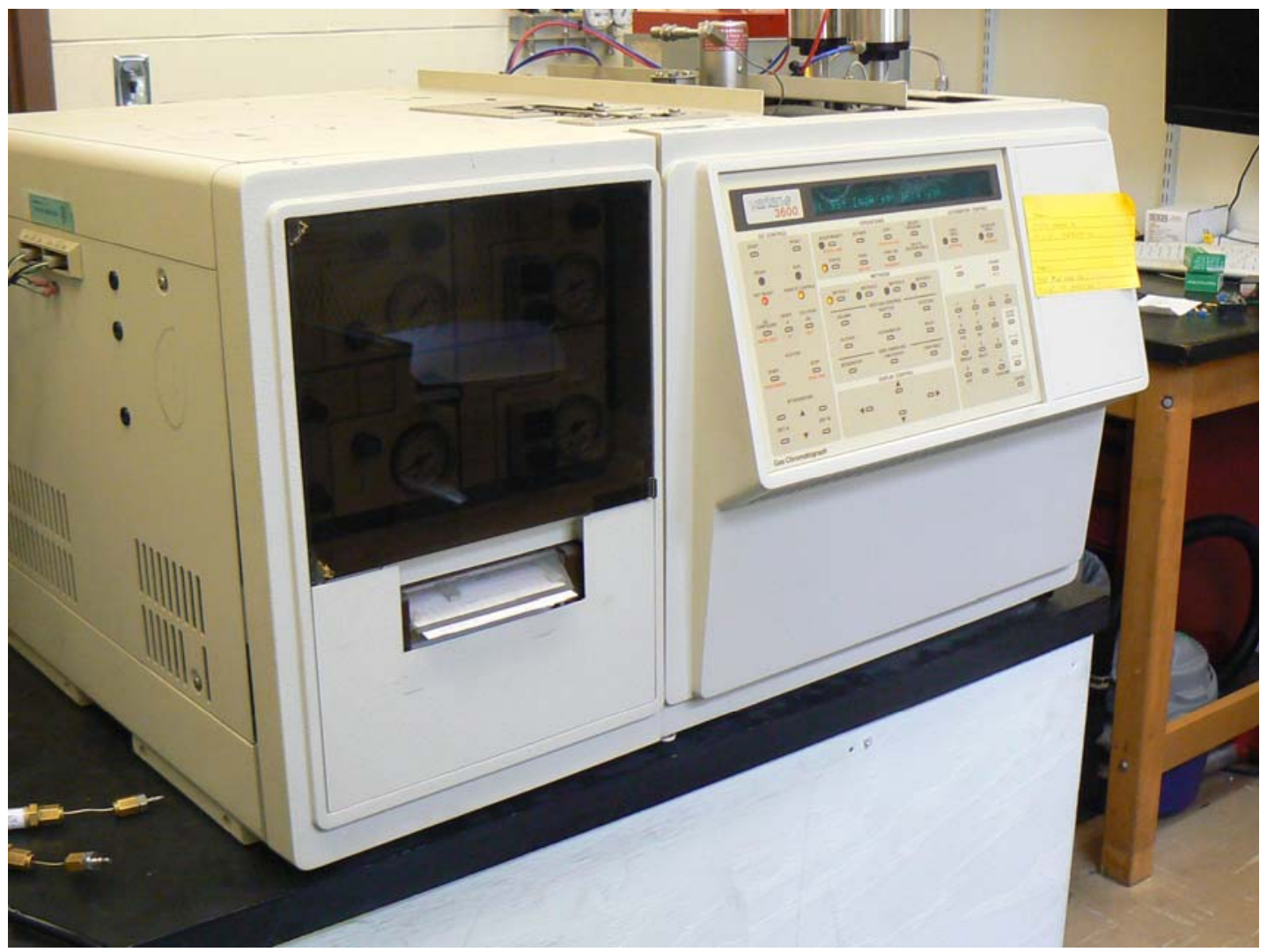

Figure 3-4 Varian 3600 Gas Chromatograph

\subsubsection{Federal Test Procedure (FTP) Transient HD Cycle}

The test cycle specified in CFR 40, part 86, subpart $\mathrm{N}$ is called the US FTP cycle. It is a transient testing cycle developed to simulate real-time driving conditions encountered by vehicles with heavy-duty diesel engines in an engine dynamometer test cell. It simulates four distinct driving conditions namely New York non-freeway (NYNF) representing light urban traffic with frequent stops, Los-Angeles non-freeway (LANF) depicting heavy urban traffic with less stops, LosAngeles freeway (LAFY) simulating crowded expressway traffic in Los Angeles and the fourth is the repetition of NYNF. The testing sequence begins with a cold- start FTP cycle run of the 
engine at ambient temperature $\left(77^{\circ} \mathrm{F}\right)$, a twenty minute soaking period and then a warm start FTP cycle run. Figure 3-5 and Figure 3-6 show the speed and load variations during the FTP cycle, respectively.

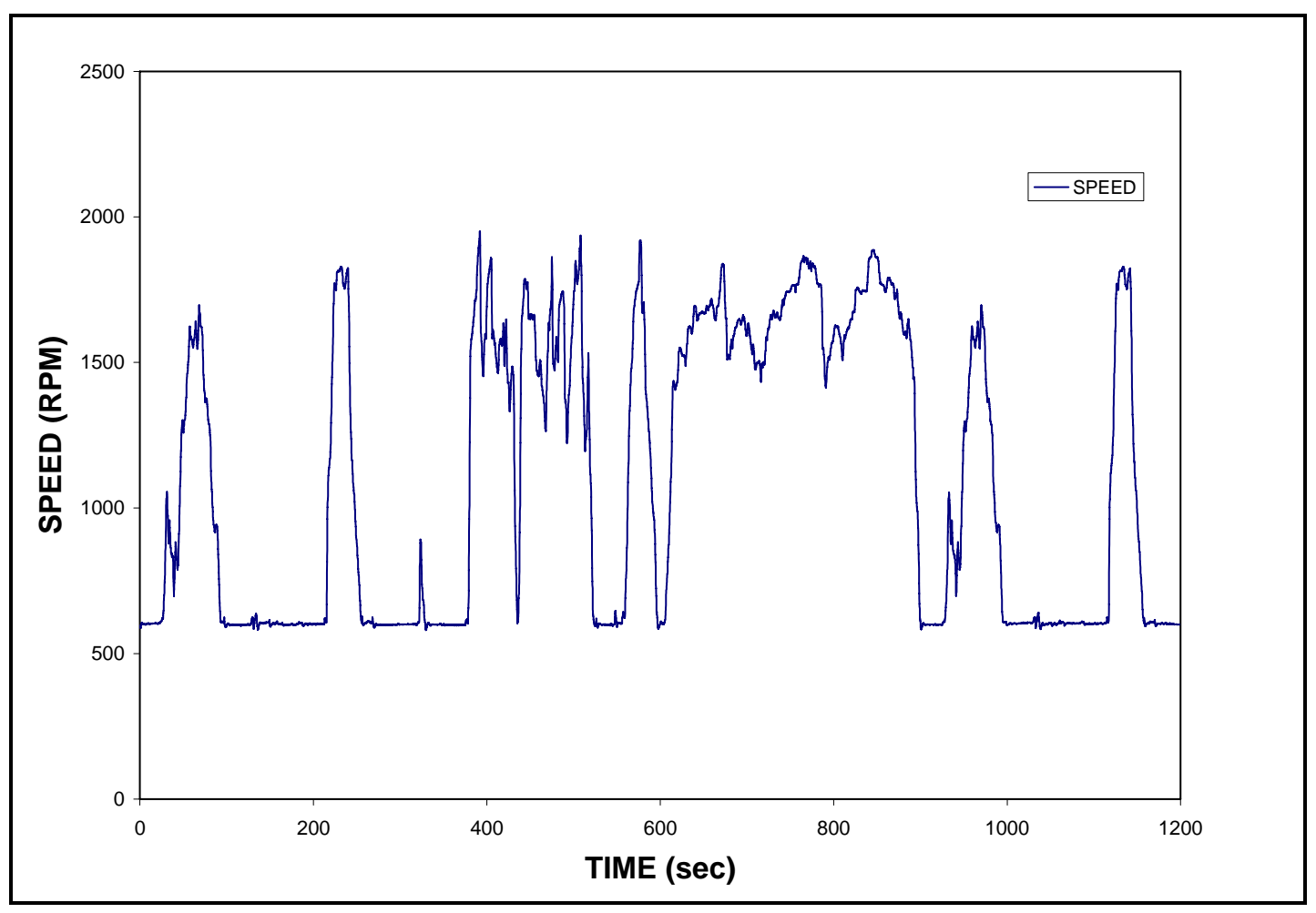

Figure 3-5 FTP Transient Heavy Duty Cycle Speed Set Points 


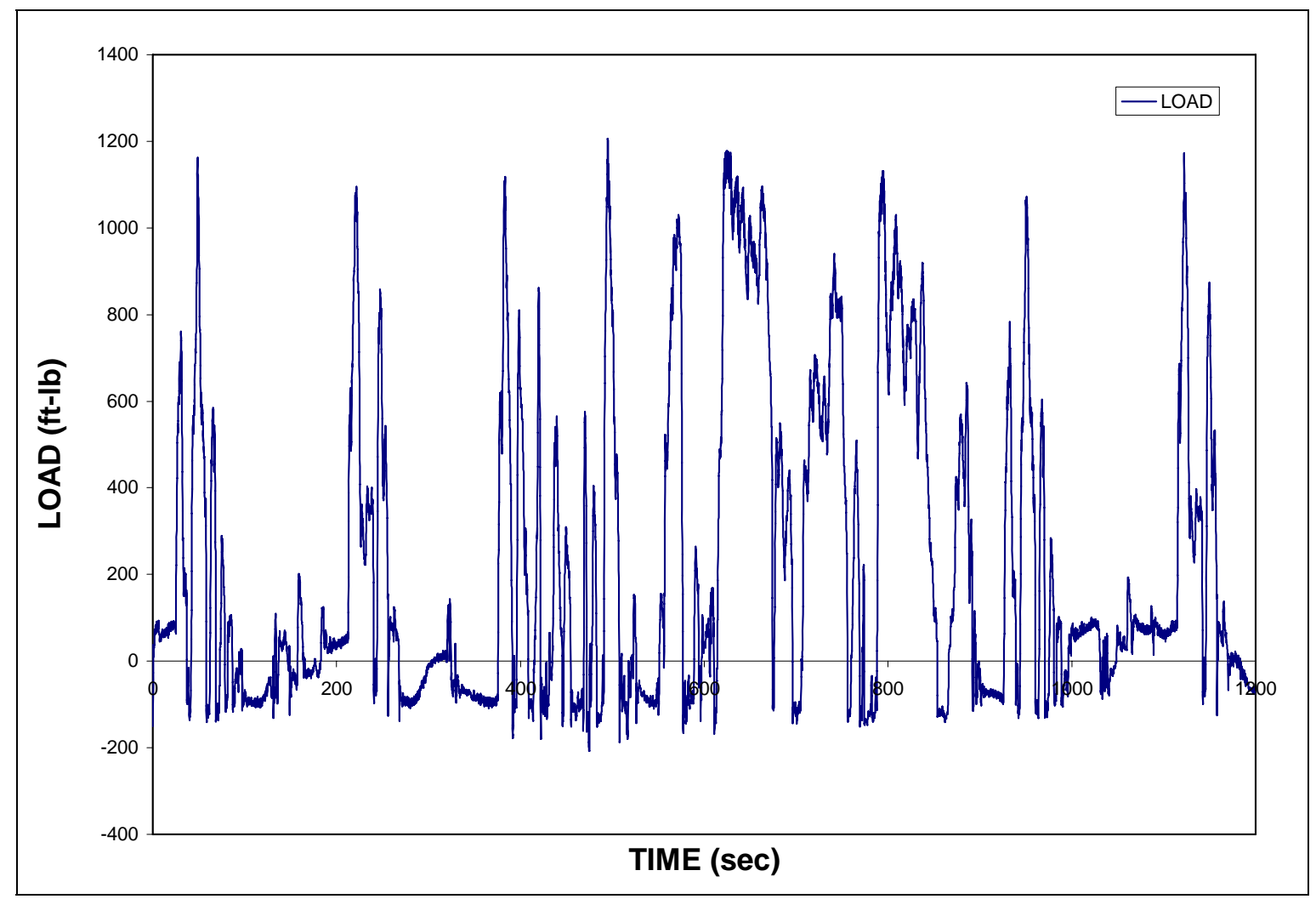

Figure 3-6 FTP Transient Heavy Duty Cycle Torque Set Points

\subsection{Gas Chromatography}

Chromatography refers to the analytical method of separation of a sample mixture into individual constituents. Gas chromatography is a field of chromatography which deals with the separation and analysis of gases. There are numerous other chromatography methods such as liquid, paper, thin-layer, ion-exchange, supercritical fluid, and electrophoresis. However only gas chromatography is reviewed here.

Hydrocarbon bag sample analysis systems normally consist of a GC with a detector and an instrument control/data acquisition computer. While the GC/detector system does the job of speciation of the sample into individual constituents and quantifying them the computer does the job of acquiring data from the GC and controlling the operating conditions such as temperature, 
sampling, valve switching, and signal processing associated with the GC. The two most basic and important components of a GC are the column and the detector. The selection of the column is based primarily on the compound(s) of interest. The column is housed in a chamber which is used to control the column to the required temperatures during the analysis. Figure 3-7 shows the commonly used setup of a GC system.

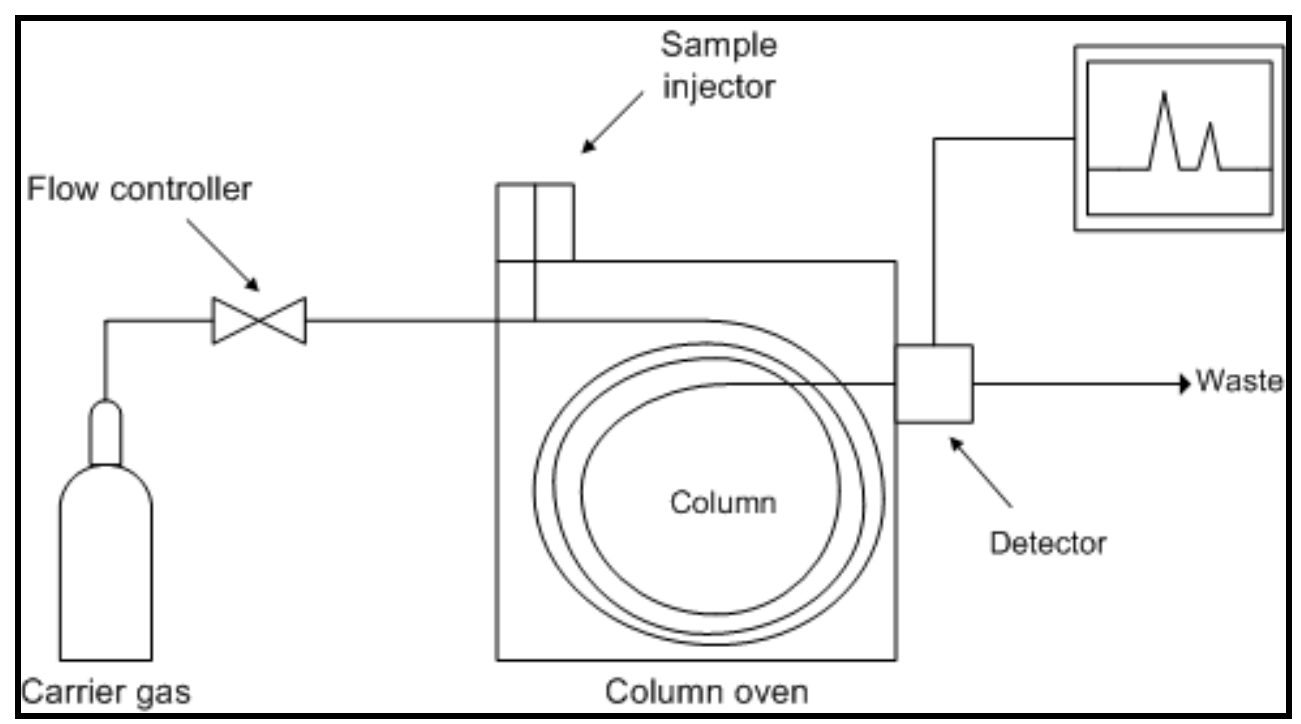

Figure 3-7 Typical Setup of a GC System [19]

A GC column consists of a certain length of thin tubing coated on the inside walls with adsorptive materials. The compounds of interest in the sample injected into the column get adsorbed onto the adsorbent coated column wall. The column temperature is normally kept below the boiling point of the compounds of interest during sample injection. With the application of the temperature rise profile to the column the adsorbed components, based on their adsorption inertia/boiling point, start eluting out of the column as a function of time, with a carrier gas. Comparison with the retention times of known standards helps in the identification of the eluting compounds. The separated samples eluting from the column flow into the FID flame. The FID has two electrodes which generate a current signal proportional to the number of ions 
formed by the ionization of the carbon atoms present in the sample passed through a hydrogen flame. This signal is then converted into a concentration value based on the height of the signal peak or the area under the signal peak in the signal versus time plot.

\subsubsection{Column}

The column is a critical component of a GC and include packed, capillary, EPA, chiral and porous layer open tubular (PLOT). It consists of a long length of tubing which can range anywhere from 10 meters to 60 meters with a very small inner diameter range of $0.20-0.53 \mathrm{~mm}$ with a fine coating of a solid or liquid adsorbent on an inert solid support packed in it [20]. Earlier columns were fabricated from copper, aluminum, glass and stainless steel. Modern GCs use fused silica capillary columns which enable high resolution separations [20]. As the sample gas flows through the column it becomes adsorbed onto the stationary phase. Each constituent in the sample desorbs off the stationary phase depending on their affinity to the stationary phase. The type of injection system and detectors should also be kept in mind while selecting a column [20].

Packed columns consist of a tube, packing material and packing retainers. In the case of gas liquid chromatography (GLC) solid supports are used in the tubing to support a stationary phase on them whereas in gas-solid chromatography (GSC) solid adsorbents without any coating are used as the packing. These supports are inert to the samples being analyzed. The most commonly used supports are diatomite and graphitized carbon supports while Teflon, inorganic salts and glass beads are used occasionally [20].

Capillary columns usually have long capillary tubes of very small inner diameter coated with a thin layer of stationary phase. They are known to have higher resolving power than the packed 
column due to their reduced resistance to carrier flow. Initially capillary columns were made of plastic and metal followed by stainless steel. Glasses like borosilicate and sodalime were also used and produced better results than metal capillaries. Fused silica emerged as the most suitable material for capillary columns. Capillary column facilitate improved detector sensitivity, stability, and signal-to-noise levels [20]. There is less column bleed in capillary columns due to the reduced thickness of the stationary phase in a capillary column.

EPA columns are available with its length, diameter, film thickness, and stationary phase configured for a particular EPA methods like the EPA 500 series, EPA 600 series, or EPA 8000 series methods. Manufacturers also consider the applicability of thicker films columns to eliminate the cryofocussing required in certain methods.

Columns with chiral stationary phases are used for the separation of optically active isomers. The speciality of the chiral stationary phase is that it can identify the difference in optical activities of the solutes in a sample. Chiral phases chemically bonded with polysiloxane have better thermal stability. The most commonly used chiral phase is Chirasil-Val [20].

PLOT columns consist of capillary tubing with a layer of adsorbent deposited on the inner wall instead of a liquid phase. Separations done with such columns are referred to as gas-solid chromatography.

\subsubsection{Adsorbents for Gas-Solid Chromatography}

The most commonly used adsorbents in gas-solid chromatography are the porous polymers. They are known to produce distinct bands when water in present in the sample and for this reason they are used for the analysis of aqueous solutions and for the determination of water in samples. They are also used for the analysis of gases, organics of low carbon number, acids and 
amines. A wide variety of porous polymers are available for specific categories of compounds making the selection of adsorbent much easier [20].

Also known as zeolites, these are aluminum silicates of alkaline earth metals and are used for the analysis of hydrogen, oxygen, nitrogen, carbon dioxide and methane. The selectivity of these sorbents to these substances is due to the matching of the pore sizes of the sieves to the molecular diameter of the substances. Due to the permanent adsorption of carbon dioxide at room temperatures the oxygen and hydrogen resolution deteriorates. The use of a pre-column helps to overcome this problem by adsorbing the carbon dioxide. The moisture content in the column packing has to be removed by heating the column to $300^{\circ} \mathrm{C}$ to prevent the rapid elution of the permanent gases [20].

Column packing containing carbon are available in two forms- carbon molecular sieves and graphitized carbon blacks. Permanent gases and hydrocarbons in the C1-C3 range can be separated using the carbonaceous sieves. Graphitized carbon blacks can be used as packing material in gas-solid as well as gas-liquid chromatography. When it is used in GLC it has to be coated with a stationary phase to deactivate its non-polar surface [20].

\subsubsection{Stationary Phase for Gas Liquid Chromatography}

The prevailing separation mechanism in GLC is the solute-stationary phase interaction and difference in the vapour pressure of the solutes [20]. Hence the phase should have selectivity towards the solutes. Bleeding from the phase can cause considerable distortion in the analysis by producing background noise. It should be able to operate over a wide temperature range. The stationary phase can be affected by contaminants in the carrier gas and the solid support. The 
viscosity and the wetting ability of the phase are important properties to be considered during phase selection. Commonly used stationary phases are polysiloxane and polyethylene glycol.

\subsubsection{Solid Supports for Gas Liquid Chromatography}

Diatomite is made up of diatom skeletons or single-celled algae found in large quantities across the globe as diatomaceous earth. The skeletons consist of hydrated microamorphorous silica with some impurities [20]. Due to its high porosity it has large surface areas. Two types of supports, namely white and pink, are made from diatomite. The pink colored supports have high specific surface areas and support $30 \%$ by weight of liquid stationary phase. The white diatomite supports have a lower surface area and can support only $25 \%$ by weight of liquid phase [20].

Diatomite supports are unsuitable when using polar analytes as they lose their inertness by bonding with the analytes and cause peak tailing. In such cases halocarbon supports can be used which have higher inertness. There are a few types available like Flouropak-80, Kel-F, and Teflon but Teflon has been found to yield the highest column efficiencies when coated with the proper stationary phase. These types of supports are normally used for the analyses of water, amines, HF, HCI, chlorosilanes, sulfur dioxide and hydrazine [20].

\subsubsection{Capillary Cages}

Due to the long lengths of capillary columns they need to be coiled to be installed in a gas chromatography. For this purpose cages are used around which the capillaries are wound. Usually columns with 0.10 to $0.32 \mathrm{~mm}$ I.D are wound of 5 to 7 inch diameter cages whereas 8 inch cages are used for megabore $(0.52 \mathrm{~mm})$ columns [20]. 


\subsection{Detectors in Gas Chromatography}

Detectors are used in gas chromatographic systems to quantify the speciated sample components present in the carrier gas. The most commonly used detectors are the thermal conductivity detector, FID and electron capture detector.

\subsubsection{Flame Ionization Detector (FID)}

The FID is the preferred detector due to its sensitivity to a wide range of organic compounds. The response of a FID is not affected by slight variations in carrier flow, temperature, or pressure. A FID consists of a flame fueled by hydrogen or hydrogen/helium mixture at the end of a jet. The sample components eluting from the column with the carrier gas are fed to the flame. The organic components pass through the flame are ionized to produce electrically charged ions. These ions are captured by collector electrodes producing a current which is proportional to the number of carbon atoms in the sample [20].

The dimensions of the jet depend on the size type of column and analysis. Tips of $0.018 \mathrm{in}$. internal diameter are used for packed columns while 0.011 in. internal diameter tips are used for capillary columns for desirable sensitivities. The smoothness of the tip is important to the detector operation and hence needs to be kept free from blockages. The flow rate of gases does influence the sensitivity of the detector as it determines the carrier gas and hydrogen ratio and depend on the type of gas used. The temperature of the detector is kept above the temperature of the column to prevent water condensation.

The most commonly used collector in a FID is a cylindrical electrode with a large surface area for maximum ion capture. An electric field applied to the collector, by means of a potential 
between the collector and a second electrode, draws the ions towards the collector. An electrometer is used to measure the current generated.

FID response, typically represented as the signal-to-concentration ratio, is mass sensitive -it responds to the number of carbon atoms entering per unit time. The response of the FID can be considerably affected by improper gas flow settings, column bleed and water in the air supply.

The FID has a wide linear range $\left(\sim 10^{7}\right)$ and can detect concentrations as low as $10^{-13} \mathrm{~g}$.C/s and has low noise.

\subsubsection{Detector Characteristics}

There are many parameters which are used to characterize a detector. The response of the detector to the flow of just pure carrier gas gives the baseline of the detector. Ideally the baseline is expected to remain constant but in reality it fluctuates due to noise. The ratio of the signal response of the detector to the concentration of the solute gives the response factor of the detector for that solute. Every detector produces a linear response only over a particular range of concentrations known as the linear dynamic range. Over this range the response factor of the detector is fairly constant.

\subsection{SAE J1151 Standard for Exhaust Methane Measurement}

This standard developed by the Society of Automotive Engineers (SAE) provides a method to determine the concentration of methane in automobile exhaust samples [21]. It is the prescribed method in the CFR for the determination of NMHCs in the exhaust samples. The setup of the instrument and the analysis procedure is explained below. 


\subsubsection{Varian 3600 Column}

A Porapak N column with 180/300 $\mu \mathrm{m}$ mesh, $610 \mathrm{~mm}$ (2ft) long, $2.16 \mathrm{~mm}$ internal diameter, and $3.18 \mathrm{~mm}$ outer diameter stainless steel column was used for the separation of air, methane and carbon monoxide from the rest of the sample. The column was conditioned for 12 hours at $150^{\circ} \mathrm{C}$ with carrier gas flow prior to first use. A Molecular sieve type 13X, 250/350 $\mu \mathrm{m}, 1220 \mathrm{~mm}$ long, $2.16 \mathrm{~mm}$ internal diameter, and $3.18 \mathrm{~mm}$ outer diameter stainless steel was used to separate methane from oxygen, nitrogen, and carbon monoxide. The column conditioning was similar to the Porapak $\mathrm{N}$ column. The FID installed in the GC was used to quantify the methane. The column and valves were maintained at a stable temperature using the oven in the GC. The setup of the valves, pressure regulators, pressure gages, and filters is shown in Figure 3-8.

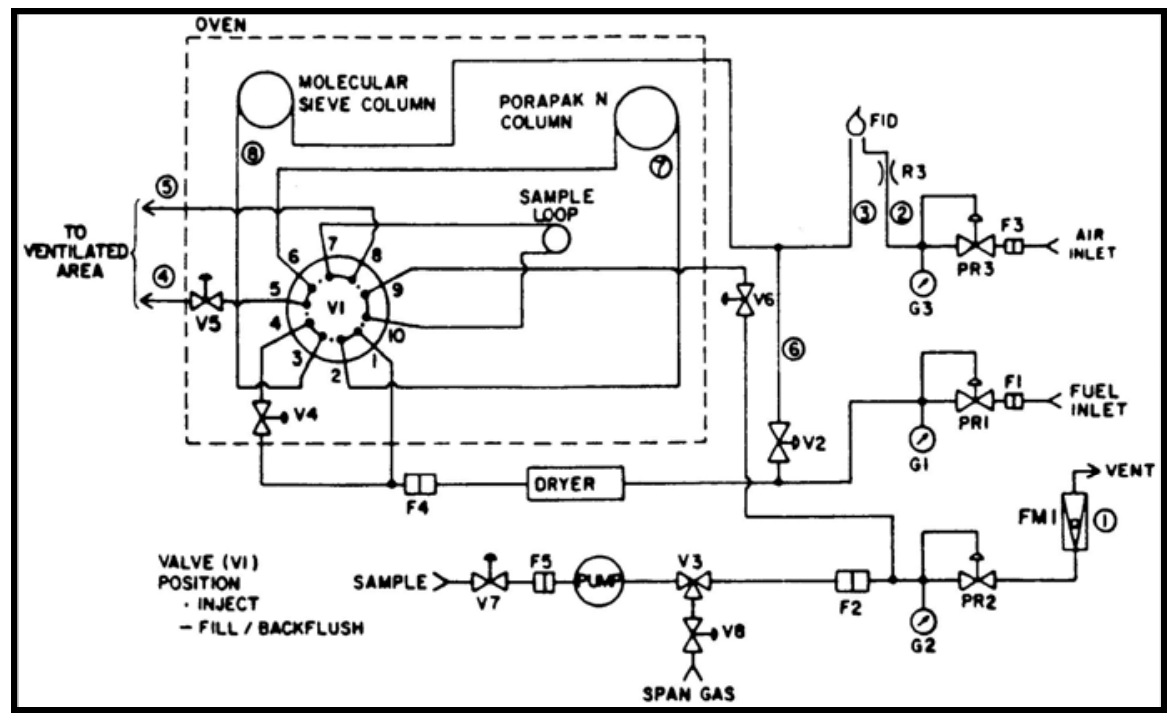

Figure 3-8 Typical Setup for SAE J1151 GC [21]

\subsubsection{Valves and Filters}

Valve V1 was used for sample injection and switching. Valve V2 served as a supplementary fuel supply to the FID. The selection of span, sample or no flow was done using valve V3. The flow resistance of the Porapak N column was matched through valve V4 while that of the Molecular 
Sieve column was matched using valve V5. V5 also allowed equalizing backflush and foreflush flow through the Porapak column. Valve V6 acted as a restrictor, controlling the sample flow into the sample loop. Valve V7 was used in conjunction with flow meter FM1 to regulate bypass sample flow rate. The bypass flow rate was set high enough so that the sample loop was flushed and filled with the next sample before the end of the analysis. Valve V8 equalized bypass flow rates of sample and span gas. Sintered metal filters F1, F3, and F4 were used to prevent grit from entering the instrument. Similar filters F2 and F5 were used in the sample stream to prevent grit from entering the pump and the instrument.

\subsubsection{Pressure Regulators and Pressure Gauges (PR1-PR3, PG1-PG3)}

Pressure regulator PR1 and gauge PG1 were used to control the flow of the fuel/carrier gas to the FID. Regulator PR2 and gauge PG2 regulated sample flow rate to the sample loop in conjunction with valve V6. Pressure was adjusted to be between 7 and $34 \mathrm{kPa}$. The air flow to the FID was controlled using restrictor R3, regulator, and gauge PR3 and PG3, respectively.

\subsubsection{Flow Rates}

The sample flow rate requirement was $2000 \mathrm{~cm}^{3} / \mathrm{min}$ (4 scfh). The back-pressure on the pressure regulator PR2 was set to a value between 7 and $34 \mathrm{kPa}$. The backflush flow through valve V1 was set to be between 80 and $100 \mathrm{~cm}^{3} / \mathrm{min}$. The carrier flow rate through the columns to the FID burner was set to about $70 \mathrm{~cm}^{3} / \mathrm{min}$ while the pressure regulator PR1 was set to $140 \mathrm{kPa}$. Mixed FID fuel was used as the carrier gas. The carrier gas flow rate through the Molecular Sieve column into the FID burner, with valve V1 in the fill backflush position, was set to be the same as that through the columns to the FID during injection. The backflush flow through valve V5 was same as the flow through the columns into the FID burner. The total hydrogen or mixed fuel 
flow to the burner was set to about $40 \mathrm{~cm}^{3} / \mathrm{min}$ using valve V2. The flow of air to the FID burner was set to ten times the hydrogen flow using pressure regulator PR3.

\subsubsection{Detector Linearity}

To ensure the linearity of detector response, a 3.114 ppmc methane gas bottle was mixed in varying percentages (40-100\%) with an ultra zero air using a gas divider to obtain seven samples. Each of these samples was analyzed three times on the GC. A least square regression straight line was obtained for the methane concentration as a function of the peak area count. The concentration of each sample was calculated using the equation from the least square straight line. Less than $2 \%$ deviation of the calculated concentrations from the actual concentration established linearity of the detector.

\subsubsection{Detector Noise}

An ultra zero air sample was analyzed on the GC ten times. The methane response was obtained from one of the calibration sample runs. The maximum peak-to-peak noise and drift from one of the ultra zero air runs was multiplied by the methane response to get a methane equivalent of the noise. Noise less than 0.16 ppm methane equivalent was considered acceptable.

\subsubsection{Precision and Column Resolution}

A 19.64 ppmC methane gas bottle sample was run 35 times. The standard deviation of the span gas readings was calculated. An average deviation less than $0.10 \mathrm{ppm}$ proved the precision of the instrument. Also the difference between the first run and the mean of the series was calculated and checked to see if less than the $0.14 \mathrm{ppm}$ or three times the standard deviation whichever was greater. The methane retention time was divided by the peak width at half height. A value greater than 10.5 represented acceptable resolution. 


\subsubsection{Sample analysis}

Analysis of each set of sample bags was preceded and succeeded by a zero and span gas run. The instrument was calibrated on the span gas run after each sample analysis. If the span gas measurement after a sample was not within $2 \%$ of the span gas value the sample was retested. In the beginning of the analysis valve V1 was placed in the fill/backflush position. The sample loop was flushed and filled with the sample. V1 was then switched to the inject position and the sample was injected into the Porapak N column. Air eluted out of the Porapak N column followed by methane leaving behind carbon dioxide, higher hydrocarbons, and water vapour. V1 was kept in the inject position only till maximum methane response was obtained. The gases were then passed on to the Molecular sieve column. V1 was switched to the fill/backflush position and the Porapak N column was flushed of the remaining sample and was ready for the next sample. The Molecular Sieve column separated the methane from air and carbon monoxide. The order of elution from the Molecular Sieve column was oxygen, nitrogen, methane, and carbon monoxide. The FID did not respond to nitrogen and carbon monoxide. The total analysis took three minutes to complete. 


\section{TEST PROGRAMS AND DATA ANALYSIS}

\subsection{Introduction}

Data was collected from a variety of test programs involving different types of fuels over a period of more than thirteen months. The focus was on the methane concentration values from the laboratory's bench analyzer, methane data from the GCs and the subsequent NMHC value obtained by subtraction. In the first half of the study, bag samples were analyzed on two different GC configurations, SAE J1151 and WVU method, for methane measurement in exhaust and the results were compared. In the latter part of the study, the methane data from a CAI model 600 HFID analyzer was compared to the methane data obtained from a GC configured on the SAE J1151 standard. Correlation between the two sets of data was studied. The methane concentrations ranged from a few ppm to concentrations in the high 100 ppm range. Fuels used include CNG, biodiesel, and diesel.

\subsection{Test Programs}

Data collected for the study were from samples collected from four different test programs. For the first half of the study the samples analyzed were from chassis dynamometer testing of CNG buses. The bag samples from the tests were analyzed using the in-house WVU GC method for THC and methane determination and a GC configured on the SAE J1151 standard. The methane concentration values obtained from the two GC systems were compared. The THC results from the WVU GC and the analyzer in the transportable laboratory were also compared. Since the methane concentration in CNG exhaust is high, a 100 ppm methane concentration gas bottle was used to calibrate both GCs. This set of data facilitated the comparison of the two GCs at higher concentration levels. 
To compare the two GCs at low-end concentrations five minute timed background run samples were collected from the engine dynamometer test cell to examine ambient background concentration levels. This was done by passing ambient air through the dilution tunnel into the analyzers. A total of ten background runs were done. The secondary hydrocarbon analyzer used, a CAI model 600 HFID, was capable of measuring THC or methane. Hence, for the first five runs the analyzer was set in the THC mode and in the methane mode for the next five. The bag samples were then analyzed using the two GC configurations as before. The calibration gas used in this case was a 3.114 ppm methane gas bottle for the SAE J1151 GC and SRM 1660a gas bottle of 3.94 ppm methane concentration for the WVU GC method.

Samples collected from FTP tests carried out using biodiesel fuel were analyzed using the two GC systems to cover the normal concentration levels. In the later half of the study samples were collected from FTP tests using twelve different fuel blends and analyzed using the SAE J1151 GC to determine the methane concentration. During the tests the CAI model 600 HFID was set in methane mode. The dilute and background bag methane concentrations from the analyzer were compared with those obtained from the GC.

A total of 17 dilute and background samples were collected with different blends of reference, candidate and additized fuels used in a fuel study. The CAI HFID analyzer was set in methane mode. The samples were analyzed on the SAE J1151 GC. This facilitated a comparison of the bench analyzer's capability of measuring methane to that of the SAE J151 GC.

To study the repeatability of the CAI HFID analyzer, four 80 liter bags were simultaneously filled with sample from a sixty minute timed background run. This was done to have enough of the same sample to perform repeated measurements of methane over a period of three days. Bag 
\#1 was first connected up to the analyzer and sample was pumped through for $2 \frac{1 / 2}{2}$ minutes, as it is done after a hot start FTP test, to obtain the bag data. After acquiring the bag data the analyzer was allowed to stay idle for 40 minutes and another bag analysis was done. This procedure mimics the time duration of bag sample analysis during an actual day of engine testing and gave a good insight into the repeatability of the CAI analyzer. Similar analysis was done using the other three bags over different days. Additionally, 3 liter Tedlar bag samples are taken from each bag after methane measurement on the analyzer and analyzed on the SAE J1151 GC.

\subsection{Gas Chromatographic Analysis}

The two GC methods used for quantification of methane are based on different columns and configured for different types of analyses. Hence there are differences in the temperature settings, analysis times and gases required for analysis.

\subsection{SAE J1151 Method}

The SAE J1151-based system takes three minutes for a single analysis and operates under isothermal conditions. Pure helium is used as carrier gas while fuel for the FID is $40 \%$ hydrogen, $60 \%$ helium blend. The temperatures of the column and auxiliary are maintained at $50^{\circ} \mathrm{C}$ throughout the analysis while that of the FID is maintained at $250^{\circ} \mathrm{C}$. Two columns are connected in series to sequentially separate the methane in the sample from the rest of the sample. The Porapak column through which the sample passes first separates methane, carbon monoxide and air from NMHC, water and carbon dioxide which are removed by backflushing. The remaining sample passes through the Molecular sieve column and elute in the following order- oxygen, nitrogen, methane and carbon monoxide. The FID responds to the methane in the sample but not to nitrogen and carbon monoxide. Though the setup shown in Figure 3-5 is 
typical, the setup used in the CAFEE laboratory is a much simpler one and does not incorporate the numerous filters, valves and pressure regulators seen in the typical setup. However two ten port pneumatic valves were used for sample routing.

\subsection{WVU In-house Method}

The WVU in-house method is more complex as it is designed to speciate the different hydrocarbons in the sample and takes thirty seven minutes to complete. It makes use of cryofocussing and heating for adsorption and elution of the components of interest, respectively. The temperature of the detector and auxiliary heater is maintained at $250^{\circ} \mathrm{C}$ and $200^{\circ} \mathrm{C}$ respectively, for the entire duration of the analysis. An alumina column is used in this GC system. Liquid nitrogen is used to cool the oven to $-60^{\circ} \mathrm{C}$. Before the start of sample injection, the column is cooled to $-60^{\circ} \mathrm{C}$ and allowed to stabilize for thirty seconds. After the start of analysis the temperature is held at $-60{ }^{\circ} \mathrm{C}$ for two and a half minutes. The temperature is then increased to $200{ }^{\circ} \mathrm{C}$ at a rate of $20{ }^{\circ} \mathrm{C} / \mathrm{min}$ and held at that point for twenty minutes. This programmed heating of the column causes the hydrocarbons in the sample to elute one by one with good enough resolution for quantification. The temperature profile of the column during the analysis is shown in Figure 4-1. 


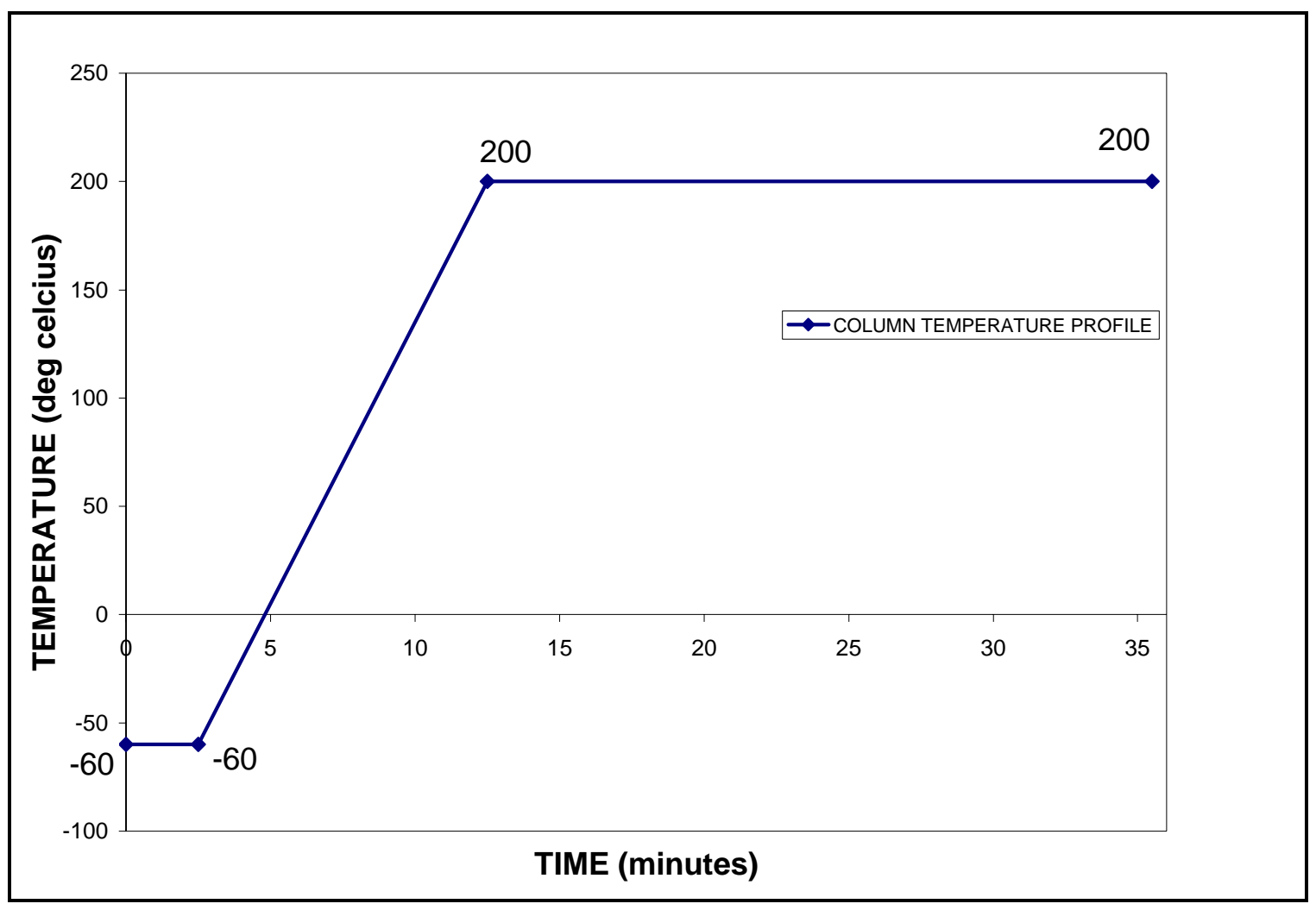

Figure 4-1 WVU Method Column Temperature Profile

\subsection{Data Analysis}

The data from the GCs is processed by the Varian GC workstation software. The software calculates the area under the signal peaks of interest in the detector signal versus time plot and coverts it to a concentration value based on the response factor of the FID to that particular hydrocarbon. This response is determined by calibrating the FID on known standards. Typical chromatograms obtained with the two GC methods for exhaust samples are shown in Figure 4-2 and Figure 4-3. Noise in the detector signal is neglected based on the signal-to-noise ratio ( $\mathrm{S} / \mathrm{N})$ preferred. This ensures that unwanted noise peaks are not considered as sample peaks. The initial peak observed in the chromatogram obtained with the SAE J1151 GC as well as the WVU inhouse GC is the synergistic effect of the oxygen to the hydrocarbon impurity in the fuel. The dips 
observed in the detector signal before the oxygen peak occurs during valve switching when momentarily there is no flow through to the FID.

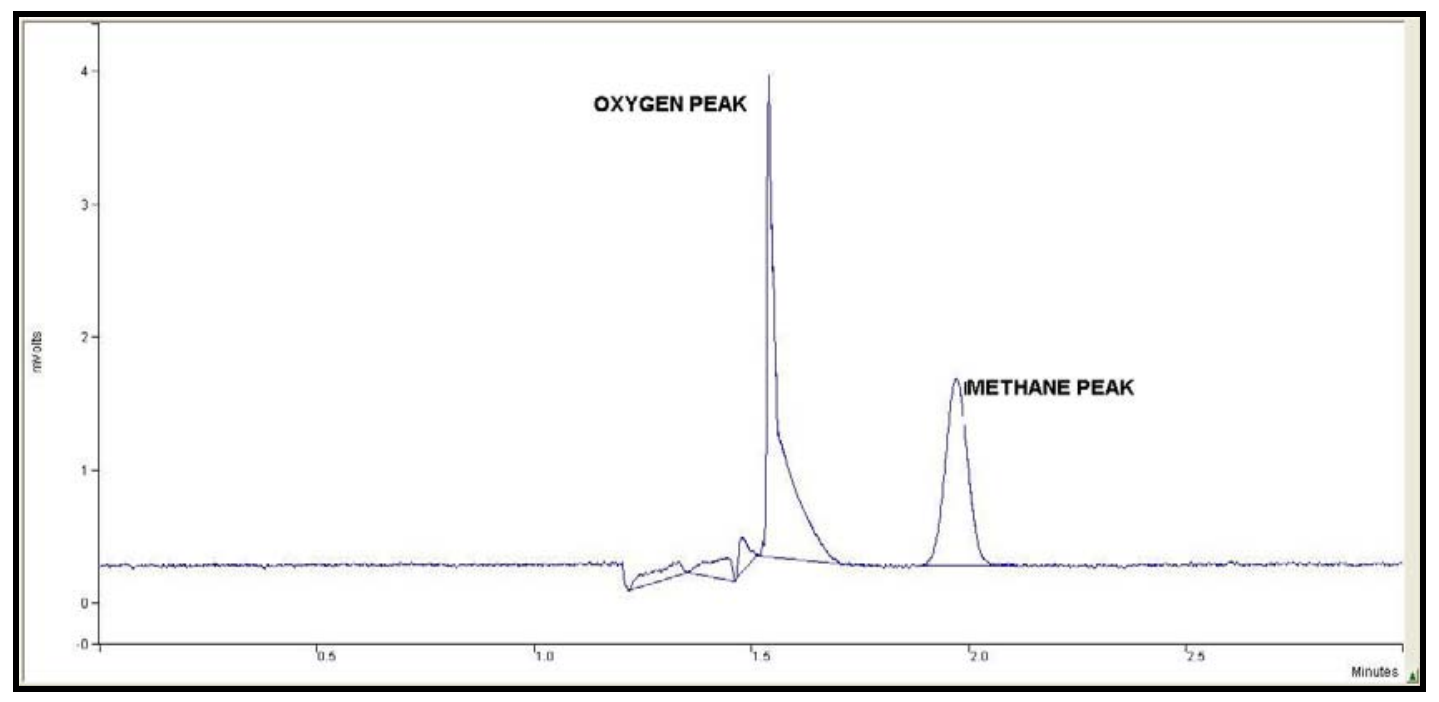

Figure 4-2 Typical Chromatogram from SAE J1151 GC Method

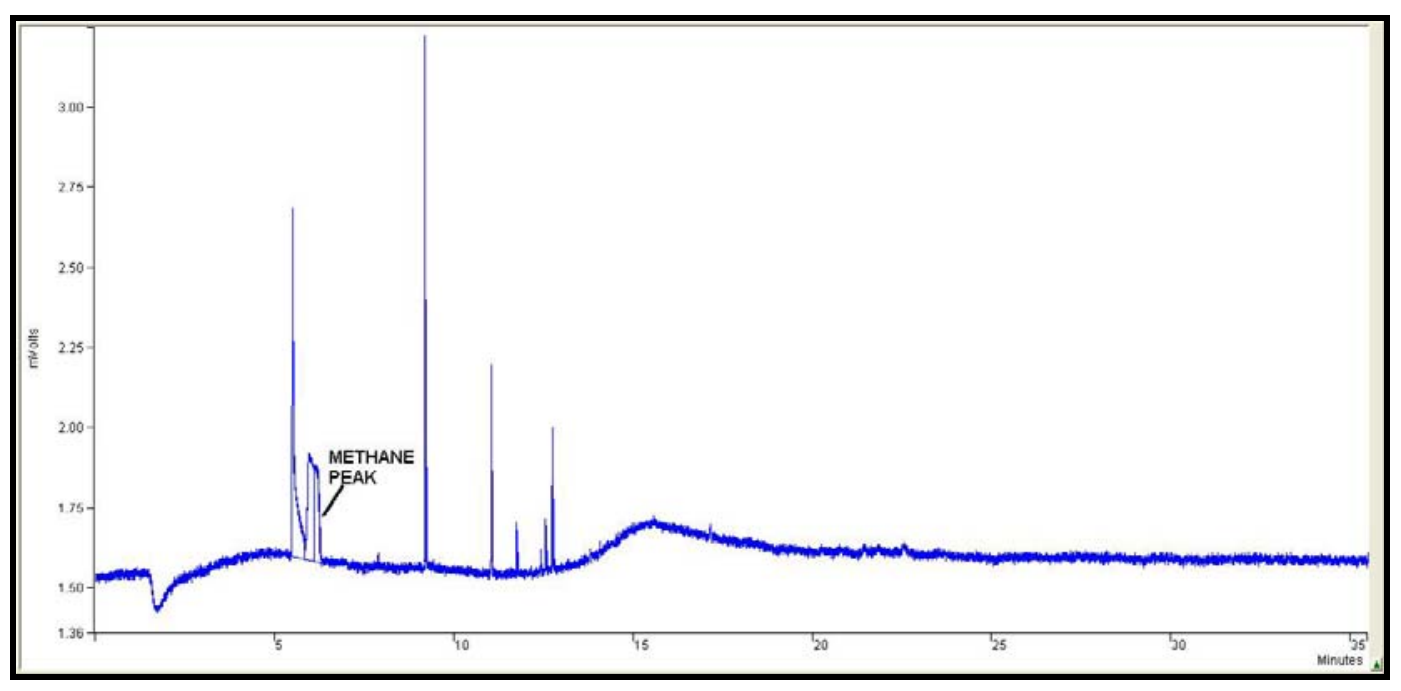

Figure 4-3 Typical Chromatogram from WVU GC Method

Since the WVU in-house GC method is primarily designed to quantify total hydrocarbons in the sample the response of the FID to propane in SRM 1660a is used to quantify unidentified hydrocarbons in the chromatogram. The two successive peaks emerging after the methane peak in the WVU GC method are propane and ethane respectively. All the other peaks are unidentified 
and are quantified on a propane response. It can be noted from the chromatograms for the two methods that the methane peaks are very different. This is due to the elution characteristics of methane to the different types of columns used in the two GC methods. 


\section{RESULTS AND DISCUSSION}

Data are presented summarizing the comparison of the WVU developed GC method for THC speciation, the SAE J1151 method for the determination of methane content in exhaust bag samples, and the California Analytical Instruments (CAI) model 600 HFID THC analyzer with non-methane cutter. The majority of the data presented used in the comparison are for background and dilute diesel exhaust bag samples from heavy-duty FTP tests. Some data obtained from CNG vehicles tested on the WVU Translab chassis dynamometer were used to compare the SAE J1151 and WVU GC methods at higher concentrations of methane.

\subsection{Comparison Between SAE J1151 and WVU GC Methods}

Correlations between the SAE J1151 and WVU GC methods were examined by using parity plots for tunnel background dilute diesel exhaust and CNG sample data. Using data from different fuels helped in testing the correlation over a wide range of methane concentrations ranging from as low as $2 \mathrm{ppm}$ to as high as $170 \mathrm{ppm}$.

In the comparison of results from the tunnel background samples, good correlation was seen in the dilute bag methane results from the SAE J1151 and CAI HFID analyzer method as shown in Figure 5-1. The correlation observed in the background bag data, not shown here, was poor with an $\mathrm{R}^{2}$ of 0.66 . The percentage differences in the two results varied from $3.25 \%$ to $14.34 \%$. The standard deviation of the percentage variations were 3.45\% from a mean variation percentage of 7.13\%. This, however, is not suspected to be any variation in the instrument response to the samples from the background bag but is believed to be due to inconsistent sample collection due to a tear in the background bag. Therefore, the background bag data from these tests will not be 
used in this study. This theory is corroborated by a test of significance of the correlation coefficient at a $1 \%$ significance level which suggested that there was positive correlation between the background results. Similar analyses of the significance of correlation coefficients and the difference in results between the methods compared were carried out for all of the individual data sets that were used for the comparison study and are summarized towards the end of this chapter.

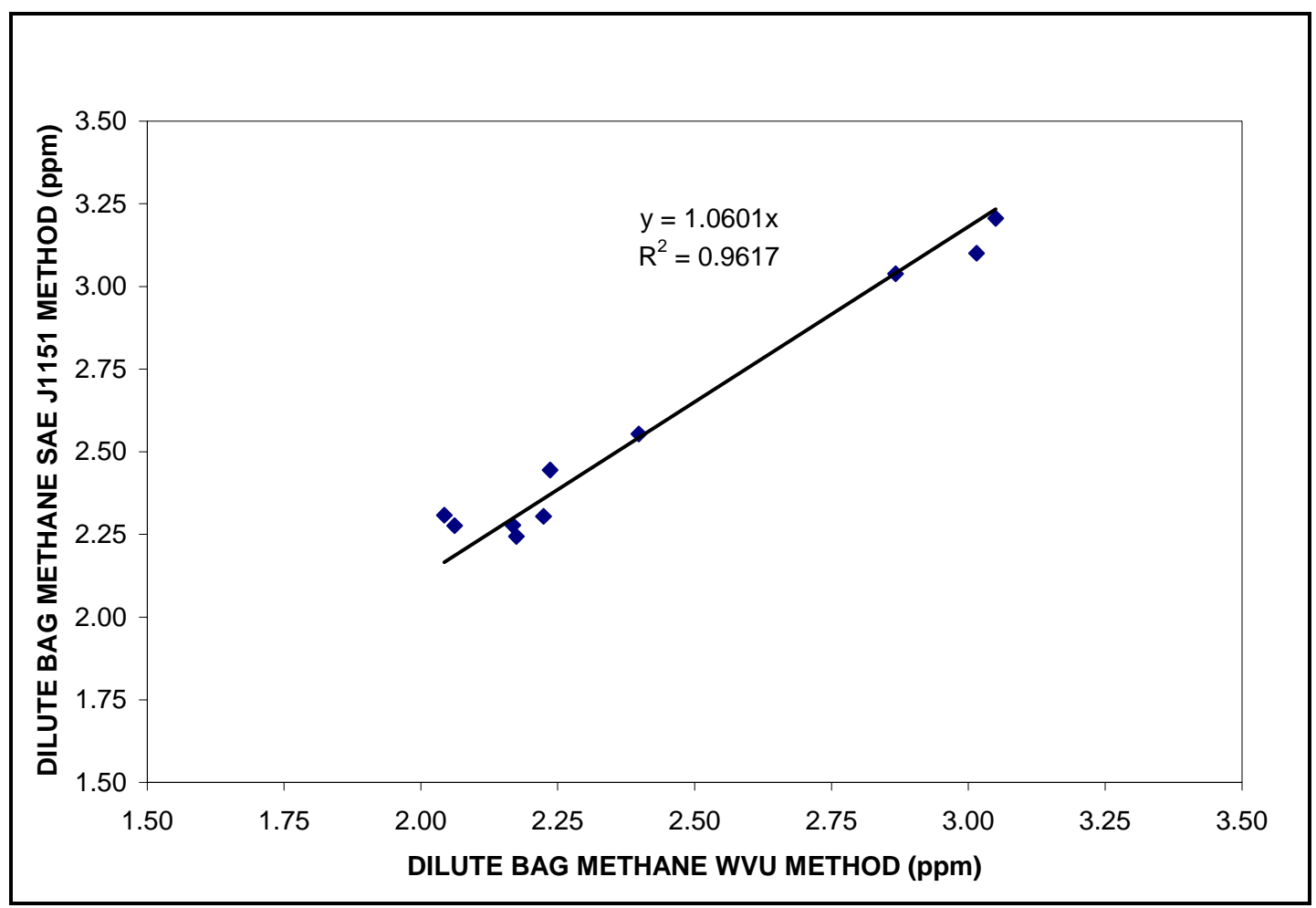

Figure 5-1 Comparison of Dilute Bag Methane between SAE J1151 and WVU Method for Tunnel Background Samples

Correlation analysis of the THC results from the WVU GC method and the Horiba bench analyzer, seen in Figure 5-2, showed poor correlation with an $\mathrm{R}^{2}$ value of -7.81 . The correlation was only slightly better between the CAI HFID and Horiba HC analyzer THC results with an $\mathrm{R}^{2}$ of 0.65 for the combined dilute and background results. The comparison of the CAI HFID and Horiba HC analyzer is shown in Figure 5-3. 


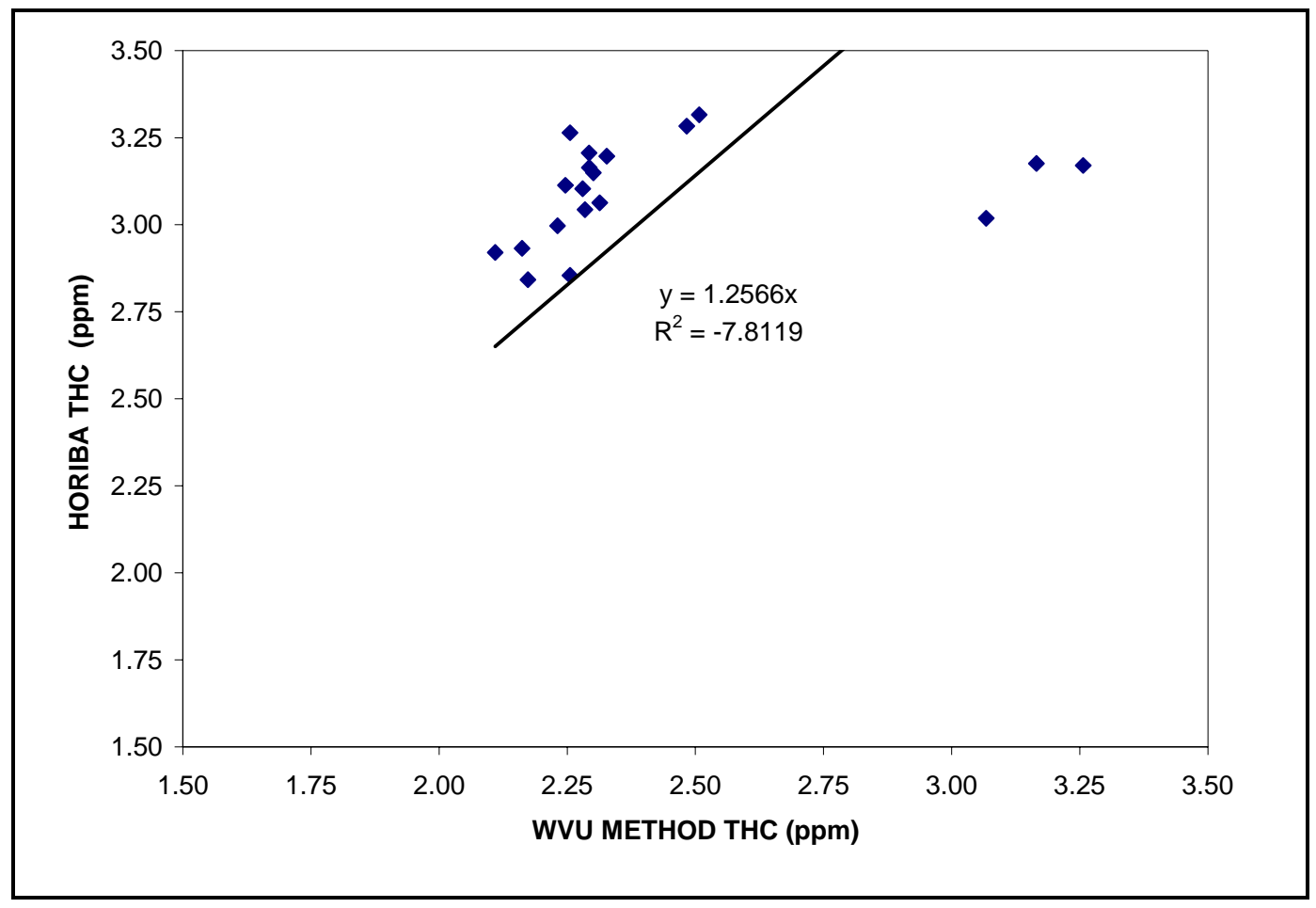

Figure 5-2 Comparison of Dilute and Background Bag THC from Horiba Analyzer and WVU GC Method

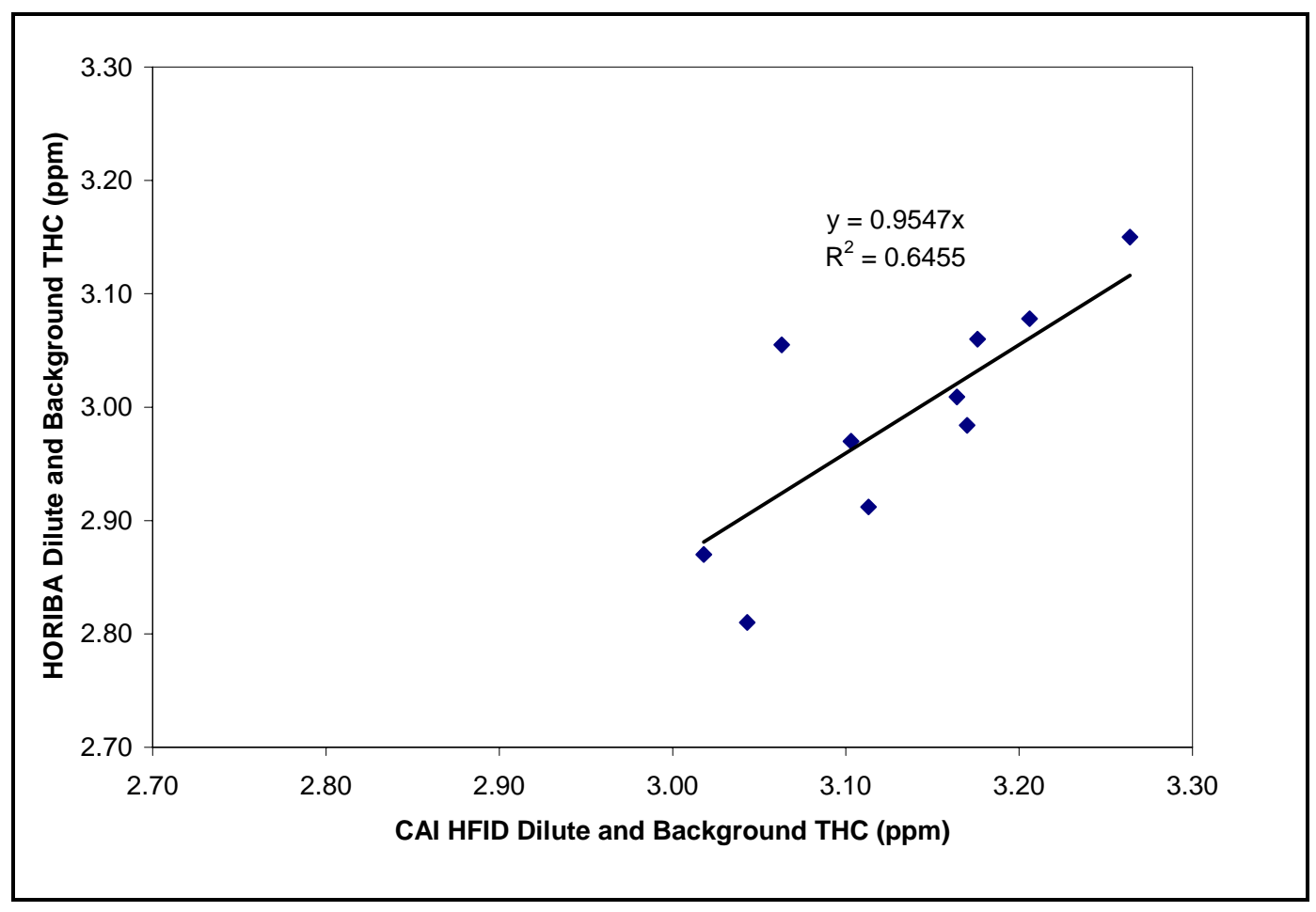

Figure 5-3 Comparison of Dilute and Background Bag THC from CAI HFID and Horiba 
The THC results from the Horiba HC analyzer and the WVU GC method for tunnel background are shown in Figure 5-4. Whereas the THC results from the two methods (also includes CAI HFID results) for diesel based exhaust samples are shown in Figure 5-5. It can be seen from the two figures that in the case of diesel based exhaust samples the THC results from the WVU GC method are about 7 ppm less than the results from the bench analyzers but the difference is much smaller in ambient air sample results. This is due to the fact that the heavy hydrocarbons typically seen in diesel exhaust tend to hang up in the sample bags and are not transferred to the detector for quantification. Since heavy hydrocarbons are not present in ambient air the differences in THC results are small.

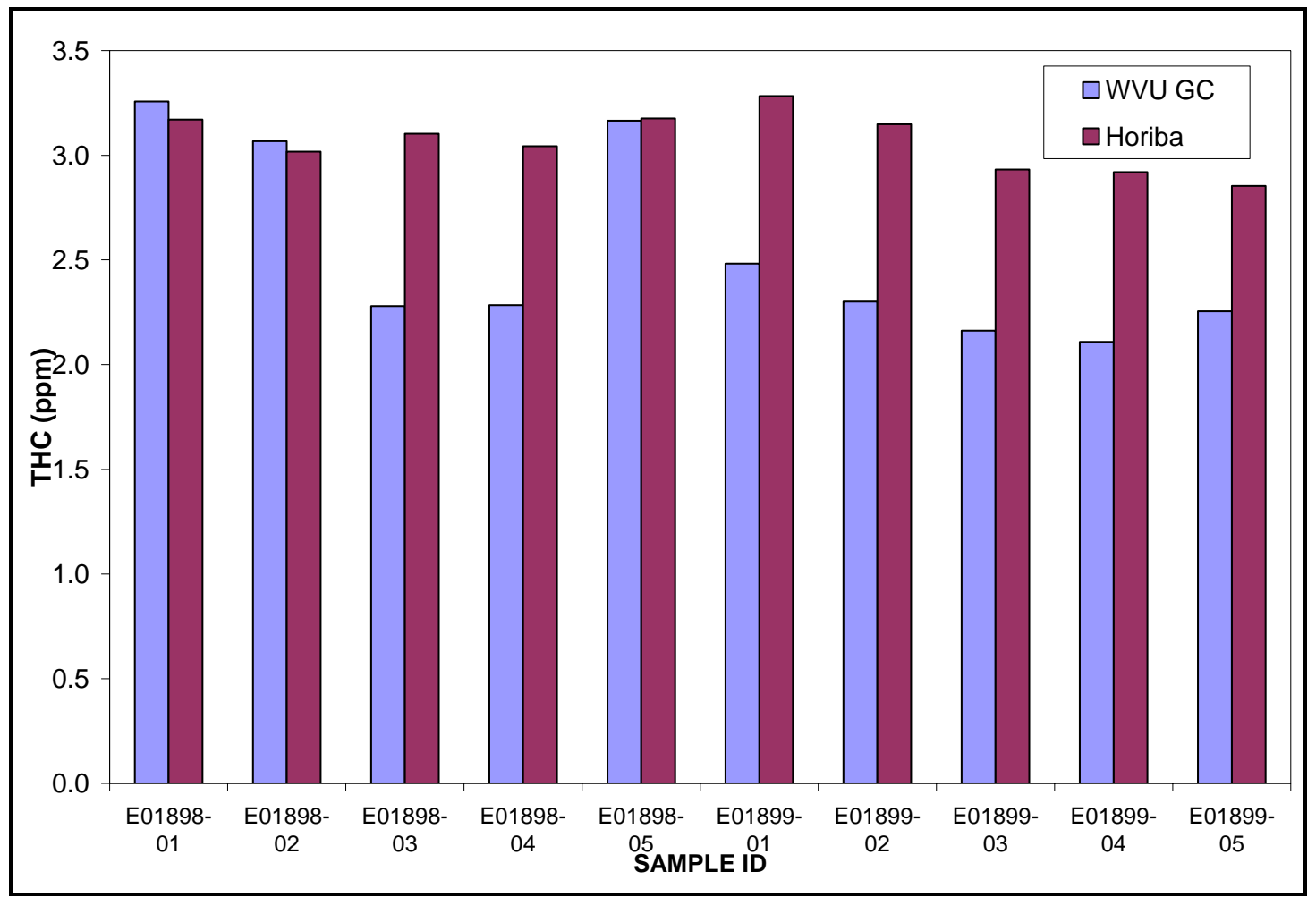

Figure 5-4 Dilute Bag THC Results for Tunnel Background Samples 


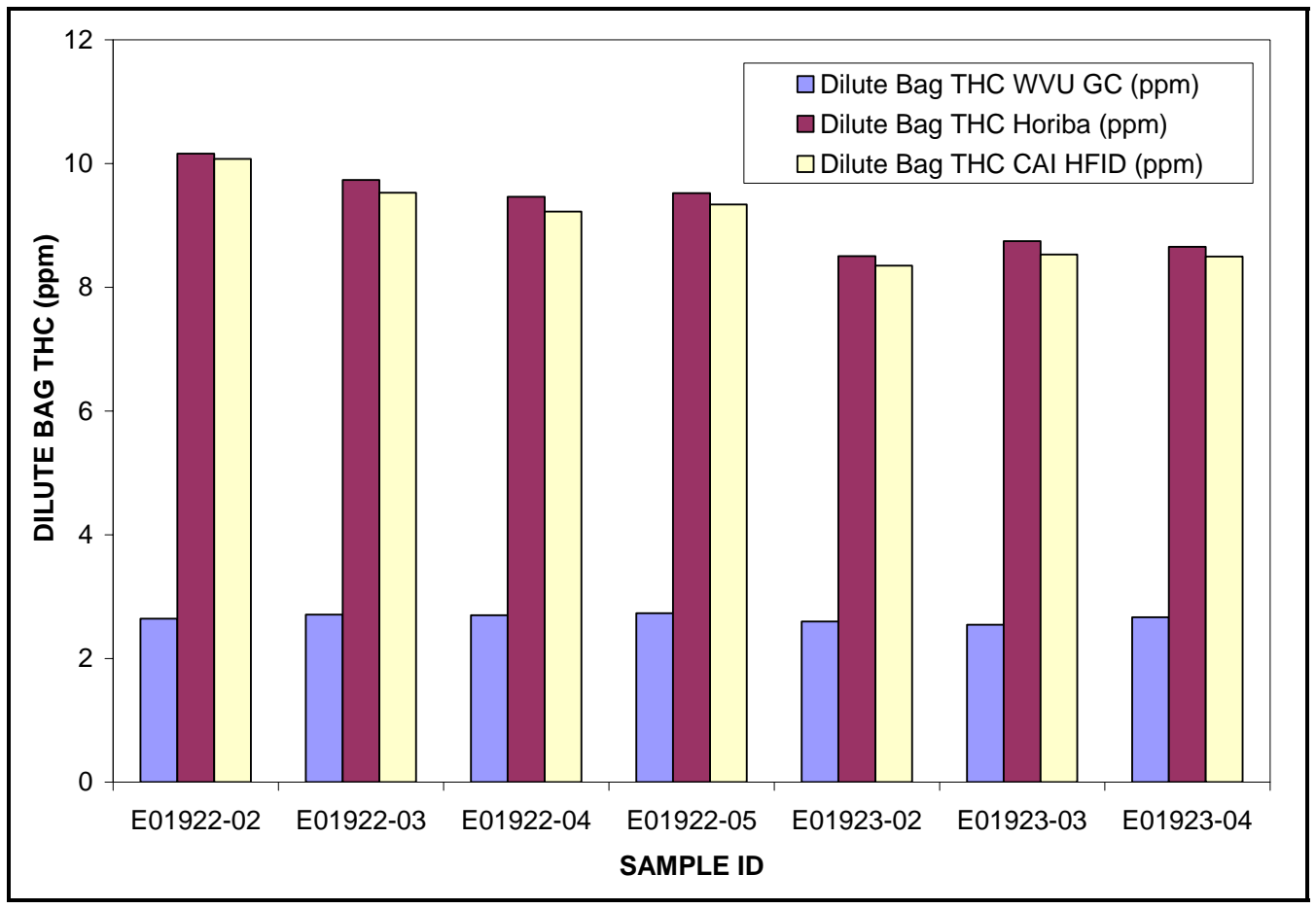

Figure 5-5 Dilute Bag THC Results for Diesel-Based Exhaust Samples

However the WVU GC method is not intended for THC measurements at ambient or dilute diesel exhaust concentration levels and similarly the CAI HFID analyzer is expected to be used for methane measurements hence these correlation are not of much importance and are for the sake of painting a general picture of the capabilities of these GC methods.

The curve fit for the methane results for CNG vehicle samples from the SAE J1151 and WVU GC’s shown in Figure 5-6. Similar to the results obtained from the background dilute bag samples, the results obtained for the CNG samples exhibit good consistency and clearly indicate an excellent correlation between the two methods with an $\mathrm{R}^{2}$ value of 0.991 . Removing the one possible outlier does not cause any significant improvement in the $\mathrm{R}^{2}$. The WVU GC method results are higher than the SAE J1151 results by 4.96\%. The percentage difference had an average of $4.77 \%$ with a standard deviation of $1.77 \%$ excluding the one possible outlier. Since this fit is done for a large set of data between $17 \mathrm{ppm}$ and $170 \mathrm{ppm}$, the trend observed is a fairly 
good indication of the strength of the relationship between the two methods i.e. there is a consistent bias of the WVU GC method methane measurements over the SAE J1151 methane measurements. The curve fit for the background samples collected in the same CNG vehicle chassis dynamometer test project corroborates the inferences from the exhaust gas sample curve fit. In this case the fit, as seen in Figure 5-7, shows that the WVU in-house method had a 5.07\% bias over the SAE J1151 method with a $\mathrm{R}^{2}$ value of 0.9985 . This goodness of fit is not perceived contradictory to the poor correlation observed with the tunnel background test data as the methane concentration ranged from $2.075 \mathrm{ppm}$ to $10.165 \mathrm{ppm}$, a higher range than the tunnel background sample methane concentration range and the inconsistent sample collection suspected in the tunnel background test background bag due to a tear in it.

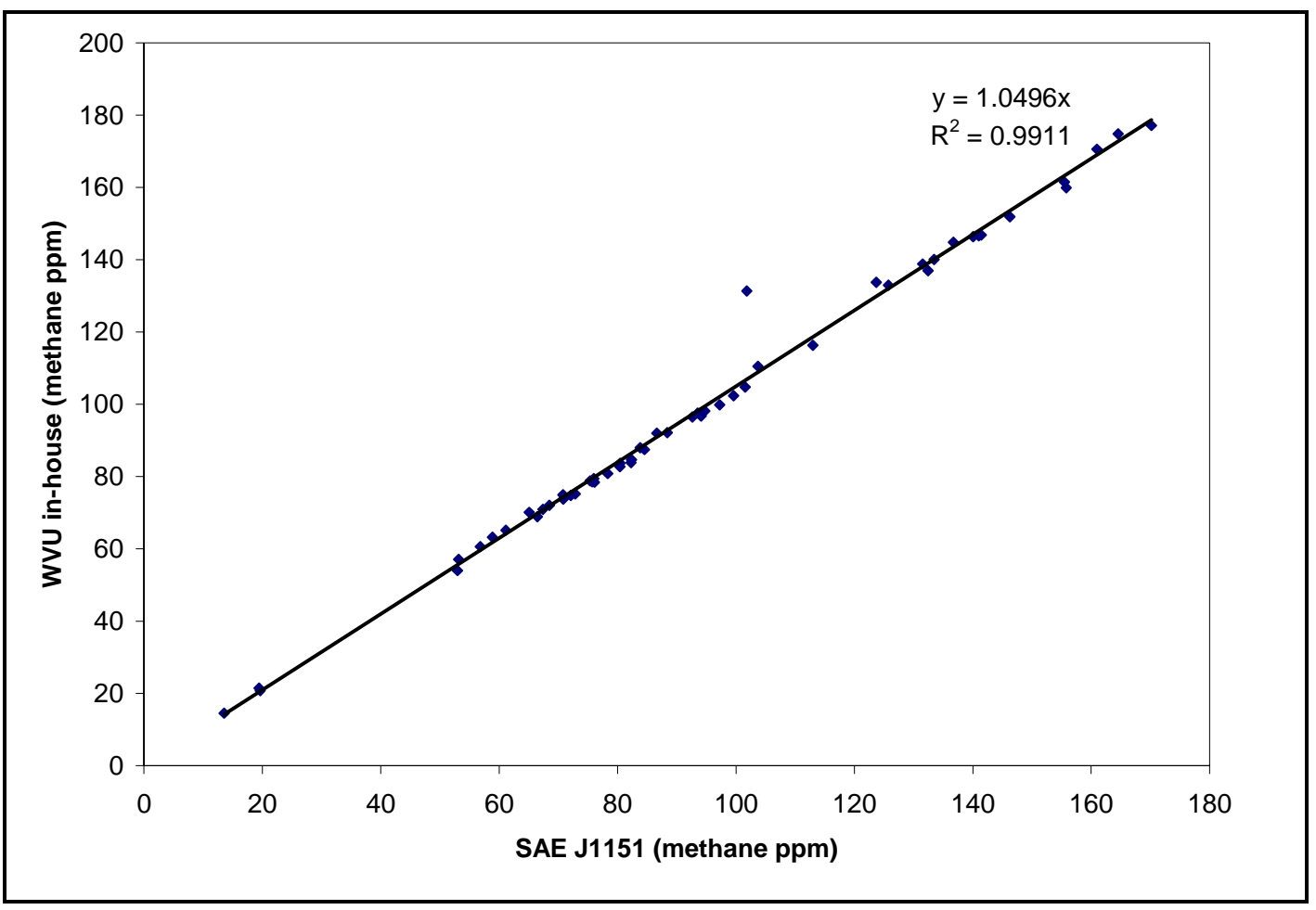

Figure 5-6 Comparison of Dilute Natural Gas Sample Methane from SAE J1151 and WVU Method 


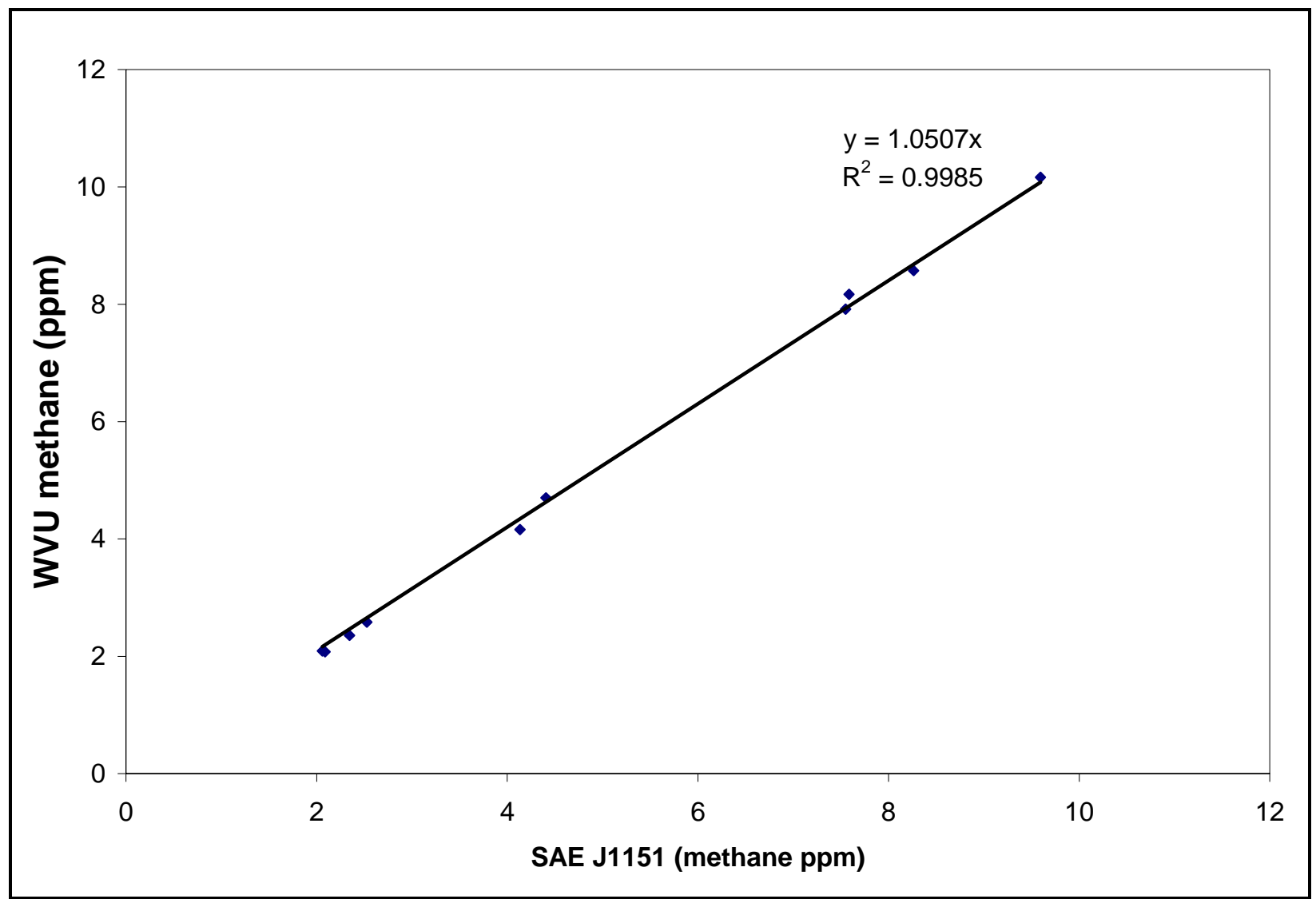

Figure 5-7 Comparison of Transportable Laboratory Background Bag Methane from SAE J1151 and WVU Method

Comparison of the methane results of the two GC for biodiesel samples showed poor correlation.

Figure 5-8 and Figure 5-9 show the comparison of the dilute and background bag values along with the trend lines respectively. However the ranges in concentrations are very small, on the order of $0.14 \mathrm{ppm}$, and within the allowable drift limits of the analyzer and thereby making it hard to identify any difference in the two methods. 


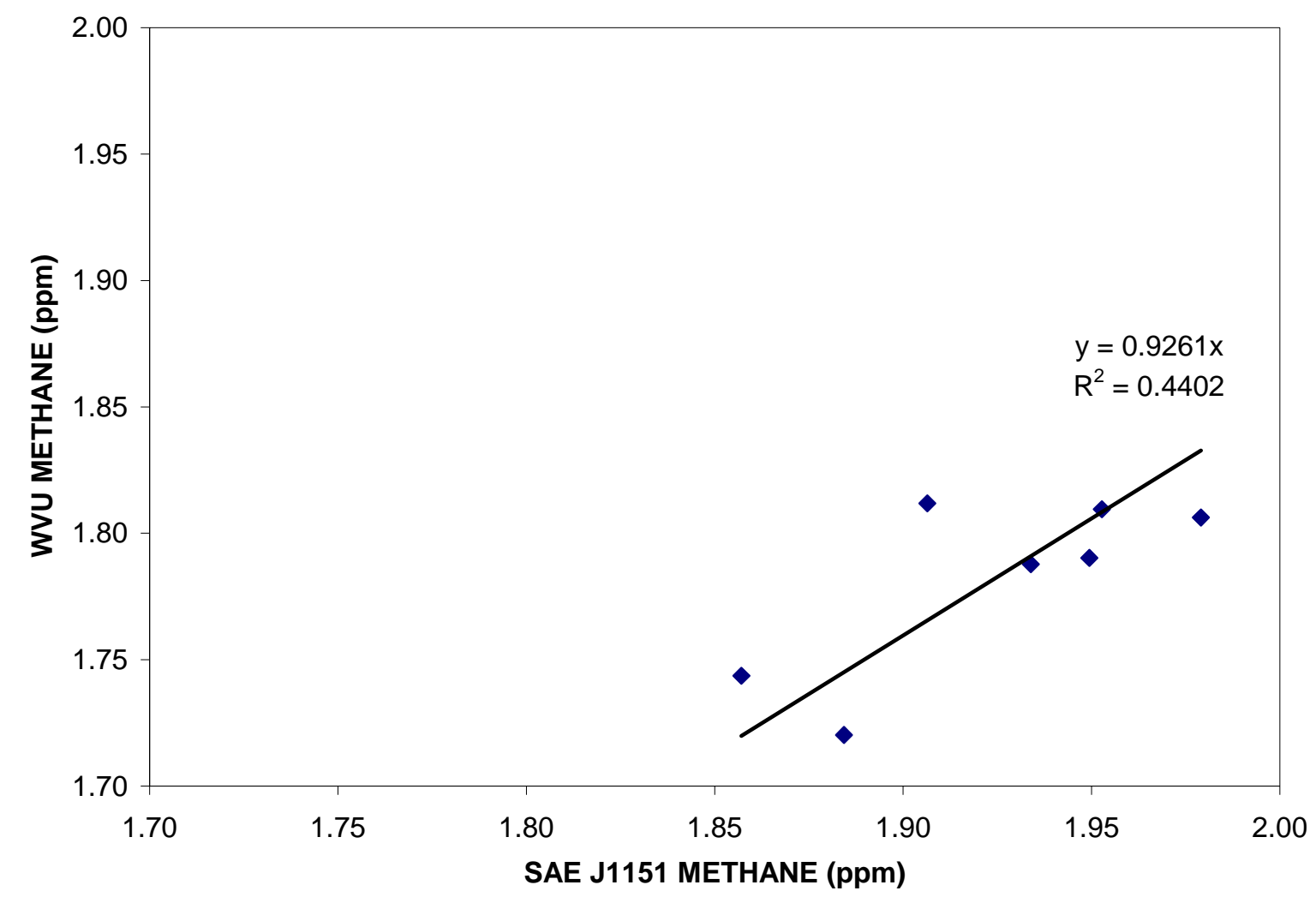

Figure 5-8 Comparison of Bio-Diesel Sample Dilute Bag Methane from SAE J1151 and WVU Method

It was also observed that the dilute bag THC results of the Horiba and CAI HFID HC analyzers, from the same test, were greater than $8 \mathrm{ppm}$ while the results from the WVU methods were less than 3 ppm. Similarly the background bag analyzer results were greater than $3.50 \mathrm{ppm}$ while the GC results were less than $2 \mathrm{ppm}$. This was due to the fact that heavy hydrocarbons in diesel exhaust hang up in the sample bag and do not emerge with the sample. These differences indicate possible deterioration in the bag samples. Within the analyzers the THC results had good agreement. 


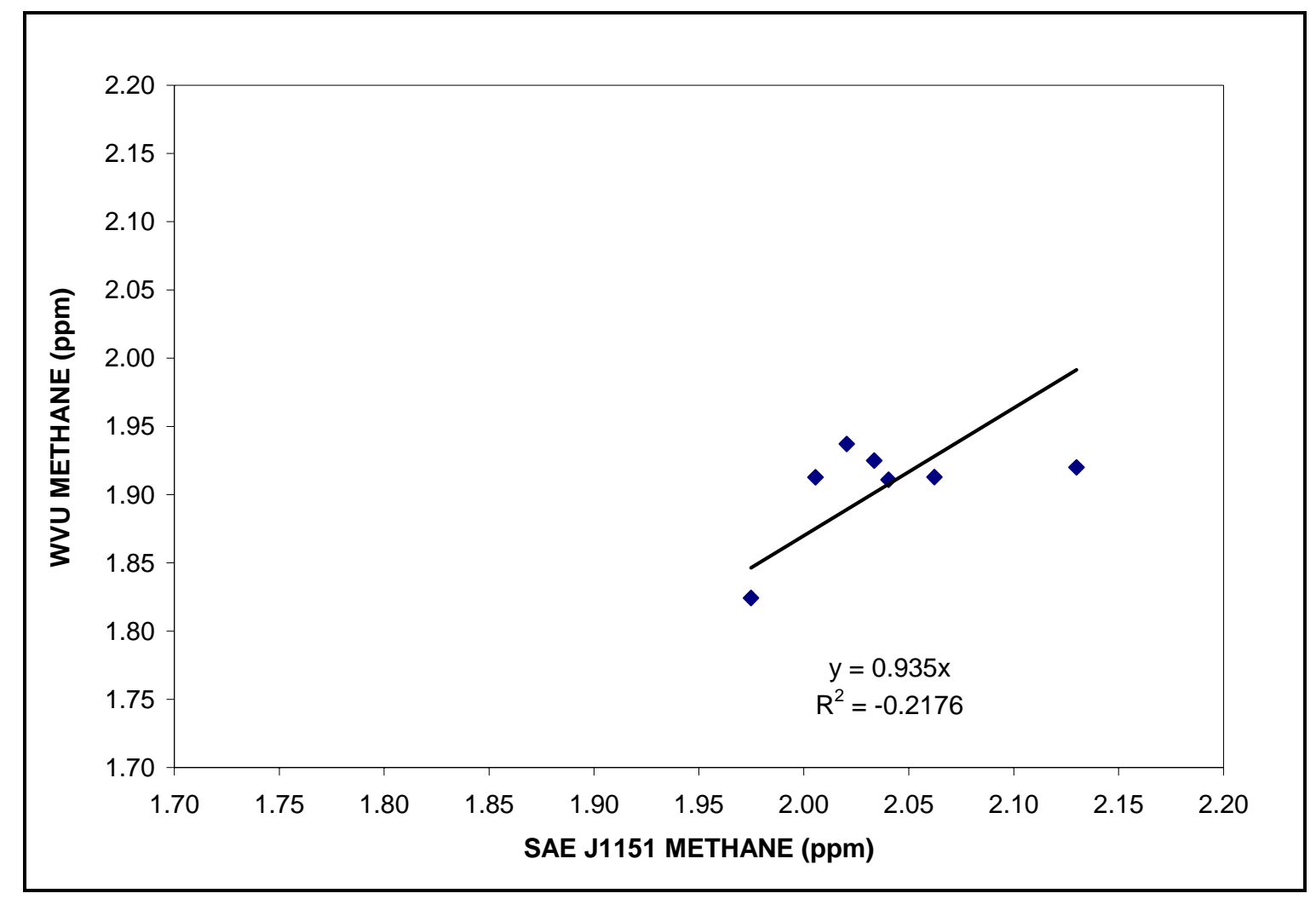

Figure 5-9 Comparison of Bio-Diesel Sample Background Bag Methane from SAE J1151 and WVU Method

\subsection{Natural Gas Sample THC Determination from SAE J1151 Methane Results}

Since it was observed that there was excellent correlation between the methane results from the SAE J1151 and WVU GC methods with a 4.96\% bias between the two the possibility of using the SAE J1151 methane results to project the THC values of the CNG samples was explored mathematically.

Comparison of the methane and THC results of the WVU GC method for correlation showed that there was near perfect correlation between the two values. The THC concentrations of the background and dilute exhaust samples, combined together, were $7.44 \%$ higher than the methane concentrations with an $\mathrm{R}^{2}$ of 0.9996 as seen in Figure 5-10. Given these strong correlations between the methane results from the two GC methods and the THC, methane results from the 
WVU GC method a THC projection factor was calculated as the product of the percentage biases observed in the two sets of data mentioned above, i.e. the bias percentage of the WVU GC methane results over the SAE J1151 results (5.0169\%), calculated as the average of biases observed in the dilute and background bags, and the bias percentage of the WVU GC THC results over the WVU GC methane results found to be $7.4407 \%$.

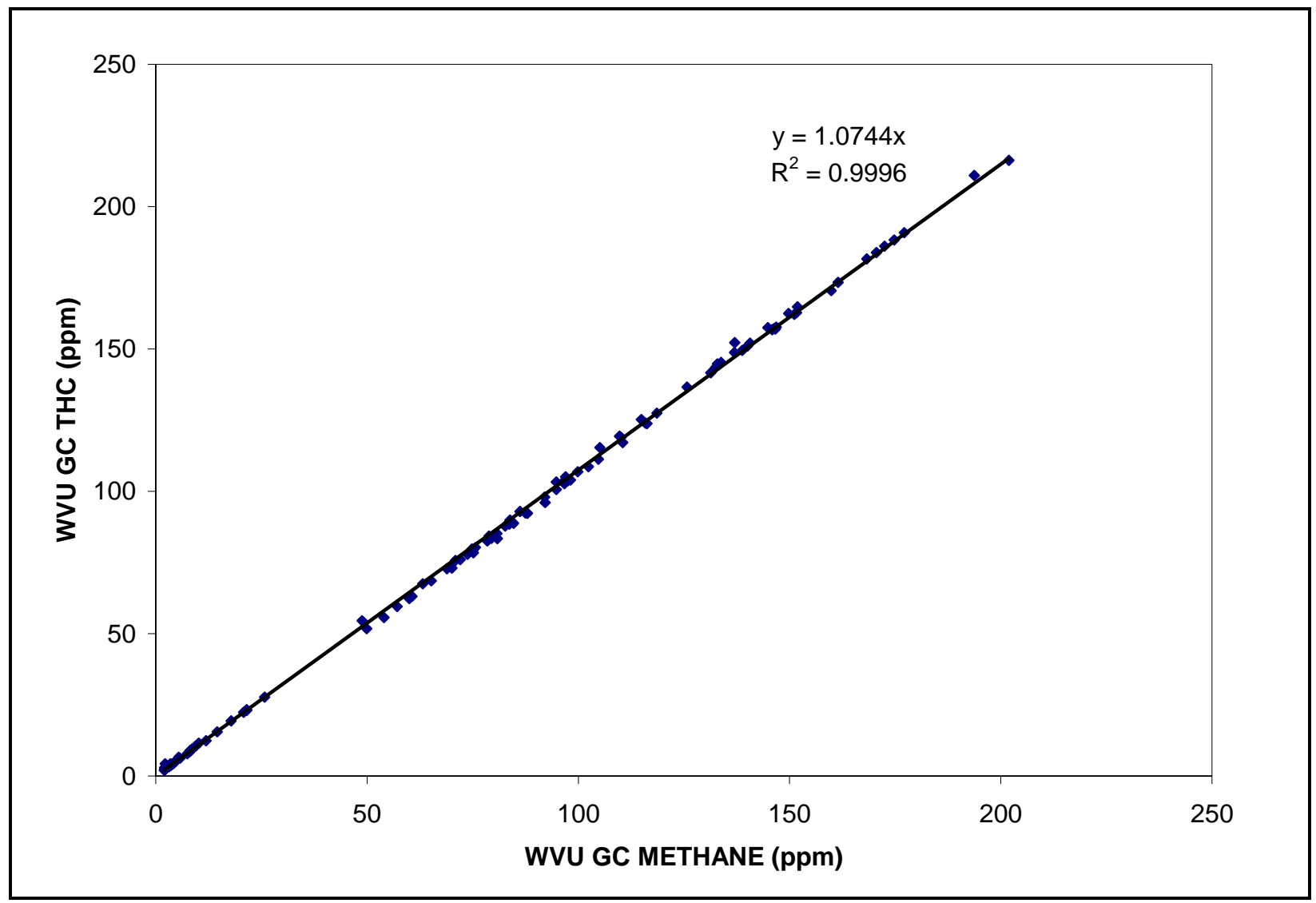

Figure 5-10 Comparison of WVU GC THC and Methane results for Natural Gas Samples

The methane results from the SAE J1151 GC for the CNG samples were multiplied by this projection factor to get a projected THC value. Examination of the agreement between these projected THC results with the actual THC results from the WVU GC method showed that the scatter plot produced a straight line of slope 0.9908 , of $R^{2} 0.997$, which is only slightly less than 
the perfect correlation slope of 1 . This suggested that the projected results were only $0.92 \%$ off from the actual values. In the regulations, a drift of $\pm 1 \%$ in the analyzer response is considered acceptable and projected results are within this limit. If instead of using the average bias percentage, of the dilute and background bag results for the methane values from the two GCs, the dilute bag bias percentage was used then the error in the projected values came down to 0.87 \%. The use of this projection factor would be analogous to CFR approved method of estimation of the NMHCs in exhaust as $98 \%$ of the THC concentration. The comparison of the projected and WVU GC THC results are shown in Figure 5-11. Hence the use of this projection factor to determine the THC concentration in CNG bag sample proves to be a very reliable method. Incorporation of this method will negate the need to analyze CNG bag samples with the WVU GC method to determine THC concentrations thus saving time and money that is invested in the analysis procedure.

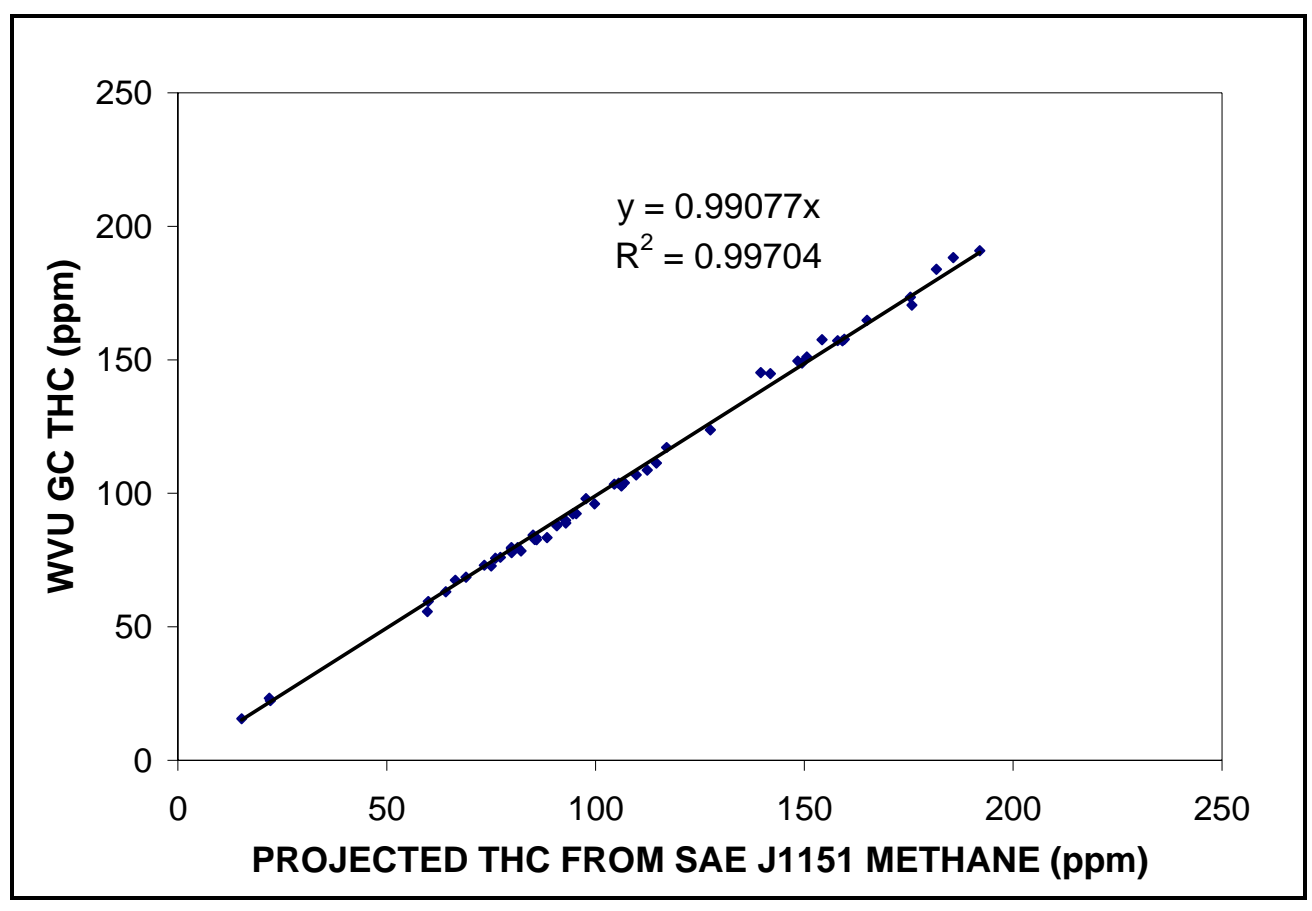

Figure 5-11 Comparison of Projected THC results and WVU GC THC Results 


\subsection{Comparison of SAE J1151 Method with CAI Model 600 HFID}

Comparison of the correlation between SAE J1151 methane results from the three liter Tedlar bags and the eighty liter engine laboratory bag data from the CAI analyzer for a heavy-duty engine, fueled by blends of biodiesel/diesel, addititized diesel and diesel, showed that the GC results were higher than the analyzer results. It is to be noted here that the three liter tedlar bags were filled with sample from the eighty liter bags.

The two methods showed good correlation for the methane results with $\mathrm{R}^{2}$ values of 0.77 and 0.84 for the dilute and background bags, respectively. For the dilute bag the average percentage difference between the GC and the analyzer results was 5.90 with a standard deviation of 1.80 . The corresponding average and standard deviation for the background bags were 3.63 and 1.59, respectively. The plots of the dilute and background bag results are shown in Figure 5-12 and Figure 5-13, respectively. From these results it is apparent that there is much better correlation between the SAE J1151 method and CAI HFID analyzer methane results than the SAE J1151 and WVU GC method methane results. In this case there were more data collected at a much wider range, of approximately $0.3 \mathrm{ppm}$, in this study. The correlation between the two methods is not strong enough to claim that the analyzer produces results as good as the GC. 


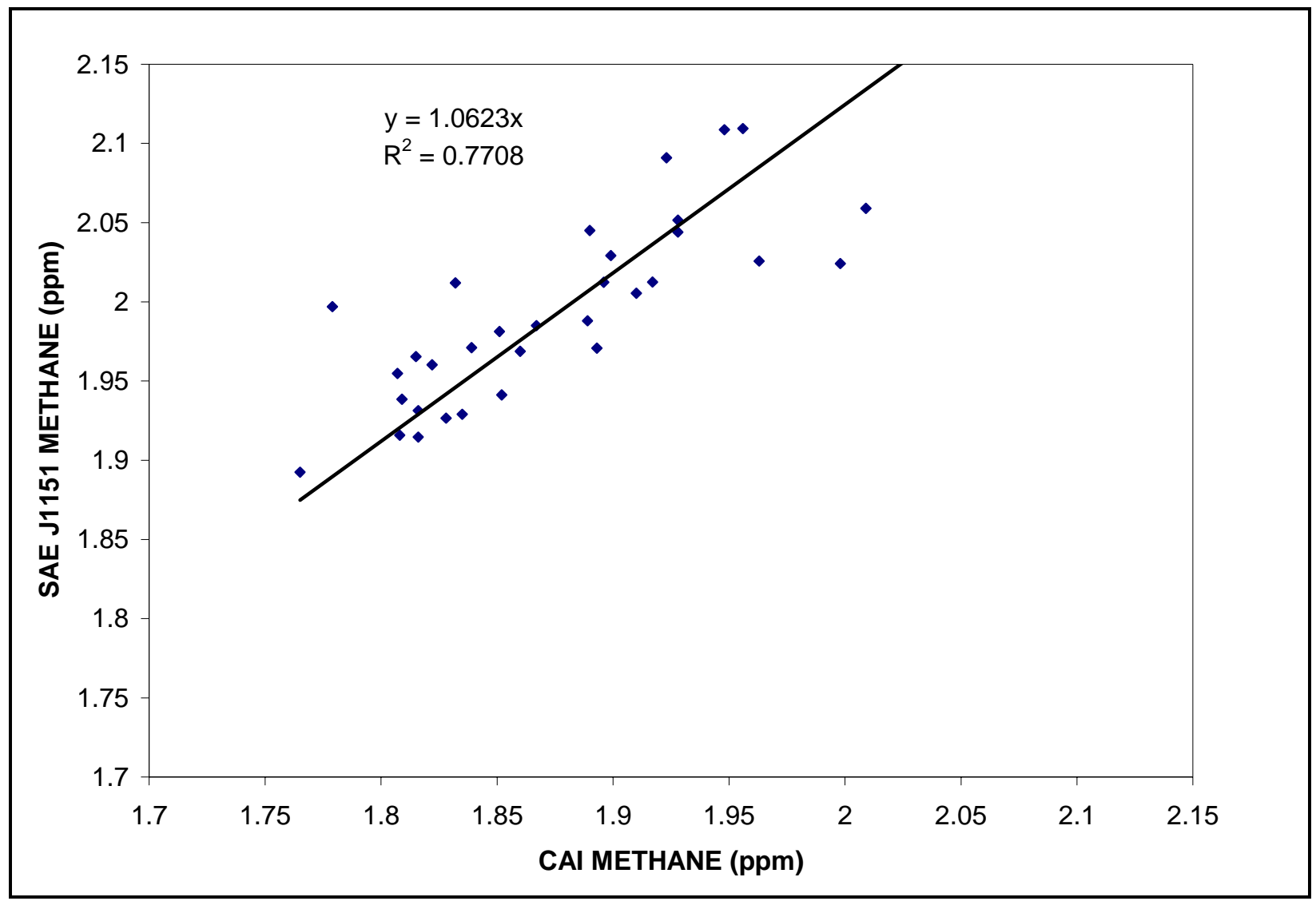

Figure 5-12 Comparison of Dilute Bag Methane from SAE J1151 and CAI HFID 


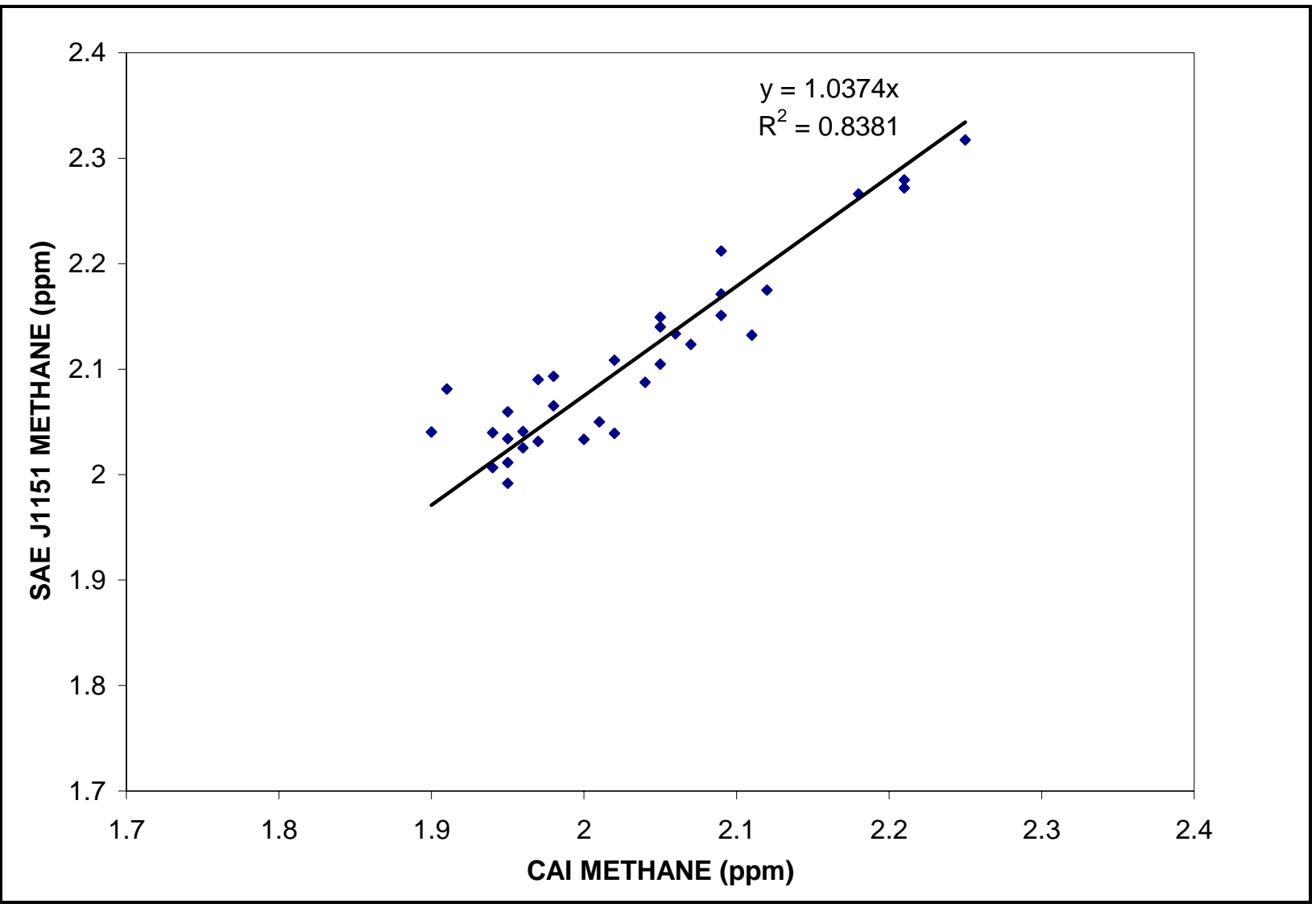

Figure 5-13 Comparison of Background Bag Methane from SAE J1151 and CAI HFID

The brake-specific NMHC concentration was calculated using the methane results obtained from the GC and the CAI analyzer shown in Figure 5-12 and Figure 5-13. The brake specific THC is calculated by the reduction program in the laboratory using the THC concentration from the Horiba THC analyzer and used to calculate the brake specific NMHC in both cases. Using the same THC value nullifies the effect of any drift, in the THC analyzer, on the comparison of the NMHC values. The brake specific NMHC value was obtained by calculating the brake-specific methane value and subtracting it from the brake-specific THC value. Comparison of the brakespecific methane values from the two methods showed very poor correlation between the two with an $\mathrm{R}^{2}$ value of -0.0353 though the individual dilute and background bag results had good correlations. This poor correlation is due to the background correction used in the calculation. 
Since the difference of the dilute and background bag values for each run with the two methods will include the dilute and background bag bias between the two methods, the poor correlation between the brake-specific methane values of the two methods is justified. However the final brake-specific NMHC values obtained showed extremely good correlation with a $\mathrm{R}^{2}$ value of 0.996 with the GC value being lower than the CAI value. This drastic improvement in the correlation is due to the fact that the brake-specific methane values obtained from the two methods are three to four orders of magnitude lower than the brake-specific THC value. Therefore subtraction of the highly uncorrelated brake-specific methane values, from the GC and CAI analyzer, does not skew the brake-specific NMHC results. Figure 5-14 and Figure 5-15 Show the comparison of the brake specific methane and NMHC values obtained from the GC and CAI analyzers, respectively.

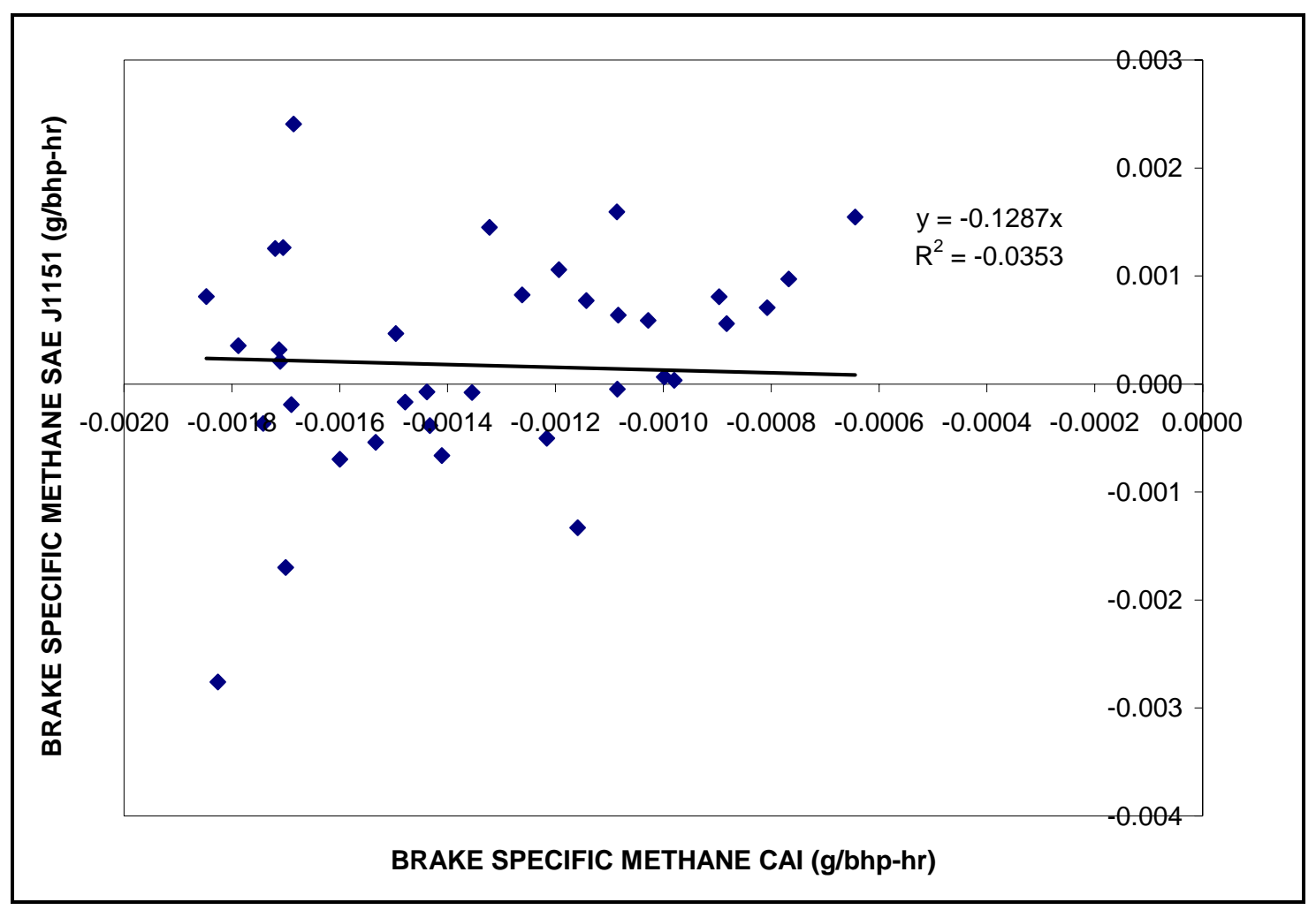

Figure 5-14 Comparison of Brake Specific Methane from SAE J1151 and CAI HFID 


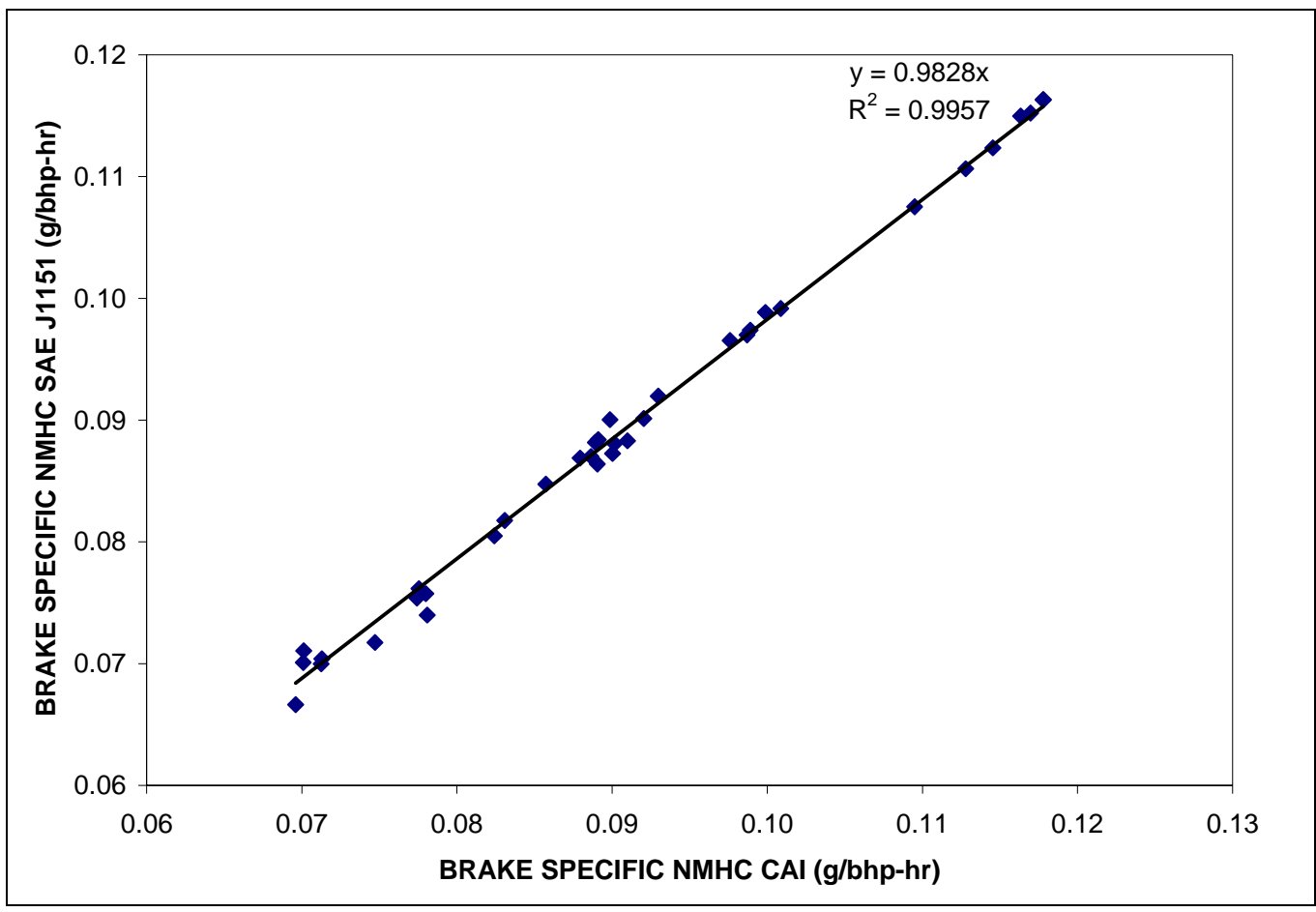

Figure 5-15 Comparison of Brake Specific NMHC from SAE J1151 and CAI HFID

Data was collected from another test program involving heavy-duty engine FTP tests using eight different diesel-based fuels. These fuels were either neat diesel fuel or additive-treated diesel fuel. The methane results of the SAE J1151 method GC analysis of the bag samples collected from these tests and CAI HFID bag data were compared as before.

The comparison of the dilute and background methane results are shown in Figure 5-16 and Figure 5-17, respectively. The results are similar to those seen with the comparison of data from heavy-duty FTP tests using diesel-based fuel shown in Figure 5-12 and Figure 5-13. In this case the correlation curve $\mathrm{R}^{2 \text { s }}$ s were 0.83 and 0.73 for the dilute and background bags, respectively, and compare well with the $\mathrm{R}^{2 \text { s }}$ s of 0.82 and 0.86 observed in the other similar study summarized earlier. 


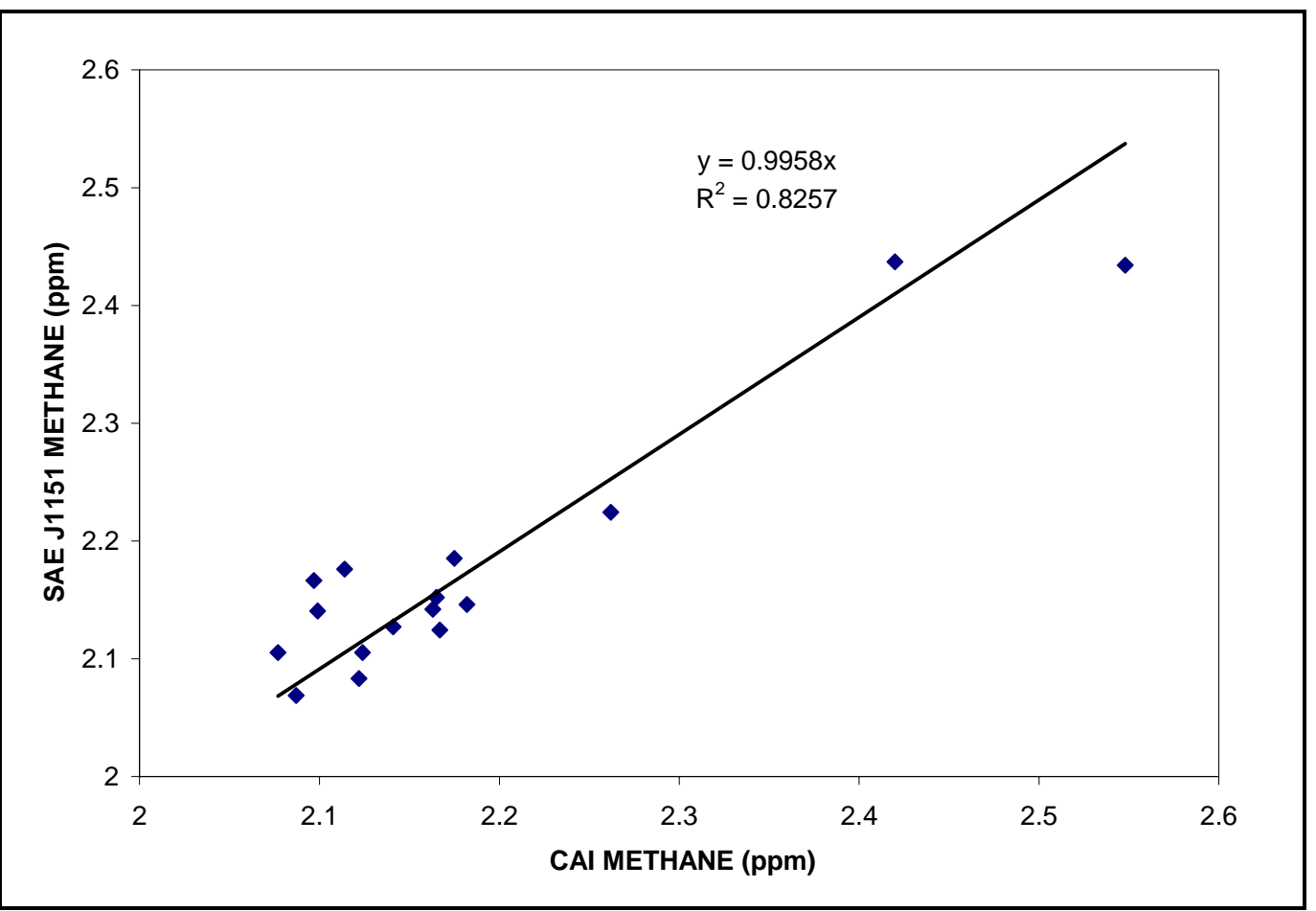

Figure 5-16 Comparison of Dilute Bag Methane from SAE J1151 and CAI HFID

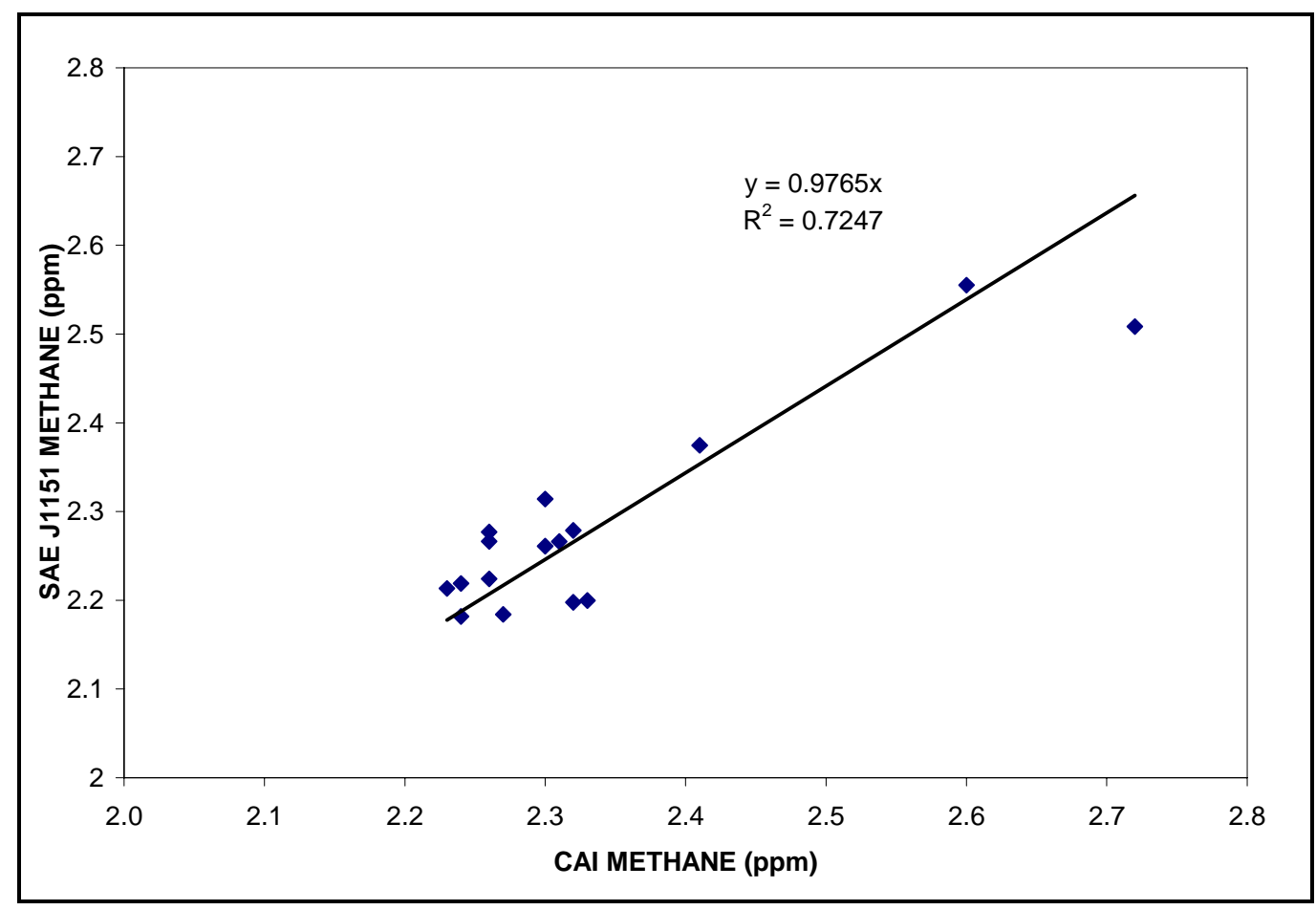

Figure 5-17 Comparison of Background Bag Methane from SAE J1151 and CAI HFID 
Two data points in each of the two comparisons shown above were removed as outliers with a good level of confidence as the two data points were obtained from the dilute and background bags of the same test sample. The brake-specific methane data had extremely poor agreement with an $\mathrm{R}^{2}$ of -0.03 while the brake specific NMHC results displayed near perfect agreement between the SAE J1151 GC method and CAI HFID analyzer with an $\mathrm{R}^{2}$ of 0.995 . The observed disparity and parity in the brake-specific methane and brake specific NMHC results, respectively, reinforce the results from the other study with diesel-based fuels and share the same reasons as mentioned before, i.e. the brake-specific methane values are inclusive of the dilute and background bag biases and hence show more scatter while the order of magnitude difference in the brake specific THC results and brake specific methane values ensures that there isn't significant difference in the final brake specific NMHC results. The brake specific methane and NMHC comparisons are shown in Figure 5-18 and Figure 5-19.

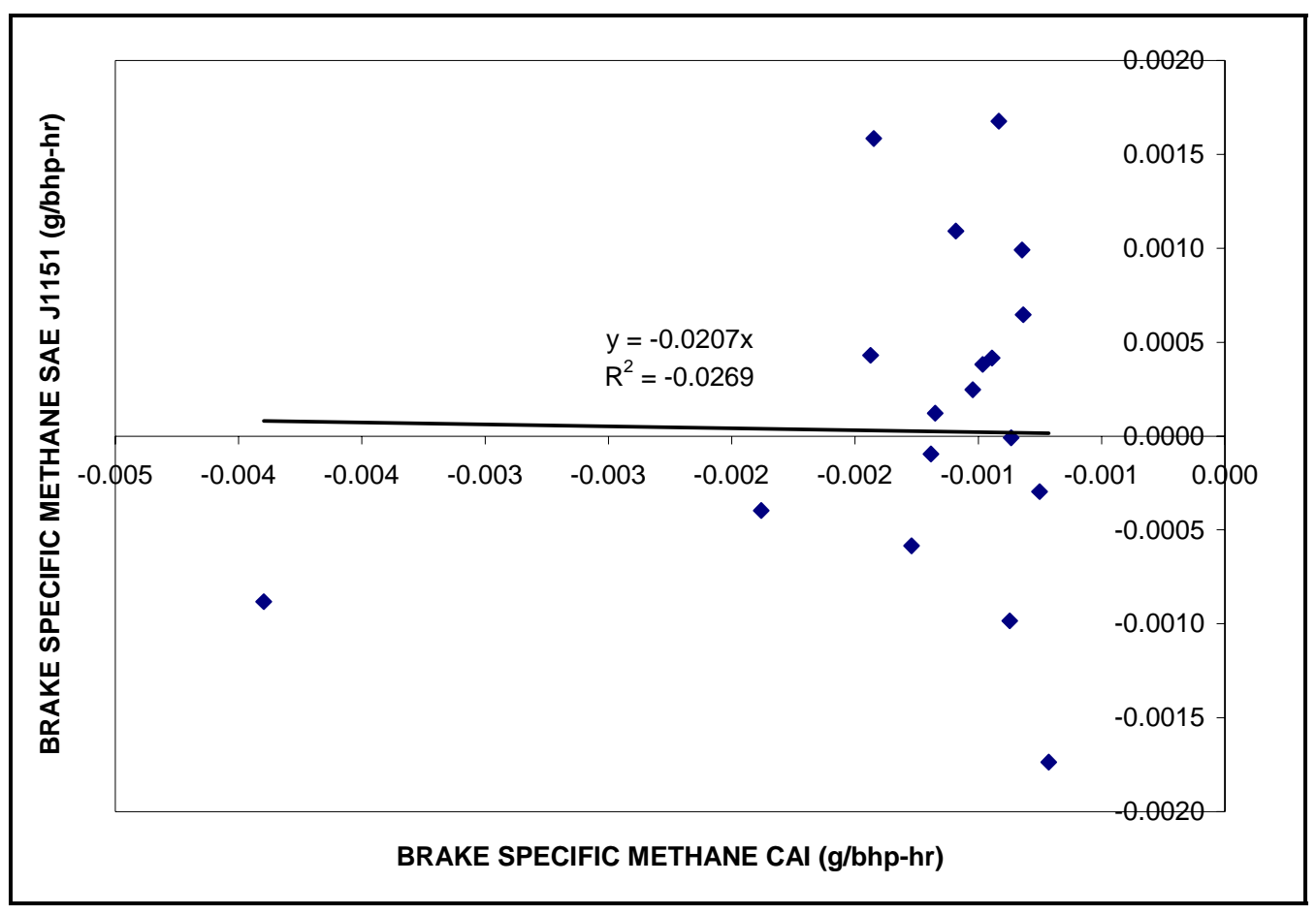

Figure 5-18 Comparison of Brake Specific Methane from SAE J1151 and CAI HFID 


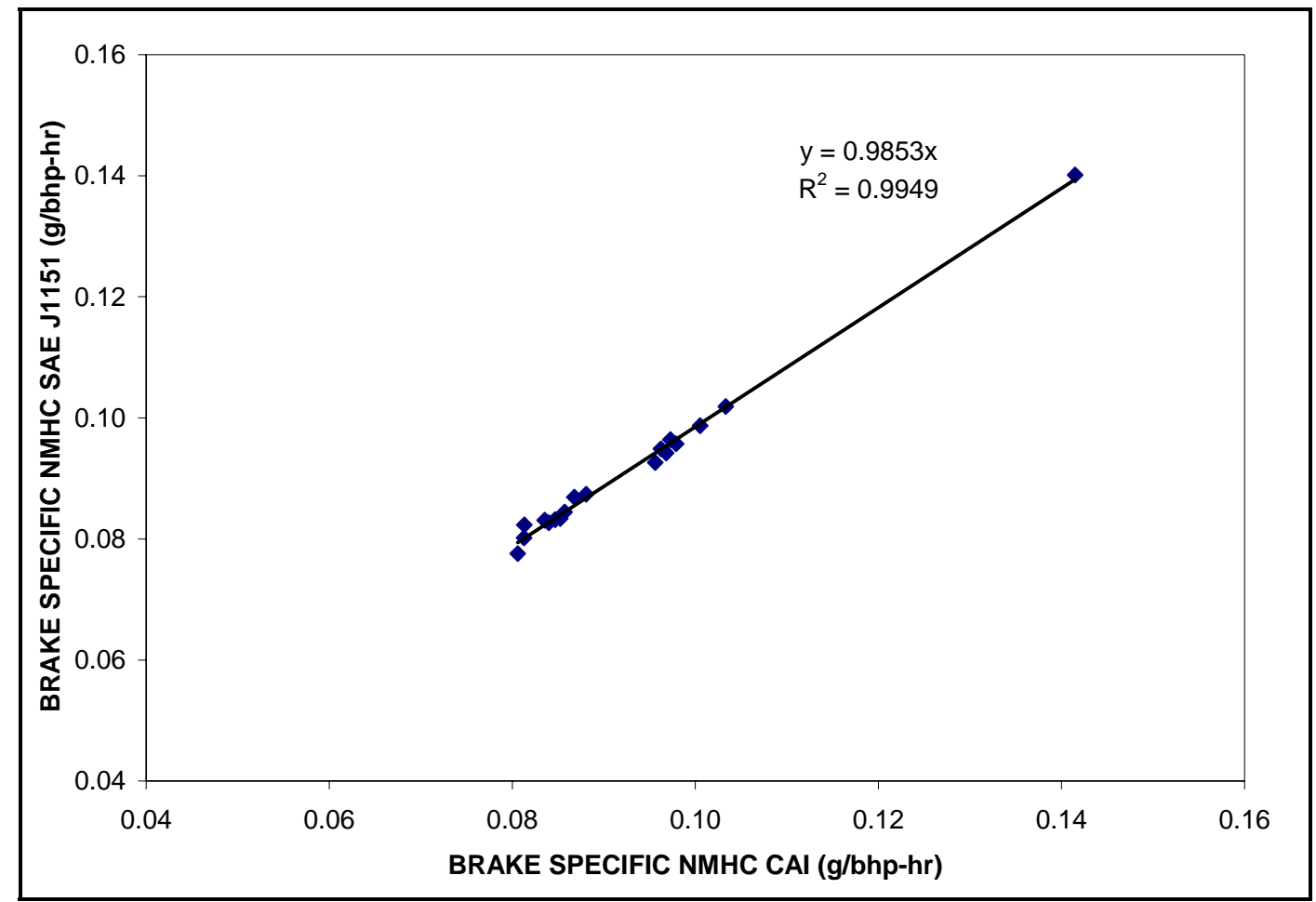

Figure 5-19 Comparison of Brake Specific NMHC from SAE J1151 and CAI HFID

Six sample bags were chosen from those obtained in this test and were analyzed with the GC on three different days. It is worth mentioning here that the initial analysis on the GC after sample collection, were done after four days. This test was conducted to study the day-to-day variation in the results from the GC. The number of days between the initial analysis and day1, day2, day3 of the day-to-day tests were 4, 7 and 8 days, respectively, for samples E02118-01, E02122-01 and E02122-03 (collected on 09/06/07) and 2, 5, 6 days for samples E02125-03, E02126-02 and E02127-02 (collected on 09/10/07) respectively. The percentage differences between the initial analysis results and the results from the three days of repeated analyses are shown in Figure 5-20 and Figure 5-21. The variation seen in results from multiple analyses of same samples is random and unpredictable. There is no noticeable trend in the results except the fact that more predominantly the variations in the background bag results are higher than the variations in the 
dilute bag results. Also the samples collected on 09/10/07 show larger variations in both the dilute and background bag results. The percentage coefficient of variations less than $2 \%$ for all the dilute sample bags except bag E02127-02 which showed 2.48\% variation. The coefficient of variation percentages seen for the background samples ranged from $0.74 \%$ to $3.95 \%$. However when the first analysis results were not included the coefficient of variation percentage range was from $0.62 \%$ to $2.27 \%$ for the background samples. It has to be noted here that there were 2 to 4 days differences between the initial analysis and the first of the repeat analyses. Also the samples were 6 to 8 days old before the initial analyses followed by the repeat analyzes were done. Considering these long durations for which the samples were stored the variations are reasonable and cannot be ascribed to the analysis method alone. Factors such as storage, handling, temperature, bag material may have influenced the results.

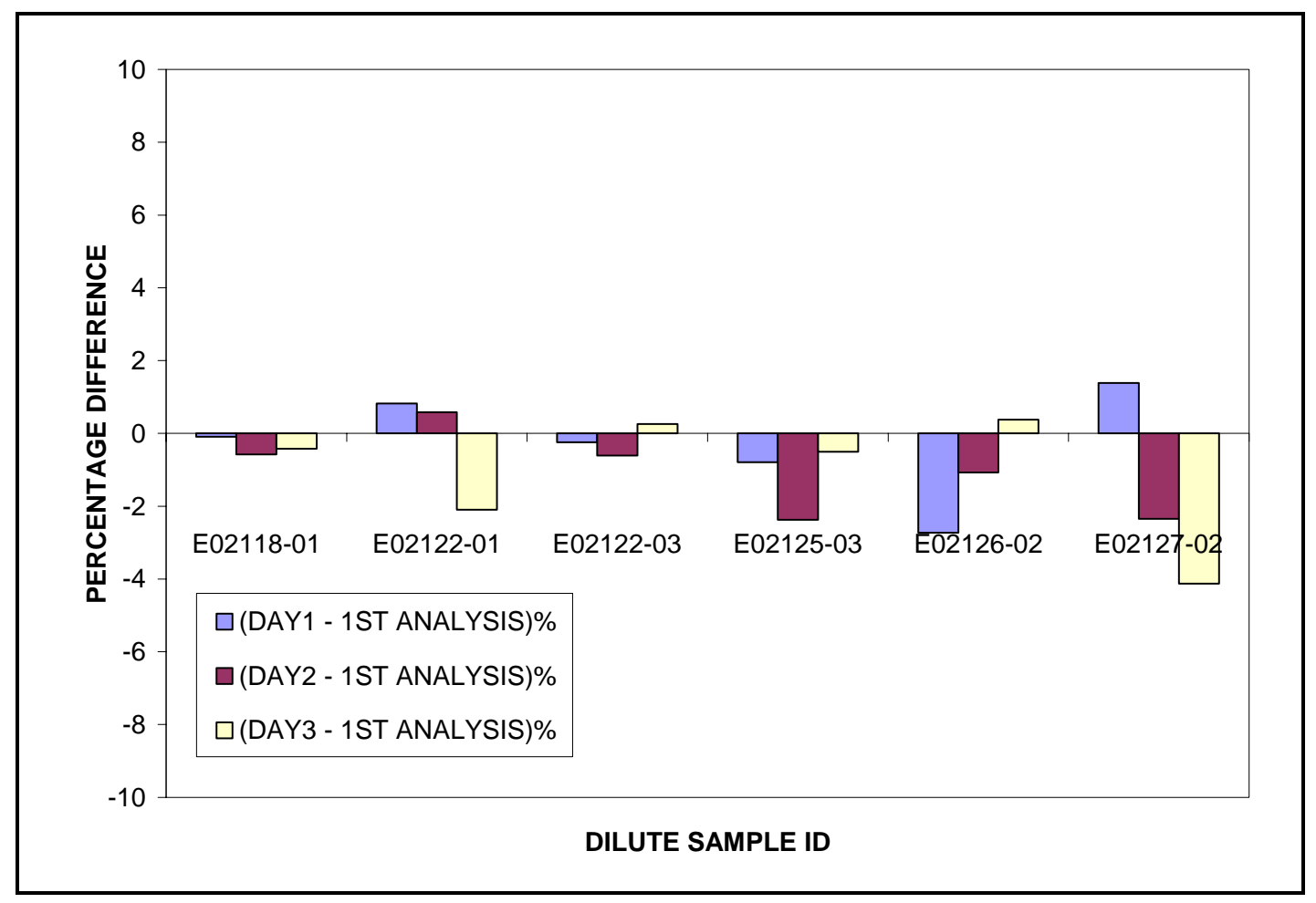

Figure 5-20 Percentage Difference in SAE J1151 Dilute Bag Methane Concentration from Initial Analysis 


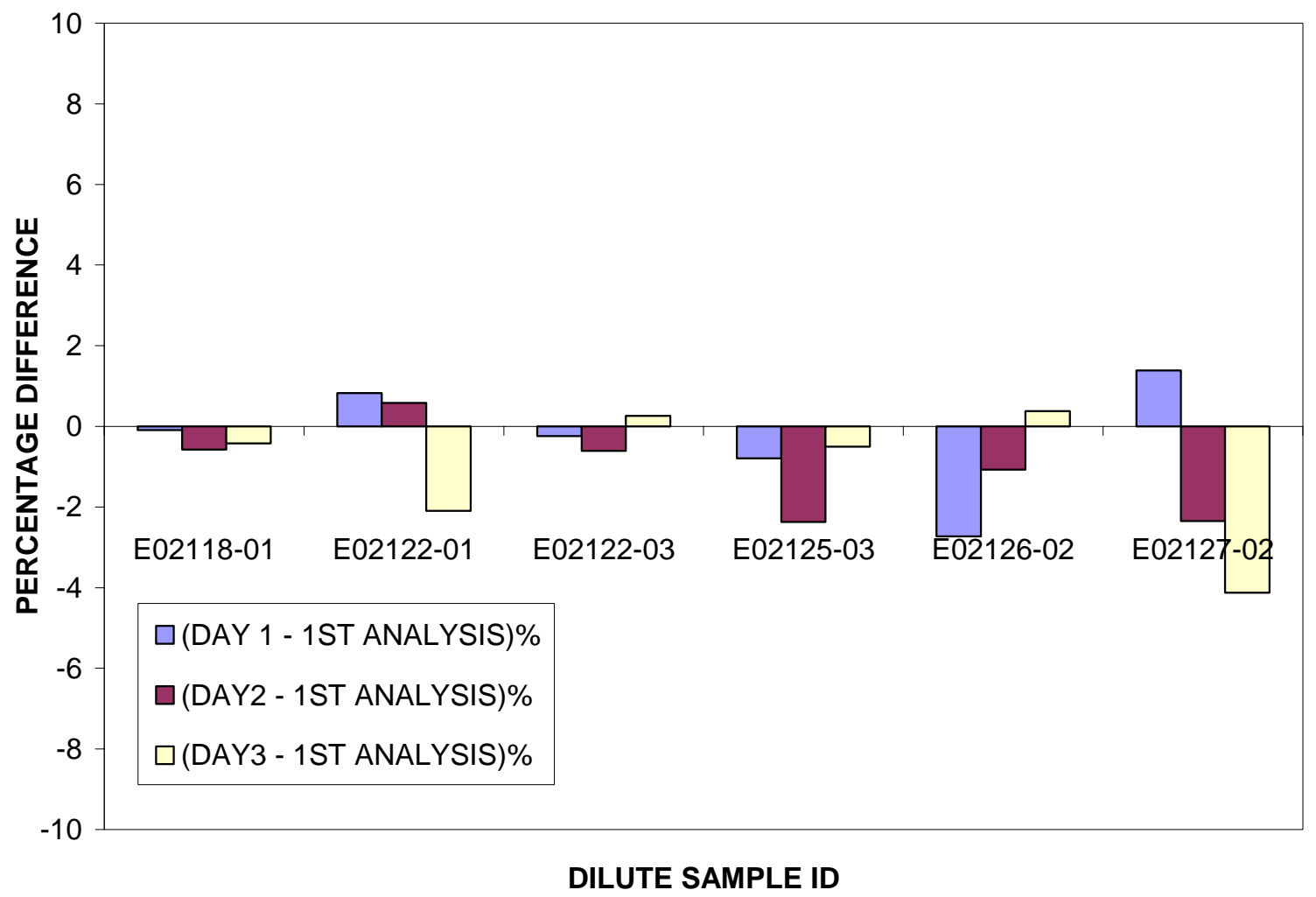

Figure 5-21 Percentage Difference in SAE J1151 Background Bag Methane Concentration from Initial Analysis

To test the repeatability of the CAI HFID analyzer, four eighty liter tedlar bags, used for bag integration sample collection, were filled simultaneously from a sixty minute tunnel background run. Each bag was used to obtain repeated bag integration values from the analyzer on a separate day. The day-to-day variations in the CAI HFID results are shown in Figure 5-22. It is worth mentioning that due to inconsistent filling of the bags, only four and three bag integration runs were possible on day 1 , and day 2, respectively, while five runs were performed each on day 4 and day 5. 


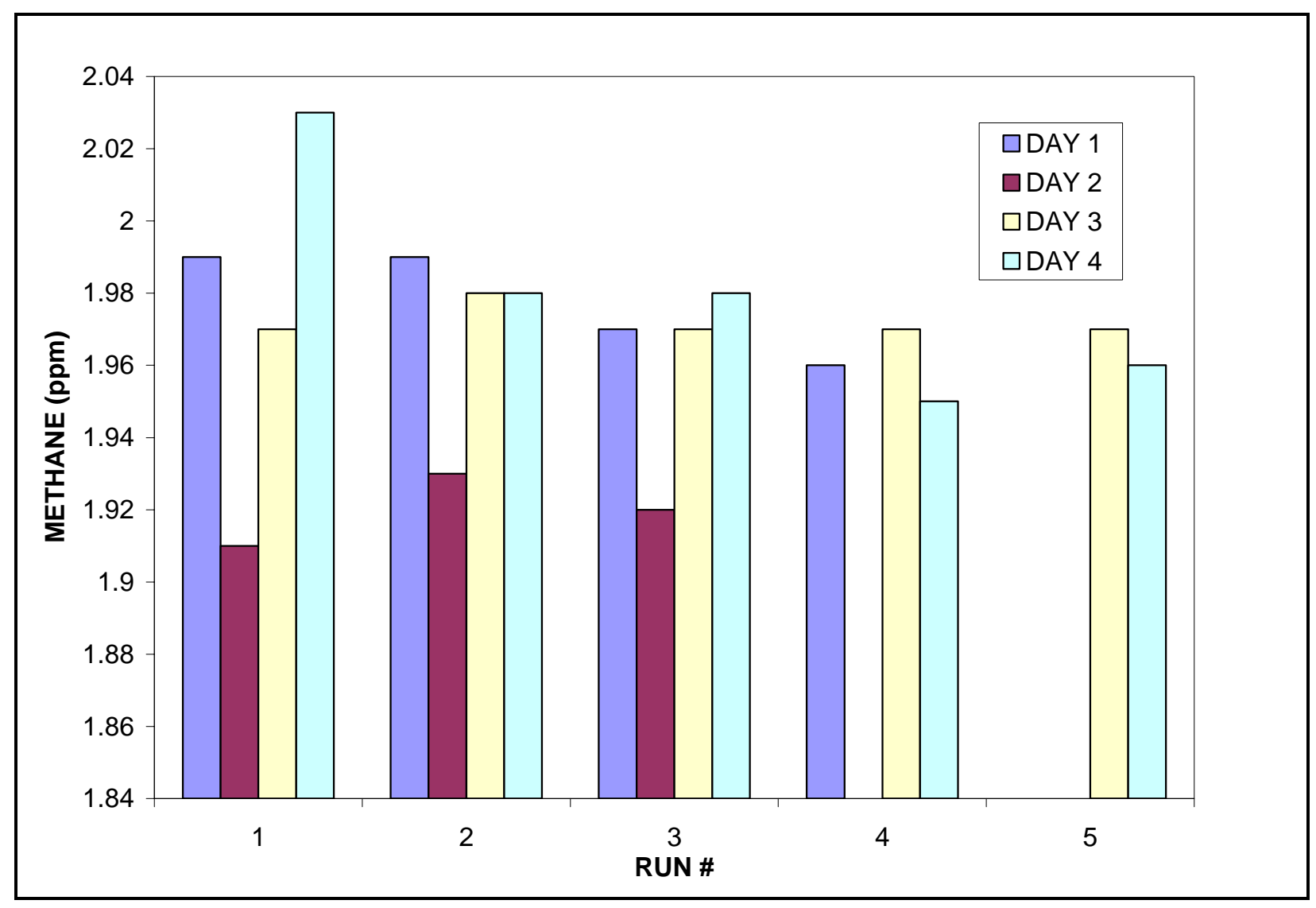

Figure 5-22 Day-to-Day Variation in Background Bag Measurements by CAI HFID

Except for day 2, the mean of bag sample values on other days were within $0.70 \%$ of mean observed on day 1 . The variation seen in day 2 mean was 3.34\% from day 1 mean. Examination of the variation through an ANOVA test in MATLAB showed that only day 2 results had a significant difference from the other days. Within day deviations were less than $0.80 \%$ of the mean on all days except day 4 which had a mean deviation of $1.68 \%$. However removing the first sample value reduced it to $0.82 \%$ indicating the possibility of an outlier. Application of the ASTM E 178 outlier determination method indicated fairly high probability of this value being an outlier. The percentage variation in means from day 1 mean decreased from day- to-day and was $-3.34 \%$ on day 2 and $-0.09 \%$ on day 4 . Considering the same deviation limits for the analyzer as required by the J1151 GC standard the CAI produces repeatable results. 
The results from the Horiba THC analyzer showed increasing variations from day to day with the day 4 mean 13.21\% higher than day 1 mean. Within day percentage coefficient of variation from the mean varied from $0.40 \%$ to $7.45 \%$ on the four days. However removing the first sample data on day 3 and day 4 decreased the average deviation from the mean to a high of $1.61 \%$ and were detected as outliers by the ASTM E 178 method. Earlier, a first sample value from day 4 testing results from the CAI HFID analyzer was removed as an outlier. This suggests that the high values being observed during the first sample measurements may be due to the instruments not reaching a stable condition. On each day the analyzers were given a minimum of thirty minutes after the sample pumps were turned on. The day-to-day THC results from the Horiba HC analyzer are shown in Figure 5-23. Additionally, based on anecdotal evidence, the hydrocarbon data from the first test of the day normally shows greater zero and span variations than the remaining tests.

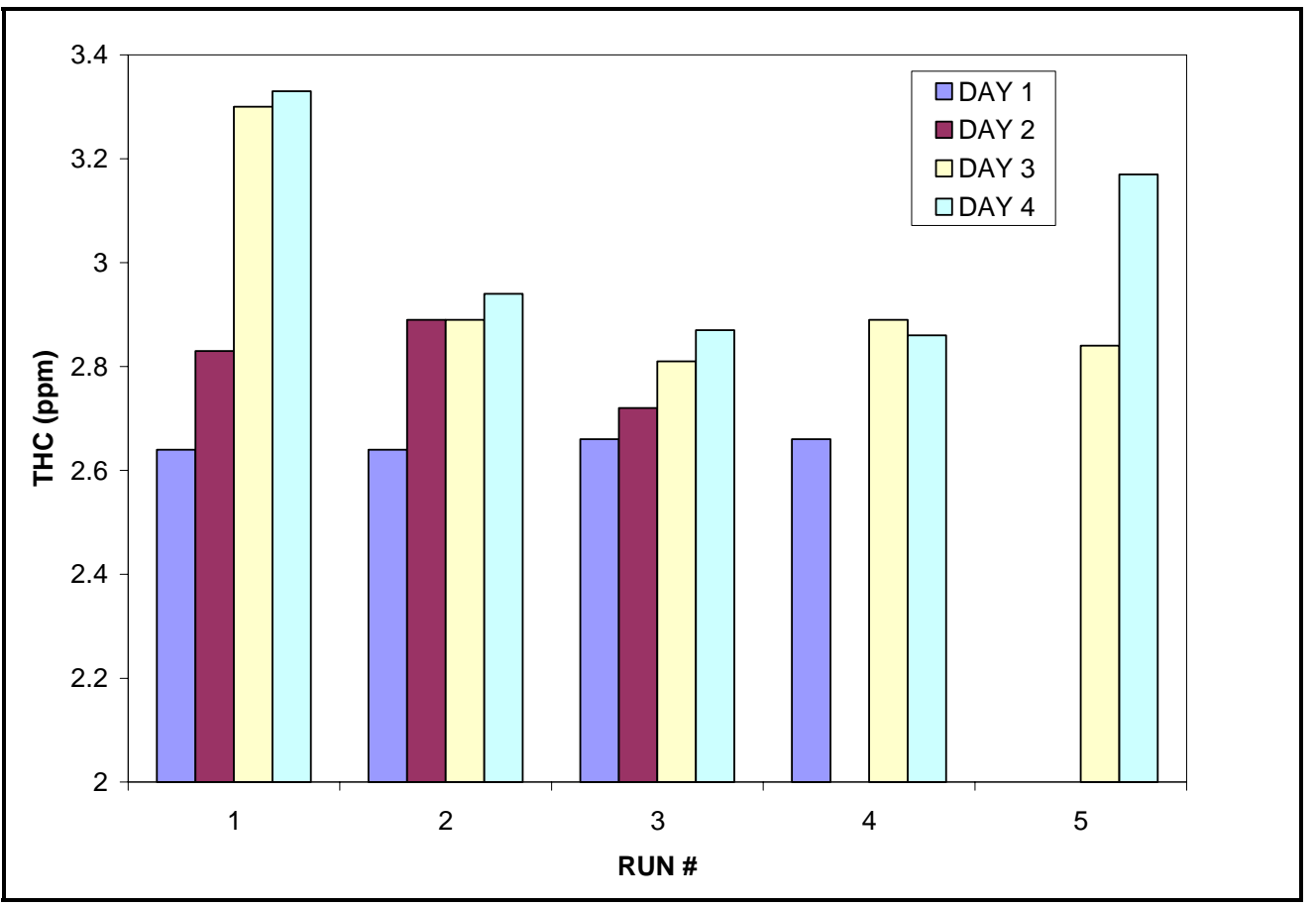

Figure 5-23 Day-to-Day Variation in Bag Measurements by Horiba THC Analyzer 


\subsection{Statistical Significance Testing}

All of the individual data sets used for correlation comparison were tested for statistical significance of the correlation coefficients obtained and the differences in the results obtained from the two methods. This helped to establish the fact that the inferences made from the data regarding the relationship between the two sets of data being compared are acceptable. The student's t-test was used to test whether the difference in the results between the SAE J1151 and WVU GC and the difference in the results between the SAE J1151 and CAI HFID analyzer results. This was done by framing a null hypothesis that the population from which the sample of differences was drawn had a zero mean and the alternate hypothesis that the mean was not zero. If the null hypothesis is accepted in the test it would in other words mean that there was no significant difference between the two methods of methane measurement being compared and if rejected it would mean the converse. All tests were performed at a $1 \%$ significance level, i.e. a 99\% confidence level.

Similar hypothesis testing was done for the correlation coefficient of each data set. For each data set instead of using the correlation coefficient generated by Microsoft Excel, in the linear regression plots, the Pearson correlation coefficient was calculated and was used for hypothesis testing. In this case the null hypothesis was that the correlation coefficient was zero, i.e. the two variables being considered had no correlation with the alternate hypothesis being there was positive correlation between the two variables. The results of the various hypothesis tests along with the correlation coefficients from Microsoft Excel and Pearson calculation are shown in Table 5-1. In the test of significance of the correlation coefficients if the result is "Reject" it means that the null hypothesis, $\mathrm{R}=0$, is rejected and the conclusion is that there is positive correlation between the two variables. A result of "Accept" indicates there is no correlation 
between the variables. In the students " $\mathrm{t}$ " test, if the result is "Accept" the conclusion is that there is no significant difference in the results obtained from the two methods and "Reject" would mean there is considerable difference in the two methods. The results obtained from the statistical significance testing of the correlation coefficients shows that they are significant at a 99\% confidence level. Also in those cases where correlation was not observed, as in the case of the comparison of methane results data from diesel blends, the statistical analysis results agreed with the inference. In this particular case good correlation was expected but the results show poor correlation. The cause of this discrepancy is unknown. 
Table 5-1 Results of Statistical Significance Testing

\begin{tabular}{|c|c|c|c|c|c|c|c|c|c|}
\hline \multirow[b]{2}{*}{ Sample } & \multirow[b]{2}{*}{ Data } & \multirow[b]{2}{*}{ Comparison } & \multicolumn{2}{|c|}{$\begin{array}{l}\text { Correlation } \\
\text { Coefficient }\end{array}$} & \multicolumn{3}{|c|}{ "R" TEST } & \multicolumn{2}{|c|}{ STUDENT 't' TEST } \\
\hline & & & Excel & Pearson & $\begin{array}{c}\text { SIG } \\
\text { LEVEL } \\
(\%)\end{array}$ & $\begin{array}{l}\text { NULLIALT } \\
\text { HYPOTHESIS }\end{array}$ & Result & $\begin{array}{c}\text { Null/Alt } \\
\text { Hypothesis }\end{array}$ & RESULT \\
\hline \multirow{2}{*}{$\begin{array}{l}\text { TUNNEL } \\
\text { BKG }\end{array}$} & Dilute & J1151 vs WVU & 0.986 & 0.986 & 1 & $\mathrm{R}=0 / \mathrm{R}>0$ & Reject & $\begin{array}{l}\text { Population } \\
\text { mean }=0\end{array}$ & Accept \\
\hline & Background & J1151 vs WVU & 0.810 & 0.81 & 1 & $\mathrm{R}=0 / \mathrm{R}>0$ & Reject & $\begin{array}{c}\text { Population } \\
\text { mean }=0\end{array}$ & Accept \\
\hline \multirow{2}{*}{$\begin{array}{l}\text { DIESEL } \\
\text { BLENDS }\end{array}$} & Dilute & J1151 vs WVU & 0.753 & 0.75 & 1 & $\mathrm{R}=0 / \mathrm{R}>0$ & Accept & $\begin{array}{l}\text { Population } \\
\text { mean }=0\end{array}$ & Accept \\
\hline & Background & J1151 vs WVU & 0.527 & 0.53 & 1 & $\mathrm{R}=0 / \mathrm{R}>0$ & Accept & $\begin{array}{l}\text { Population } \\
\text { mean }=0\end{array}$ & Accept \\
\hline \multirow{2}{*}{$\begin{array}{l}\text { NATURAL } \\
\text { GAS } \\
\text { SAMPLES }\end{array}$} & Dilute & J1151 vs WVU & 0.996 & 0.996 & 1 & $\mathrm{R}=0 / \mathrm{R}>0$ & Reject & $\begin{array}{l}\text { Population } \\
\text { mean }=0\end{array}$ & Accept \\
\hline & Background & J1151 vs WVU & 0.999 & 0.999 & 1 & $\mathrm{R}=0 / \mathrm{R}>0$ & Reject & $\begin{array}{l}\text { Population } \\
\text { mean }=0\end{array}$ & Accept \\
\hline \multirow{4}{*}{$\begin{array}{l}\text { DIESEL } \\
\text { BLENDS } \\
\text { (TEST1) }\end{array}$} & Dilute & J1151 vs CAI & 0.905 & 0.905 & 1 & $\mathrm{R}=0 / \mathrm{R}>0$ & Reject & $\begin{array}{c}\text { Population } \\
\text { mean }=0\end{array}$ & Accept \\
\hline & Background & J1151 vs CAI & 0.930 & 0.93 & 1 & $\mathrm{R}=0 / \mathrm{R}>0$ & Reject & $\begin{array}{c}\text { Population } \\
\text { mean }=0\end{array}$ & Accept \\
\hline & $\begin{array}{c}\text { Brake specific } \\
\text { methane }\end{array}$ & J1151 vs CAI & 0.294 & 0.037 & 1 & $\mathrm{R}=0 / \mathrm{R}>0$ & Accept & $\begin{array}{l}\text { Population } \\
\text { mean }=0\end{array}$ & Accept \\
\hline & $\begin{array}{c}\text { Brake specific } \\
\text { NMHC }\end{array}$ & J1151 vs CAI & 0.998 & 0.998 & 1 & $\mathrm{R}=0 / \mathrm{R}>0$ & Reject & $\begin{array}{c}\text { Population } \\
\text { mean }=0\end{array}$ & Accept \\
\hline \multirow{4}{*}{$\begin{array}{l}\text { IESEL } \\
\text { BLENDS } \\
\text { (TEST 2) }\end{array}$} & Dilute & J1151 vs WVU & 0.939 & 0.923 & 1 & $\mathrm{R}=0 / \mathrm{R}>0$ & Reject & $\begin{array}{l}\text { Population } \\
\text { mean }=0\end{array}$ & Accept \\
\hline & Background & J1151 vs WVU & 0.904 & 0.905 & 1 & $\mathrm{R}=0 / \mathrm{R}>0$ & Reject & $\begin{array}{l}\text { Population } \\
\text { mean }=0\end{array}$ & Accept \\
\hline & $\begin{array}{c}\text { Brake specific } \\
\text { methane }\end{array}$ & J1151 vs WVU & 0.222 & 2.13E-05 & 1 & $\mathrm{R}=0 / \mathrm{R}>0$ & Accept & $\begin{array}{l}\text { Population } \\
\text { mean }=0\end{array}$ & Accept \\
\hline & $\begin{array}{c}\text { Brake specific } \\
\text { NMHC }\end{array}$ & J1151 vs WVU & 0.997 & 0.997 & 1 & $\mathrm{R}=0 / \mathrm{R}>0$ & Reject & $\begin{array}{c}\text { Population } \\
\text { mean }=0\end{array}$ & Accept \\
\hline
\end{tabular}




\section{RECOMMENDATIONS and CONCLUSIONS}

\subsection{Conclusions}

The ever tightening regulations on automobile exhaust emissions pose challenges to engineers to develop exhaust measurement devices capable of measuring very low concentrations of pollutants in exhaust accurately and in a cost effective manner. While developing new technologies to meet the strict regulations is one side of the coin the other side represents the advancements required in measurement techniques.

FID-based analyzers are the most suited instruments for exhaust hydrocarbon measurement due to their linearity and response characteristics. Gas chromatography provides an alternative but cannot be used for real time measurements. Comparison of two gas chromatography based systems at WVU gave an insight into instrument-to-instrument correlations. The SAE J1151 GC method had good agreement with the WVU GC method, which was set up to measure total hydrocarbons in CNG vehicle samples, with the WVU GC method having a 5\% bias over the SAE J1151 method. The projection factor that was developed to estimate THC concentrations in CNG samples from the methane concentrations obtained with the SAE J1151 GC method produced results which only had an error of $0.92 \%$.

Correlations at ambient air concentrations were also good but there were cases which suggested otherwise making it hard to draw conclusions. The WVU method cannot be used for THC measurement of diesel-based samples as the heavy hydrocarbons typically seen in diesel exhaust tend to hang-up in the sample bags. This was well supported by the poor agreement between the WVU GC method and the Horiba analyzer results. 
The correlation observed between CAI analyzer and SAE J1151 in measuring methane was not good enough to make a claim on the reliability of CAI HFID analyzer. However, since the methane concentration in diesel based exhaust samples is very low, the final brake specific NMHC is not affected much. The error observed in the brake-specific NMHC results calculated from the CAI methane results for two test programs were 1.72 and $1.47 \%$.

The day-to-day results from the SAE J1151 GC for diesel-based exhaust samples showed greater variability but were small enough to not cause any significant changes in the brake specific NMHC results. No visible trend was observed in the results and fluctuations were on either side of initial analysis results. The day-to-day results of CAI analyzer for tunnel background samples were very good. There was less than $0.7 \%$ variation in the means of the results obtained from the CAI analyzer over four days. Within day average percentage deviations from the mean were less than $0.85 \%$. Horiba analyzer showed increasing results with day 4 mean 13.21\% higher than day 1 mean. Percentage coefficient of variation from the mean was less than $1.65 \%$. High values were observed twice in the results from the Horiba HC analyzer during first sample measurement and once in the CAI HFID methane results indicating the possibility of insufficient instrument stabilization time.

\subsection{Recommendations}

The following are perceived as areas which can be explored towards making improvements to the existing hydrocarbon and methane measurement systems at the Center for Alternative Fuels, Engines and Emissions at WVU. 
- The day-to-day variations of the SAE J1151 GC measurements could be investigated further for CNG exhaust samples. This would be essential for accurate estimation of THC.

- The correlation between the SAE J1151 GC and CAI HFID analyzer should be examined further over a wider range of concentrations.

- The effect of the flow rates of the gases associated with the SAE J1151 GC method on the instrument response can be investigated. The current setup takes three minutes for an analysis. The possible avenues for further reducing this time can be explored.

- The accuracy of the projection factor for the determination of CNG exhaust THC from methane concentration can be verified and/or improved by further statistical analyses of data from different sources.

- Currently the Horiba and CAI analyzer responses are not optimized and the flow rates are set to factory recommended values. Optimization of the fuel and air flow rates of these analyzers will help improving the reliability and consistency of their results. 


\section{REFERENCES}

1. Majewski, W. A. and Khair, M. K., Diesel Emissions and Their Control, First Edition, SAE Publications, Warrendale, PA, 2006.

2. “Protection of Environment," Code of Federal Regulations Title 40 Part 86, Office of Federal Register National Archives and Records Administration, Washington, DC, 2006.

3. Teague, D. W., Lesniak, E. J. Jr and Loeser, E. H., “A Recommended Flame Ionization Detector Procedure for Automotive Exhaust Hydrocarbons," SAE Paper No. 700468, SAE International, Warrendale, PA, 1970.

4. Weaver, C. S., Chan, L. M., Dudek, W. D. and Lautman, L. A., "NMHC by Subtraction Doesn't Work for Natural Gas Vehicles,” SAE Paper No. 972642, SAE International, Warrendale, PA, 1997.

5. Jackson, M. W., “Analysis for Exhaust Gas Hydrocarbons - Non-Dispersive Infrared Versus Flame-Ionization,” Journal of Air Pollution Control Association, Vol. 16, No. 12, pp. 697-702, Air Pollution Control Association, Pittsburgh, PA, 1966.

6. Sternberg, J. C., Gallaway, W. S., Jones, D. T. L., Brenner, J., Callen, E. and Weiss, M. D., Gas Chromatography, p. 231, Academic Press, New York, NY, 1962.

7. Condon, R. D., Scholly, P. R., Averill, W. and Scott, R. P. W., Gas Chromatography, Butterworths, p. 30, Washington, DC, 1960.

8. McKee, H. C. and Mills, K. D., "A Comparison of Various Sources of Automotive Emissions,” Journal of Air Pollution Control Association, Vol. 13, pp. 516-522, Air Pollution Control Association, Pittsburgh, PA, 1961.

9. Jones, J. L., Schuck, E. A., Eldridge, N. E. and Cranz, F. W., "Measurement of Automobile Exhaust Gas Hydrocarbons," Journal of Air Pollution Control Association, Vol. 13, pp. 73-77, Air Pollution Control Association, Pittsburgh, PA, 1963.

10. Zafonte, L., Lapan, M. H., Usmen, R. K., Loo, J. F., Richert, J., Sherman, M. T. and Ryan, C. J., "Development of the Direct Nonmethane Hydrocarbon Measurement Technique for Vehicle Testing,” SAE Paper No. 2003-01-0390, Warrendale, PA, 2003.

11. "Protection of Environment," Code of Federal Regulations Title 40 Part 1065, Office of Federal Register National Archives and Records Administration, Washington, DC, 2006.

12. Reschke, G. D., "Optimization of a Flame Ionization Detector for Determination of Hydrocarbon in Diluted Automotive Exhausts,” SAE Paper No. 770141, Warrendale, PA, 1977.

13. Staab, J., Baronick, J. D. and Kroniesen, A., "Improving the Method of Hydrocarbon Analysis,” SAE Paper No. 810427, Warrendale, PA, 1981. 
14. Schofield, K., "Problems with Flame Ionization Detectors in Automotive Exhaust Hydrocarbon Measurements,” Environmental Science and Technology, Vol. 8, pp. 826-834, American Chemical Society, Washington, DC, 1974.

15. Sun, E., McMahon, W., Peterson, D., Wong, J. and Tsurumi, K., "Oxygen Quench Effects on Flame Ionization Detector for Hydrocarbon Emission Measurements," SAE Paper No. 2004-01-1431, Warrendale, PA, 2004.

16. Sherman, M. T., Akard, M. L. and Nakamura, H., "Flame Ionization Detector Oxygen Quench Effects on Hydrocarbon Emission Results,” SAE Paper No. 2004-01-1960, Warrendale, PA, 2004.

17. Sherman, M. T., Henney, T. J., Akard, M. L. and Lipke, W. F., “Analysis of Flame Ionization Detector Oxygen Quench Effects Using Blended Cylinders,” SAE Paper No. 2005-01-0688, Warrendale, PA, 2005.

18. Hira, H., "FIA-726 LE Investigation Under 9ml/min Sample Flowrate," Horiba Report MRP62_012, Horiba Ltd, Kyoto, Japan, 1999.

19. Welsh, R., "Gas Liquid Chromatography," Wikipedia - The Free Encyclopedia, Wikimedia Foundation, St Petersburg, Florida, 2005, http://en.wikipedia.org/wiki/Image:Gas_chromatograph.png.

20. Grob, R. L. and Barry, E. F., Modern Principles of Gas Chromatography, Fourth Edition, pp. 67-300, John Wiley and Sons, Hoboken, NJ, 2004.

21. "Methane Measurement Using Gas Chromatography," SAE Surface Vehicle Recommended Practice SAE J1151, Warrendale, PA, 1976. 


\section{APPENDICES}

Table 8-1 Tunnel Background Sample Results from SAE J1151 and WVU GC Methods

\begin{tabular}{|c|c|c|c|c|c|c|}
\hline \multirow{2}{*}{$\begin{array}{c}\text { SAMPLE } \\
\text { ID }\end{array}$} & \multicolumn{2}{|c|}{$\begin{array}{c}\text { SAE J1151 } \\
\text { Methane (ppm) }\end{array}$} & \multicolumn{2}{c|}{$\begin{array}{c}\text { WVU } \\
\text { Methane (ppm) }\end{array}$} & \multicolumn{2}{c|}{$\begin{array}{c}\text { Difference } \\
\text { (J1151-WVU) (\%) }\end{array}$} \\
\cline { 2 - 7 } & dilute & background & dilute & background & Dilute & Background \\
\hline E01898-01 & 3.10 & 2.30 & 3.015 & 2.226 & 2.75 & 3.15 \\
\hline E01898-02 & 3.04 & 2.27 & 2.867 & 2.199 & 5.63 & 3.31 \\
\hline E01898-03 & 2.30 & 2.41 & 2.224 & 2.216 & 3.48 & 8.22 \\
\hline E01898-04 & 2.28 & 2.27 & 2.168 & 2.186 & 4.83 & 3.82 \\
\hline E01898-05 & 3.21 & 2.35 & 3.050 & 2.190 & 4.85 & 6.85 \\
\hline E01899-01 & 2.55 & 2.61 & 2.398 & 2.425 & 6.10 & 7.10 \\
\hline E01899-02 & 2.44 & 2.56 & 2.236 & 2.240 & 8.54 & 12.54 \\
\hline E01899-03 & 2.31 & 2.36 & 2.043 & 2.187 & 11.50 & 7.39 \\
\hline E01899-04 & 2.28 & 2.26 & 2.062 & Rejected & 3.11 & - \\
\hline E01899-05 & 2.24 & 2.25 & 2.174 & 2.097 & 9.42 & 6.79 \\
\hline Average & $\mathbf{2 . 5 8}$ & $\mathbf{2 . 3 6}$ & $\mathbf{2 . 4 2}$ & $\mathbf{2 . 2 2}$ & $\mathbf{6 . 0 2}$ & $\mathbf{6 . 5 7}$ \\
\hline SD & $\mathbf{0 . 3 9}$ & $\mathbf{0 . 1 3}$ & $\mathbf{0 . 4 0}$ & $\mathbf{0 . 0 9}$ & $\mathbf{2 . 9 2}$ & $\mathbf{2 . 9 4}$ \\
\hline
\end{tabular}

Table 8-2 THC Results from Horiba HC Analyzer and WVU GC

\begin{tabular}{|c|c|c|c|c|c|c|}
\hline \multirow{2}{*}{$\begin{array}{c}\text { SAMPLE } \\
\text { ID }\end{array}$} & \multicolumn{2}{|c|}{ WVU THC (ppm) } & \multicolumn{2}{c|}{ Horiba THC (ppm) } & \multicolumn{2}{c|}{$\begin{array}{c}\text { Difference } \\
\text { (Horiba - WVU) (\%) }\end{array}$} \\
\cline { 2 - 7 } & Dilute & Background & Dilute & Background & Dilute & Background \\
\hline E01898-01 & 3.26 & 2.29 & 3.17 & 3.21 & -2.74 & 28.49 \\
\hline E01898-02 & 3.07 & 2.31 & 3.02 & 3.06 & -1.63 & 24.47 \\
\hline E01898-03 & 2.28 & 2.29 & 3.10 & 3.16 & 26.51 & 27.53 \\
\hline E01898-04 & 2.28 & 2.25 & 3.04 & 3.11 & 24.92 & 27.83 \\
\hline E01898-05 & 3.17 & 2.26 & 3.18 & 3.26 & 0.33 & 30.90 \\
\hline E01899-01 & 2.48 & 2.51 & 3.28 & 3.32 & 24.36 & 24.38 \\
\hline E01899-02 & 2.30 & 2.33 & 3.15 & 3.20 & 26.93 & 27.21 \\
\hline E01899-03 & 2.16 & 2.23 & 2.93 & 3.00 & 26.28 & 25.56 \\
\hline E01899-04 & 2.11 & Rejected & 2.92 & 2.94 & 27.76 & - \\
\hline E01899-05 & 2.26 & 2.17 & 2.85 & 2.84 & 20.98 & 23.53 \\
\hline Average & $\mathbf{2 . 5 4}$ & $\mathbf{2 . 2 9}$ & $\mathbf{3 . 0 6}$ & $\mathbf{3 . 1 1}$ & $\mathbf{1 7 . 3 7}$ & $\mathbf{2 6 . 6 6}$ \\
\hline SD & $\mathbf{0 . 4 5}$ & $\mathbf{0 . 0 9}$ & $\mathbf{0 . 1 4}$ & $\mathbf{0 . 1 5}$ & $\mathbf{1 3 . 0 7}$ & $\mathbf{2 . 3 7}$ \\
\hline
\end{tabular}

\footnotetext{
* Sample GC analysis results rejected due to error in analysis
} 
Table 8-3 THC Results from Horiba and CAI HFID Analyzers

\begin{tabular}{|c|c|c|c|c|c|c|}
\hline \multirow{2}{*}{ Sample ID } & \multicolumn{2}{|c|}{ Horiba THC (ppm) } & \multicolumn{2}{c|}{$\begin{array}{c}\text { CAI HFID THC } \\
\text { (ppm) }\end{array}$} & \multicolumn{2}{c|}{$\begin{array}{c}\text { Difference } \\
\text { (Horiba - CAI) (\%) }\end{array}$} \\
\cline { 2 - 7 } & Dilute & Background & Dilute & Background & Dilute & Background \\
\hline E01898-01 & 3.17 & 3.21 & 2.98 & 3.08 & 6.23 & 4.16 \\
\hline E01898-02 & 3.02 & 3.06 & 2.87 & 3.06 & 5.16 & 0.26 \\
\hline E01898-03 & 3.10 & 3.16 & 2.97 & 3.01 & 4.48 & 5.15 \\
\hline E01898-04 & 3.04 & 3.11 & 2.81 & 2.91 & 8.29 & 6.90 \\
\hline E01898-05 & 3.18 & 3.26 & 3.06 & 3.15 & 3.79 & 3.62 \\
\hline Average & $\mathbf{3 . 1 0}$ & $\mathbf{3 . 1 6}$ & $\mathbf{2 . 9 4}$ & $\mathbf{3 . 0 4}$ & $\mathbf{5 . 5 9}$ & $\mathbf{4 . 0 2}$ \\
\hline SD & $\mathbf{0 . 0 6}$ & $\mathbf{0 . 0 7}$ & $\mathbf{0 . 0 9}$ & $\mathbf{0 . 0 8}$ & $\mathbf{1 . 5 7}$ & $\mathbf{2 . 1 9}$ \\
\hline
\end{tabular}

Table 8-4 Transportable Chassis Laboratory Background Sample Methane Results from SAE J1151 and WVU GC Method

\begin{tabular}{|c|c|c|c|}
\hline $\begin{array}{c}\text { Sample } \\
\text { ID }\end{array}$ & $\begin{array}{c}\text { SAE J1151 } \\
\text { Methane } \\
(\mathbf{p p m})\end{array}$ & $\begin{array}{c}\text { WVU } \\
\text { Methane } \\
(\mathbf{p p m})\end{array}$ & $\begin{array}{c}\text { Difference } \\
\text { (WVU - J1151) } \\
(\%)\end{array}$ \\
\hline $4705-01$ & 0 & 2.14 & - \\
\hline $4723-01$ & 2.06 & 2.09 & 1.53 \\
\hline $4718-01$ & 2.09 & 2.08 & -0.70 \\
\hline $4683-01$ & 2.35 & 2.36 & 0.40 \\
\hline $4661-01$ & 2.53 & 2.58 & 2.20 \\
\hline $4682-01$ & 4.14 & 4.16 & 0.59 \\
\hline $4635-01$ & 4.41 & 4.70 & 6.22 \\
\hline $4660-01$ & 7.55 & 7.92 & 4.63 \\
\hline $4641-01$ & 7.59 & 8.17 & 7.14 \\
\hline $4712-01$ & 8.26 & 8.57 & 3.62 \\
\hline $4717-01$ & 9.59 & 10.16 & 5.62 \\
\hline
\end{tabular}


Table 8-5 Natural Gas Sample Dilute Bag Methane Results from SAE J1151 and WVU GC

\begin{tabular}{|c|c|c|c|}
\hline $\begin{array}{c}\text { Sample } \\
\text { ID }\end{array}$ & $\begin{array}{c}\text { SAE } \\
\text { J1151 } \\
\text { (ppm) }\end{array}$ & $\begin{array}{c}\text { WVU } \\
\text { Methane } \\
\text { (ppm) }\end{array}$ & $\begin{array}{c}\text { Difference } \\
\text { (WVU - } \\
\text { J1151) (\%) }\end{array}$ \\
\hline $4627-02$ & 61.13 & 65.18 & 6.64 \\
\hline $4632-01$ & 65.05 & 70.12 & 7.79 \\
\hline $4633-01$ & 78.34 & 80.86 & 3.22 \\
\hline $4638-01$ & 56.83 & 60.65 & 6.73 \\
\hline $4639-01$ & 53.15 & 57.12 & 7.46 \\
\hline $4650-01$ & 72.85 & 75.20 & 3.22 \\
\hline $4651-01$ & 76.10 & 78.43 & 3.07 \\
\hline $4653-01$ & 52.95 & 54.01 & 2.00 \\
\hline $4657-01$ & 70.78 & 74.91 & 5.84 \\
\hline $4657-02$ & 94.72 & 98.15 & 3.62 \\
\hline $4657-04$ & 80.41 & 83.67 & 4.06 \\
\hline $4658-01$ & 75.72 & 78.53 & 3.71 \\
\hline $4658-02$ & 84.54 & 87.49 & 3.49 \\
\hline $4658-03$ & 70.76 & 74.98 & 5.96 \\
\hline $4659-02$ & 68.45 & 72.05 & 5.25 \\
\hline $4662-02$ & 92.64 & 96.47 & 4.13 \\
\hline $4663-03$ & 86.63 & 92.02 & 6.23 \\
\hline $4664-01$ & 82.29 & 83.84 & 1.89 \\
\hline $4664-02$ & 80.40 & 82.70 & 2.87 \\
\hline $4667-2$ & 94.11 & 96.74 & 2.80 \\
\hline $4668-03$ & 101.54 & 104.79 & 3.21 \\
\hline $4669-01$ & 99.60 & 102.38 & 2.80 \\
\hline $4670-01$ & 97.23 & 99.85 & 2.69 \\
\hline $4671-01$ & 67.36 & 70.93 & 5.29 \\
\hline $4673-01$ & 72.10 & 74.78 & 3.72 \\
\hline $4677-02$ & 93.53 & 97.54 & 4.29 \\
\hline $4679-01$ & 19.61 & 20.79 & 6.02 \\
\hline $4680-01$ & 58.86 & 63.20 & 7.38 \\
\hline
\end{tabular}

Table 8-6 Table 8-5 Continued

\begin{tabular}{|c|c|c|c|}
\hline $\begin{array}{c}\text { Sample } \\
\text { ID }\end{array}$ & $\begin{array}{c}\text { SAE } \\
\text { J1151 } \\
\text { Methane } \\
\text { (ppm) }\end{array}$ & $\begin{array}{c}\text { WVU } \\
\text { Methane } \\
\text { (ppm) }\end{array}$ & $\begin{array}{c}\text { Difference } \\
\text { (WVU - } \\
\text { J1151) } \\
\text { (\%) }\end{array}$ \\
\hline $4684-02$ & 75.37 & 78.84 & 4.62 \\
\hline $4685-01$ & 82.33 & 84.68 & 2.86 \\
\hline $4685-02$ & 83.80 & 88.00 & 5.01 \\
\hline $4686-01$ & 70.83 & 73.75 & 4.13 \\
\hline $4688-01$ & 66.45 & 68.91 & 3.70 \\
\hline $4689-01$ & 75.99 & 79.44 & 4.55 \\
\hline $4693-02$ & 103.71 & 110.50 & 6.54 \\
\hline $4694-01$ & 88.41 & 92.12 & 4.19 \\
\hline $4699-01$ & 112.98 & 116.30 & 2.94 \\
\hline $4702-01$ & 155.76 & 159.87 & 2.64 \\
\hline $4707-01$ & 170.18 & 177.16 & 4.11 \\
\hline $4707-02$ & 141.03 & 146.65 & 3.99 \\
\hline $4710-01$ & 155.45 & 161.46 & 3.86 \\
\hline $4714-02$ & 146.25 & 151.89 & 3.86 \\
\hline $4714-03$ & 136.71 & 144.83 & 5.94 \\
\hline $4715-02$ & 132.45 & 136.96 & 3.40 \\
\hline $4716-01$ & 125.72 & 132.90 & 5.71 \\
\hline $4716-02$ & 123.69 & 133.78 & 8.16 \\
\hline $4719-03$ & 164.55 & 174.79 & 6.23 \\
\hline $4720-01$ & 140.03 & 146.39 & 4.54 \\
\hline $4720-02$ & 141.44 & 146.83 & 3.81 \\
\hline $4721-01$ & 133.45 & 140.06 & 4.95 \\
\hline $4721-02$ & 131.52 & 138.80 & 5.53 \\
\hline $4722-1$ & 13.54 & 14.52 & 7.19 \\
\hline $4726-01$ & 160.96 & 170.55 & 5.96 \\
\hline $4727-01$ & 101.81 & 131.34 & 29.01 \\
\hline $4728-01$ & 19.43 & 21.50 & 10.64 \\
\hline
\end{tabular}


Table 8-7 Natural Gas Samples THC and Methane Results from WVU GC

\begin{tabular}{|c|c|c|c|}
\hline $\begin{array}{c}\text { Sample } \\
\text { ID }\end{array}$ & $\begin{array}{c}\text { WVU } \\
\text { THC } \\
\text { (ppm) }\end{array}$ & $\begin{array}{c}\text { WVU } \\
\text { Methane } \\
\text { (ppm) }\end{array}$ & $\begin{array}{c}\text { Difference } \\
\text { (THC - } \\
\text { Methane) } \\
\text { (\%) }\end{array}$ \\
\hline $4626-01$ & 6.23 & 5.72 & 8.92 \\
\hline $4627-02$ & 68.58 & 65.18 & 5.22 \\
\hline $4631-02$ & 80.26 & 75.67 & 6.07 \\
\hline $4632-01$ & 73.05 & 70.12 & 4.18 \\
\hline $4633-01$ & 83.44 & 80.86 & 3.19 \\
\hline $4635-01$ & 5.19 & 4.70 & 10.54 \\
\hline $4638-01$ & 63.13 & 60.65 & 4.09 \\
\hline $4639-01$ & 59.54 & 57.12 & 4.23 \\
\hline $4640-01$ & 51.74 & 49.92 & 3.63 \\
\hline $4641-01$ & 8.94 & 8.17 & 9.48 \\
\hline $4649-01$ & 62.36 & 59.98 & 3.96 \\
\hline $4650-01$ & 78.41 & 75.20 & 4.28 \\
\hline $4651-01$ & 82.64 & 78.43 & 5.36 \\
\hline $4653-01$ & 55.67 & 54.01 & 3.09 \\
\hline $4654-01$ & 12.45 & 11.91 & 4.58 \\
\hline $4657-01$ & 79.68 & 74.91 & 6.38 \\
\hline $4657-02$ & 103.97 & 98.15 & 5.93 \\
\hline $4657-03$ & 100.64 & 94.78 & 6.17 \\
\hline $4657-04$ & 88.45 & 83.67 & 5.71 \\
\hline $4658-01$ & 82.72 & 78.53 & 5.34 \\
\hline $4658-02$ & 92.38 & 87.49 & 5.59 \\
\hline $4658-03$ & 79.27 & 74.98 & 5.71 \\
\hline $4659-02$ & 76.03 & 72.05 & 5.53 \\
\hline $4659-03$ & 2.46 & 2.31 & 6.52 \\
\hline $4660-01$ & 8.42 & 7.92 & 6.36 \\
\hline $4661-01$ & 3.60 & 2.58 & 39.25 \\
\hline $4662-02$ & 103.40 & 96.47 & 7.19 \\
\hline $4663-03$ & 97.98 & 92.02 & 6.47 \\
\hline $4664-01$ & 89.87 & 83.84 & 7.19 \\
\hline $4664-02$ & 87.81 & 82.70 & 6.18 \\
\hline $4665-01$ & 2.65 & 2.13 & 24.38 \\
\hline $4666-01$ & 2.94 & 2.27 & 29.79 \\
\hline $4667-02$ & 102.72 & 96.74 & 6.18 \\
\hline $4668-03$ & 111.30 & 104.79 & 6.21 \\
\hline $4669-01$ & 108.64 & 102.38 & 6.11 \\
\hline $4670-01$ & 106.90 & 99.85 & 7.06 \\
\hline $4671-01$ & 75.73 & 70.93 & 6.77 \\
\hline $4673-01$ & 79.73 & 74.78 & 6.62 \\
\hline $4674-01$ & 2.08 & 2.02 & 3.00 \\
\hline $4676-01$ & 4.31 & 2.20 & 95.62 \\
\hline $4677-02$ & 103.77 & 97.54 & 6.39 \\
\hline
\end{tabular}

Table 8-8 Table 8-7 Continued

\begin{tabular}{|c|c|c|c|}
\hline $\begin{array}{c}\text { Sample } \\
\text { ID }\end{array}$ & $\begin{array}{c}\text { WVU } \\
\text { THC } \\
\text { (ppm) }\end{array}$ & $\begin{array}{c}\text { WVU } \\
\text { Methane } \\
\text { (ppm) }\end{array}$ & $\begin{array}{c}\text { Difference } \\
\text { (THC - } \\
\text { Methane) } \\
\text { (\%) }\end{array}$ \\
\hline $4678-01$ & 23.09 & 21.51 & 7.34 \\
\hline $4679-01$ & 22.40 & 20.79 & 7.74 \\
\hline $4680-01$ & 67.52 & 63.20 & 6.83 \\
\hline $4681-01$ & 85.20 & 80.73 & 5.55 \\
\hline $4682-01$ & 4.41 & 4.16 & 6.01 \\
\hline $4683-01$ & 2.74 & 2.36 & 16.16 \\
\hline $4684-02$ & 84.32 & 78.84 & 6.94 \\
\hline $4685-01$ & 88.82 & 84.68 & 4.89 \\
\hline $4685-02$ & 92.35 & 88.00 & 4.94 \\
\hline $4686-01$ & 77.85 & 73.75 & 5.55 \\
\hline $4687-01$ & 3.30 & 3.15 & 4.69 \\
\hline $4688-01$ & 72.83 & 68.91 & 5.68 \\
\hline $4689-01$ & 83.48 & 79.44 & 5.08 \\
\hline $4690-01$ & 7.87 & 7.44 & 5.75 \\
\hline $4692-01$ & 3.94 & 3.67 & 7.41 \\
\hline $4693-02$ & 117.12 & 110.50 & 5.99 \\
\hline $4694-01$ & 96.03 & 92.12 & 4.25 \\
\hline $4695-01$ & 27.69 & 25.74 & 7.59 \\
\hline $4696-01$ & 4.02 & 3.62 & 11.18 \\
\hline $4696-01$ & 4.09 & 3.69 & 10.81 \\
\hline $4697-01$ & 6.55 & 5.38 & 21.57 \\
\hline $4698-02$ & 2.32 & 2.20 & 5.44 \\
\hline $4699-01$ & 123.81 & 116.30 & 6.46 \\
\hline $4700-01$ & 92.93 & 86.21 & 7.80 \\
\hline $4701-01$ & 123.95 & 115.89 & 6.96 \\
\hline $4702-01$ & 170.49 & 159.87 & 6.64 \\
\hline $4703-01$ & 119.00 & 110.10 & 8.08 \\
\hline $4704-01$ & 10.52 & 9.40 & 11.95 \\
\hline $4705-01$ & 2.64 & 2.14 & 23.57 \\
\hline $4706-02$ & 125.27 & 114.91 & 9.02 \\
\hline $4707-01$ & 190.85 & 177.16 & 7.72 \\
\hline $4707-02$ & 157.05 & 146.65 & 7.09 \\
\hline $4708-01$ & 105.13 & 97.02 & 8.36 \\
\hline $4709-01$ & 216.26 & 201.93 & 7.10 \\
\hline $4710-01$ & 173.42 & 161.46 & 7.41 \\
\hline $4711-01$ & 162.54 & 149.76 & 8.53 \\
\hline $4712-01$ & 9.56 & 8.57 & 11.50 \\
\hline $4713-01$ & 3.05 & 2.16 & 41.01 \\
\hline $4714-02$ & 164.81 & 151.89 & 8.51 \\
\hline
\end{tabular}


Table 8-9 Table 8-7 Continued

\begin{tabular}{|c|c|c|c|}
\hline $\begin{array}{c}\text { Sample } \\
\text { ID }\end{array}$ & $\begin{array}{l}\text { WVU } \\
\text { THC } \\
\text { (ppm) }\end{array}$ & $\begin{array}{l}\text { WVU } \\
\text { Methane } \\
\text { (ppm) }\end{array}$ & $\begin{array}{c}\text { Difference } \\
\text { (THC - } \\
\text { Methane) (\%) }\end{array}$ \\
\hline 4714-03 & 157.54 & 144.83 & 8.78 \\
\hline $4715-01$ & 143.63 & 132.54 & 8.37 \\
\hline $4715-02$ & 148.79 & 136.96 & 8.64 \\
\hline $4715-03$ & 136.58 & 125.73 & 8.63 \\
\hline $4716-01$ & 144.79 & 132.90 & 8.95 \\
\hline $4716-02$ & 145.25 & 133.78 & 8.57 \\
\hline $4717-01$ & 11.55 & 10.16 & 13.66 \\
\hline $4718-01$ & 2.77 & 2.08 & 33.32 \\
\hline $4719-02$ & 2.30 & 2.19 & 4.69 \\
\hline $4719-03$ & 188.32 & 174.79 & 7.74 \\
\hline $4720-01$ & 157.18 & 146.39 & 7.37 \\
\hline $4720-02$ & 157.72 & 146.83 & 7.42 \\
\hline $4721-01$ & 151.08 & 140.06 & 7.87 \\
\hline 4721-02 & 149.55 & 138.80 & 7.75 \\
\hline $4722-01$ & 15.57 & 14.52 & 7.28 \\
\hline $4723-01$ & 2.29 & 2.09 & 9.60 \\
\hline 4724-02 & 186.13 & 172.52 & 7.89 \\
\hline $4725-01$ & 127.47 & 118.60 & 7.48 \\
\hline $4726-01$ & 183.86 & 170.55 & 7.81 \\
\hline $4727-01$ & 141.70 & 131.34 & 7.89 \\
\hline $4728-01$ & 23.33 & 21.50 & 8.51 \\
\hline $4728-02$ & 19.41 & 17.80 & 9.04 \\
\hline $4729-01$ & 162.74 & 151.67 & 7.30 \\
\hline $4729-01$ & 162.18 & 151.12 & 7.32 \\
\hline $4730-01$ & 4.29 & 3.45 & 24.58 \\
\hline $4733-01$ & 3.82 & 3.61 & 5.61 \\
\hline 4734-01 & 2.40 & 2.11 & 13.68 \\
\hline $4735-02$ & 54.58 & 48.85 & 11.73 \\
\hline $4736-01$ & 156.82 & 145.88 & 7.50 \\
\hline $4736-02$ & 144.45 & 133.30 & 8.36 \\
\hline $4737-01$ & 103.25 & 94.79 & 8.93 \\
\hline $4737-02$ & 115.39 & 105.08 & 9.81 \\
\hline $4738-01$ & 152.09 & 140.61 & 8.17 \\
\hline $4739-01$ & 152.23 & 136.99 & 11.12 \\
\hline $4740-01$ & 210.99 & 193.70 & 8.92 \\
\hline 4741-01 & 181.64 & 168.30 & 7.93 \\
\hline $4742-01$ & 119.39 & 109.75 & 8.78 \\
\hline $4743-01$ & 4.27 & 3.95 & 8.19 \\
\hline
\end{tabular}


Table 8-10 Comparison of Projected Natural Gas THC and THC from WVU GC Method

\begin{tabular}{|c|c|c|c|c|}
\hline $\begin{array}{c}\text { Sample } \\
\text { ID }\end{array}$ & $\begin{array}{c}\text { SAE } \\
\text { J1151 } \\
\text { Methane } \\
\text { (ppm) }\end{array}$ & $\begin{array}{c}\text { Projection Factor } \\
\mathbf{X} \\
\text { (J1151 Methane }) \\
\text { (ppm) }\end{array}$ & $\begin{array}{c}\text { WVU } \\
\text { THC } \\
\text { (ppm) }\end{array}$ & $\begin{array}{c}\text { Difference } \\
\text { (WVU - J1151) } \\
\text { (\%) }\end{array}$ \\
\hline $4627-02$ & 61.13 & 68.97 & 68.58 & 0.56 \\
\hline $4632-01$ & 65.05 & 73.40 & 73.05 & 0.48 \\
\hline $4633-01$ & 78.34 & 88.39 & 83.44 & 5.93 \\
\hline $4638-01$ & 56.83 & 64.12 & 63.13 & 1.56 \\
\hline $4639-01$ & 53.15 & 59.97 & 59.54 & 0.73 \\
\hline $4650-01$ & 72.85 & 82.20 & 78.41 & 4.83 \\
\hline $4651-01$ & 76.10 & 85.86 & 82.64 & 3.90 \\
\hline $4653-01$ & 52.95 & 59.74 & 55.67 & 7.31 \\
\hline $4657-01$ & 70.78 & 79.86 & 79.68 & 0.22 \\
\hline $4657-02$ & 94.72 & 106.88 & 103.97 & 2.79 \\
\hline $4657-04$ & 80.41 & 90.72 & 88.45 & 2.57 \\
\hline $4658-01$ & 75.72 & 85.43 & 82.72 & 3.28 \\
\hline $4658-02$ & 84.54 & 95.38 & 92.38 & 3.25 \\
\hline $4658-03$ & 70.76 & 79.84 & 79.27 & 0.73 \\
\hline $4659-02$ & 68.45 & 77.24 & 76.03 & 1.59 \\
\hline $4662-02$ & 92.64 & 104.53 & 103.40 & 1.09 \\
\hline $4663-03$ & 86.63 & 97.74 & 97.98 & -0.24 \\
\hline $4664-01$ & 82.29 & 92.84 & 89.87 & 3.31 \\
\hline $4664-02$ & 80.40 & 90.71 & 87.81 & 3.30 \\
\hline $4667-2$ & 94.11 & 106.18 & 102.72 & 3.37 \\
\hline $4668-03$ & 101.54 & 114.56 & 111.30 & 2.93 \\
\hline $4669-01$ & 99.60 & 112.38 & 108.64 & 3.44 \\
\hline $4670-01$ & 97.23 & 109.70 & 106.90 & 2.63 \\
\hline $4671-01$ & 67.36 & 76.01 & 75.73 & 0.37 \\
\hline $4673-01$ & 72.10 & 81.35 & 79.73 & 2.04 \\
\hline $4677-02$ & 93.53 & 105.53 & 103.77 & 1.69 \\
\hline $4679-01$ & 19.61 & 22.13 & 22.40 & -1.22 \\
\hline $4680-01$ & 58.86 & 66.41 & 67.52 & -1.64 \\
\hline $4684-02$ & 75.37 & 85.04 & 84.32 & 0.85 \\
\hline $4685-01$ & 82.33 & 92.89 & 88.82 & 4.59 \\
\hline $4685-02$ & 83.80 & 94.55 & 92.35 & 2.39 \\
\hline $4686-01$ & 70.83 & 79.92 & 77.85 & 2.66 \\
\hline $4688-01$ & 66.45 & 74.98 & 72.83 & 2.95 \\
\hline $4689-01$ & 75.99 & 85.74 & 83.48 & 2.70 \\
\hline $4693-02$ & 103.71 & 117.02 & 117.12 & -0.08 \\
\hline $4694-01$ & 88.41 & 99.76 & 96.03 & 3.88 \\
\hline $4699-01$ & 112.98 & 127.48 & 123.81 & 2.96 \\
\hline $4702-01$ & 155.76 & 175.75 & 170.49 & 3.08 \\
\hline $4707-01$ & 170.18 & 192.01 & 190.85 & 0.61 \\
\hline
\end{tabular}


Table 8-11 Table 8-10 Continued

\begin{tabular}{|c|c|c|c|c|}
\hline $\begin{array}{c}\text { Sample } \\
\text { ID }\end{array}$ & $\begin{array}{c}\text { SAE } \\
\text { J1151 } \\
\text { Methane } \\
\text { (ppm) }\end{array}$ & $\begin{array}{c}\text { Projection Factor } \\
\mathbf{x} \\
(\mathbf{J} 1151 \text { Methane }) \\
(\mathbf{p p m})\end{array}$ & $\begin{array}{c}\text { WVU } \\
\text { THC } \\
\text { (ppm) }\end{array}$ & $\begin{array}{c}\text { (WVU -J1151) } \\
\mathbf{( \% )}\end{array}$ \\
\hline $4707-02$ & 141.03 & 159.12 & 157.05 & 1.32 \\
\hline $4710-01$ & 155.45 & 175.40 & 173.42 & 1.14 \\
\hline $4714-02$ & 146.25 & 165.01 & 164.81 & 0.12 \\
\hline $4714-03$ & 136.71 & 154.25 & 157.54 & -2.09 \\
\hline $4715-02$ & 132.45 & 149.44 & 148.79 & 0.44 \\
\hline $4716-01$ & 125.72 & 141.85 & 144.79 & -2.03 \\
\hline $4716-02$ & 123.69 & 139.56 & 145.25 & -3.91 \\
\hline $4719-03$ & 164.55 & 185.66 & 188.32 & -1.41 \\
\hline $4720-01$ & 140.03 & 157.99 & 157.18 & 0.52 \\
\hline $4720-02$ & 141.44 & 159.59 & 157.72 & 1.18 \\
\hline $4721-01$ & 133.45 & 150.57 & 151.08 & -0.33 \\
\hline $4721-02$ & 131.52 & 148.40 & 149.55 & -0.77 \\
\hline $4722-1$ & 13.54 & 15.28 & 15.57 & -1.88 \\
\hline $4726-01$ & 160.96 & 181.61 & 183.86 & -1.22 \\
\hline $4727-01$ & 101.81 & 109.38 & 141.70 & -22.81 \\
\hline $4728-01$ & 19.43 & 21.93 & 23.33 & -6.02 \\
\hline
\end{tabular}


Table 8-12 Bio-Diesel Sample Methane Results from SAE J1151 and WVU GC Methods

\begin{tabular}{|c|c|c|c|c|c|c|}
\hline \multirow{2}{*}{ Sample ID } & \multicolumn{2}{|c|}{$\begin{array}{c}\text { SAE J1151 } \\
\text { Methane (ppm) }\end{array}$} & \multicolumn{2}{c|}{$\begin{array}{c}\text { WVU } \\
\text { Methane (ppm) }\end{array}$} & \multicolumn{2}{c|}{$\begin{array}{c}\text { Difference } \\
\text { (J1151 - WVU) (\%) }\end{array}$} \\
\cline { 2 - 7 } & Dilute & Background & Dilute & Background & Dilute & Background \\
\hline E01923-02 & 1.86 & 1.97 & 1.74 & 1.82 & 6.51 & 8.26 \\
\hline E01923-03 & 1.88 & 2.01 & 1.72 & 1.91 & 9.54 & 4.85 \\
\hline E01923-04 & 1.91 & 2.02 & 1.81 & 1.94 & 5.22 & 4.29 \\
\hline E01922-04 & 1.93 & 2.03 & 1.79 & 1.92 & 8.18 & 5.64 \\
\hline E01922-03 & 1.95 & 2.04 & 1.79 & 1.91 & 8.89 & 6.78 \\
\hline E01922-05 & 1.95 & 2.06 & 1.81 & 1.91 & 7.91 & 7.81 \\
\hline E01922-02 & 1.98 & 2.13 & 1.81 & 1.92 & 9.57 & 10.94 \\
\hline
\end{tabular}


Table 8-13 Diesel Blend FTP Exhaust Sample Results from SAE J1151 GC and CAI HFID Analyzer

\begin{tabular}{|c|c|c|c|c|c|c|}
\hline \multirow{2}{*}{ Sample ID } & \multicolumn{2}{|c|}{$\begin{array}{l}\text { SAEJ1151 Methane } \\
(\mathrm{ppm})\end{array}$} & \multicolumn{2}{|c|}{$\begin{array}{l}\text { CAI HFID Methane } \\
(p p m)\end{array}$} & \multirow{2}{*}{$\begin{array}{c}\text { Brake } \\
\text { Specific THC } \\
\text { (g/bhp-hr) }\end{array}$} & \multirow{2}{*}{$\begin{array}{c}\text { Work } \\
\text { (g/bhp-hr) }\end{array}$} \\
\hline & Dilute & Background & Dilute & Background & & \\
\hline e01984-02 & 2.16 & 2.28 & 2.05 & 2.21 & 0.1149 & 25.25 \\
\hline e01984-03 & 2.17 & 2.27 & 2.04 & 2.21 & 0.111 & 25.25 \\
\hline e01984-04 & 2.22 & 2.32 & 2.09 & 2.25 & 0.108 & 25.24 \\
\hline e01986-02 & 2.09 & 2.17 & 1.92 & 2.09 & 0.0872 & 25.25 \\
\hline e01986-03 & 2.03 & 2.15 & 1.90 & 2.05 & 0.0865 & 25.26 \\
\hline e01986-04 & 1.99 & 2.11 & 1.87 & 2.02 & 0.0842 & 25.26 \\
\hline e01988-02 & 2.03 & 2.08 & 1.96 & 2.09 & 0.1139 & 25.3 \\
\hline e01988-03 & 1.97 & 2.04 & 1.89 & 2.02 & 0.1162 & 25.3 \\
\hline e01988-04 & 1.98 & 2.07 & 1.85 & 1.98 & 0.1169 & 25.3 \\
\hline e01988-05 & 1.94 & 2.05 & 1.85 & 2.01 & 0.1161 & 25.29 \\
\hline e01990-02 & 1.93 & 2.03 & 1.83 & 1.96 & 0.0966 & 25.33 \\
\hline e01990-03 & 1.96 & 2.03 & 1.82 & 1.95 & 0.0978 & 25.32 \\
\hline e01990-04 & 1.94 & 2.04 & 1.81 & 1.94 & 0.092 & 25.31 \\
\hline e01992-03 & 2.00 & 2.08 & 1.78 & 1.91 & 0.0876 & 25.32 \\
\hline e01992-04 & 1.89 & 2.04 & 1.77 & 1.9 & 0.0887 & 25.32 \\
\hline e01994-02 & 1.97 & 2.01 & 1.82 & 1.95 & 0.0899 & 25.32 \\
\hline e01994-03 & 2.01 & 2.09 & 1.83 & 1.97 & 0.0909 & 25.31 \\
\hline e01994-04 & 1.97 & 2.09 & 1.84 & 1.98 & 0.0879 & 25.31 \\
\hline e01996-02 & 2.02 & 2.08 & 2.00 & 2.15 & 0.0887 & 25.27 \\
\hline e01996-03 & 2.01 & 2.13 & 1.91 & 2.06 & 0.0875 & 25.29 \\
\hline e01996-04 & 2.01 & 2.09 & 1.90 & 2.04 & 0.0889 & 25.29 \\
\hline e01998-02 & 2.01 & 2.12 & 1.92 & 2.07 & 0.0816 & 25.28 \\
\hline e01998-03 & 2.11 & 2.13 & 1.95 & 2.11 & 0.0764 & 25.27 \\
\hline e01998-04 & 2.05 & 2.15 & 1.93 & 2.09 & 0.0807 & 25.29 \\
\hline e02000-02 & 1.99 & 2.10 & 1.89 & 2.05 & 0.0758 & 25.28 \\
\hline e02000-03 & 2.05 & 2.14 & 1.89 & 2.05 & 0.0757 & 25.27 \\
\hline e02000-04 & 1.97 & 2.03 & 1.86 & 2 & 0.0768 & 25.27 \\
\hline e02002-02 & 1.93 & 2.03 & 1.84 & 1.97 & 0.0988 & 25.31 \\
\hline e02002-03 & 1.91 & 1.99 & 1.82 & 1.95 & 0.0998 & 25.32 \\
\hline e02002-04 & 1.93 & 2.01 & 1.82 & 1.94 & 0.0981 & 25.31 \\
\hline e02004-02 & 2.17 & 2.24 & 2.09 & 2.26 & 0.073 & 25.29 \\
\hline e02004-03 & 2.06 & 2.27 & 2.01 & 2.18 & 0.0683 & 25.3 \\
\hline e02004-04 & 2.11 & 2.17 & 1.96 & 2.12 & 0.0679 & 25.28 \\
\hline e02006-02 & 1.92 & 2.04 & 1.81 & 1.96 & 0.0697 & 25.27 \\
\hline e02006-03 & 1.95 & 2.06 & 1.81 & 1.95 & 0.0699 & 25.28 \\
\hline e02006-04 & 2.04 & 2.21 & 1.93 & 2.09 & 0.0684 & 25.28 \\
\hline
\end{tabular}


Table 8-14 Diesel Blend FTP Exhaust Sample Brake Specific Methane and NMHC from SAE J1151 GC and CAI HFID Analyzer

\begin{tabular}{|c|c|c|c|c|c|c|}
\hline Sample ID & $\begin{array}{l}\text { GC Brake } \\
\text { Specific } \\
\text { Methane } \\
\text { (g/bhp-hr) }\end{array}$ & $\begin{array}{l}\text { CAI Brake } \\
\text { Specific } \\
\text { Methane } \\
\text { (g/bhp-hr) }\end{array}$ & $\begin{array}{c}\text { GC Brake } \\
\text { Specific } \\
\text { NMHC } \\
\text { (g/bhp-hr) }\end{array}$ & $\begin{array}{c}\text { CAI Brake } \\
\text { Specific } \\
\text { NMHC } \\
\text { (g/bhp-hr) }\end{array}$ & $\begin{array}{l}\text { Brake Specific } \\
\text { Methane } \\
\text { Difference } \\
\text { (CAI - GC) (\%) }\end{array}$ & $\begin{array}{c}\text { Brake Specific } \\
\text { NMHC } \\
\text { Difference } \\
\text { (CAI - GC) (\%) }\end{array}$ \\
\hline e01984-02 & $-7.17 \mathrm{E}-05$ & $-1.44 \mathrm{E}-03$ & 0.1150 & 0.1163 & 1907.53 & 1.19 \\
\hline e01984-03 & 3.56E-04 & $-1.79 \mathrm{E}-03$ & 0.1106 & 0.1128 & 402.08 & 1.94 \\
\hline e01984-04 & $4.68 \mathrm{E}-04$ & $-1.50 \mathrm{E}-03$ & 0.1075 & 0.1095 & 219.86 & 1.83 \\
\hline e01986-02 & $8.11 E-04$ & $-1.85 \mathrm{E}-03$ & 0.0864 & 0.0890 & 127.78 & 3.08 \\
\hline e01986-03 & $-3.85 E-04$ & $-1.43 \mathrm{E}-03$ & 0.0869 & 0.0879 & 272.14 & 1.21 \\
\hline e01986-04 & $-5.40 \mathrm{E}-04$ & $-1.53 \mathrm{E}-03$ & 0.0847 & 0.0857 & 183.73 & 1.17 \\
\hline e01988-02 & $1.55 \mathrm{E}-03$ & $-6.44 \mathrm{E}-04$ & 0.1124 & 0.1145 & -58.31 & 1.95 \\
\hline e01988-03 & $9.74 \mathrm{E}-04$ & $-7.68 \mathrm{E}-04$ & 0.1152 & 0.1170 & -21.18 & 1.51 \\
\hline e01988-04 & 5.60E-04 & $-8.83 \mathrm{E}-04$ & 0.1163 & 0.1178 & 57.66 & 1.24 \\
\hline e01988-05 & $-1.90 \mathrm{E}-04$ & $-1.69 \mathrm{E}-03$ & 0.1163 & 0.1178 & 788.34 & 1.29 \\
\hline e01990-02 & $6.47 \mathrm{E}-05$ & $-9.98 E-04$ & 0.0965 & 0.0976 & 1444.31 & 1.10 \\
\hline e01990-03 & 8.09E-04 & $-8.96 \mathrm{E}-04$ & 0.0970 & 0.0987 & 10.80 & 1.76 \\
\hline e01990-04 & 3.50E-05 & $-9.80 \mathrm{E}-04$ & 0.0920 & 0.0930 & 2701.81 & 1.10 \\
\hline e01992-03 & 5.90E-04 & $-1.03 E-03$ & 0.0870 & 0.0886 & 74.42 & 1.86 \\
\hline e01992-04 & $-1.33 E-03$ & $-1.16 \mathrm{E}-03$ & 0.0900 & 0.0899 & -12.85 & -0.19 \\
\hline e01994-02 & $1.59 \mathrm{E}-03$ & $-1.09 \mathrm{E}-03$ & 0.0883 & 0.0910 & -31.90 & 3.04 \\
\hline e01994-03 & $7.73 \mathrm{E}-04$ & $-1.14 \mathrm{E}-03$ & 0.0901 & 0.0920 & 47.80 & 2.13 \\
\hline e01994-04 & $-5.02 E-04$ & $-1.22 \mathrm{E}-03$ & 0.0884 & 0.0891 & 142.10 & 0.81 \\
\hline e01996-02 & $1.45 E-03$ & $-1.32 \mathrm{E}-03$ & 0.0872 & 0.0900 & -8.82 & 3.18 \\
\hline e01996-03 & $-6.61 E-04$ & $-1.41 \mathrm{E}-03$ & 0.0882 & 0.0889 & 113.33 & 0.85 \\
\hline e01996-04 & 8.26E-04 & $-1.26 \mathrm{E}-03$ & 0.0881 & 0.0902 & 52.81 & 2.37 \\
\hline e01998-02 & $-1.66 \mathrm{E}-04$ & $-1.48 \mathrm{E}-03$ & 0.0818 & 0.0831 & 788.20 & 1.60 \\
\hline e01998-03 & 2.41E-03 & $-1.69 \mathrm{E}-03$ & 0.0740 & 0.0781 & -29.98 & 5.53 \\
\hline e01998-04 & 2.09E-04 & $-1.71 \mathrm{E}-03$ & 0.0805 & 0.0824 & 717.25 & 2.38 \\
\hline e02000-02 & $-3.64 \mathrm{E}-04$ & $-1.74 \mathrm{E}-03$ & 0.0762 & 0.0775 & 378.11 & 1.81 \\
\hline e02000-03 & 3.18E-04 & $-1.71 \mathrm{E}-03$ & 0.0754 & 0.0774 & 437.88 & 2.69 \\
\hline e02000-04 & 1.06E-03 & $-1.19 \mathrm{E}-03$ & 0.0757 & 0.0780 & 12.78 & 2.97 \\
\hline e02002-02 & $-4.61 E-05$ & $-1.09 \mathrm{E}-03$ & 0.0988 & 0.0999 & 2254.83 & 1.05 \\
\hline e02002-03 & 6.38E-04 & $-1.08 \mathrm{E}-03$ & 0.0992 & 0.1009 & 69.82 & 1.74 \\
\hline e02002-04 & 7.07E-04 & $-8.08 \mathrm{E}-04$ & 0.0974 & 0.0989 & 14.18 & 1.56 \\
\hline e02004-02 & $1.26 \mathrm{E}-03$ & $-1.72 \mathrm{E}-03$ & 0.0717 & 0.0747 & 36.94 & 4.15 \\
\hline e02004-03 & $-2.76 \mathrm{E}-03$ & $-1.83 \mathrm{E}-03$ & 0.0711 & 0.0701 & -33.81 & -1.31 \\
\hline e02004-04 & $1.26 \mathrm{E}-03$ & $-1.70 \mathrm{E}-03$ & 0.0666 & 0.0696 & 35.00 & 4.45 \\
\hline e02006-02 & $-6.95 E-04$ & $-1.60 \mathrm{E}-03$ & 0.0704 & 0.0713 & 130.10 & 1.28 \\
\hline e02006-03 & -7.86E-05 & $-1.35 \mathrm{E}-03$ & 0.0700 & 0.0713 & 1623.31 & 1.82 \\
\hline e02006-04 & $-1.70 \mathrm{E}-03$ & $-1.70 \mathrm{E}-03$ & 0.0701 & 0.0701 & 0.11 & 0.00 \\
\hline Average & - & - & - & - & - & 1.84 \\
\hline SD & & - & - & - & - & 1.28 \\
\hline
\end{tabular}


Table 8-15 Diesel Blend FTP Exhaust Sample (Test 2) Results from SAE J1151 GC and CAI HFID Analyzer

\begin{tabular}{|c|c|c|c|c|c|c|}
\hline \multirow{2}{*}{ Sample ID } & \multicolumn{2}{|c|}{$\begin{array}{c}\text { SAE J151 Methane } \\
\text { (ppm) }\end{array}$} & \multicolumn{2}{c|}{$\begin{array}{c}\text { CAI HFID Methane } \\
\text { (ppm) }\end{array}$} & $\begin{array}{c}\text { Work } \\
\text { (g/bhp-hr) }\end{array}$ & $\begin{array}{c}\text { Brake Specific } \\
\text { THC (g/bhp-hr) }\end{array}$ \\
\cline { 2 - 7 } & Dilute & Background & Dilute & Background & \\
\hline E02118-01 & 2.44 & 2.56 & 2.55 & 2.72 & 24.92 & 0.1405 \\
\hline E02118-02 & 2.43 & 2.51 & 2.42 & 2.6 & 24.94 & 0.0942 \\
\hline E02120-02 & 2.22 & 2.37 & 2.26 & 2.41 & 24.94 & 0.0859 \\
\hline E02120-03 & 2.14 & 2.31 & 2.16 & 2.3 & 24.95 & 0.0806 \\
\hline E02120-04 & 2.11 & 2.22 & 2.12 & 2.26 & 24.92 & 0.0828 \\
\hline E02121-02 & 2.12 & 2.20 & 2.17 & 2.32 & 24.96 & 0.0968 \\
\hline E02121-03 & 2.15 & 2.20 & 2.18 & 2.33 & 24.95 & 0.0959 \\
\hline E02121-04 & 2.15 & 2.27 & 2.17 & 2.31 & 24.93 & 0.0964 \\
\hline E02122-01 & 2.07 & 2.19 & 2.19 & 2.37 & 24.95 & 0.0828 \\
\hline E02122-02 & 2.08 & 2.18 & 2.12 & 2.27 & 24.96 & 0.0847 \\
\hline E02122-03 & 2.09 & 2.24 & 2.41 & 2.67 & 24.94 & 0.0767 \\
\hline E02124-01 & 2.13 & 2.26 & 2.14 & 2.3 & 25.01 & 0.0868 \\
\hline E02124-02 & 2.07 & 2.18 & 2.09 & 2.24 & 25.01 & 0.0801 \\
\hline E02125-03 & 2.18 & 2.28 & 2.11 & 2.26 & 24.98 & 0.0953 \\
\hline E02126-01 & 2.19 & 2.28 & 2.18 & 2.32 & 24.96 & 0.1025 \\
\hline E02126-02 & 2.14 & 2.22 & 2.10 & 2.24 & 24.96 & 0.0997 \\
\hline E02127-01 & 2.11 & 2.21 & 2.08 & 2.23 & 25.00 & 0.0828 \\
\hline E02127-02 & 2.17 & 2.27 & 2.10 & 2.26 & 24.97 & 0.0838 \\
\hline
\end{tabular}


Table 8-16 Diesel Blend FTP Exhaust Sample (Test 2) Brake Specific Methane and NMHC from SAE J1151 and CAI HFID Analyzer

\begin{tabular}{|c|c|c|c|c|c|c|}
\hline Sample ID & $\begin{array}{c}\text { GC Brake } \\
\text { Specific } \\
\text { Methane } \\
\text { (g/bhp-hr) }\end{array}$ & $\begin{array}{c}\text { CAI Brake } \\
\text { Specific } \\
\text { Methane } \\
\text { (g/bhp-hr) }\end{array}$ & $\begin{array}{c}\text { GC Brake } \\
\text { Specific } \\
\text { NMHC } \\
\text { (g/bhp-hr) }\end{array}$ & $\begin{array}{c}\text { CAI Brake } \\
\text { Specific } \\
\text { NMHC } \\
\text { (g/bhp-hr) }\end{array}$ & \multicolumn{2}{|c|}{$\begin{array}{c}\text { Difference Brake } \\
\text { specific NMHC } \\
\text { (CAI - GC) (\%) }\end{array}$} \\
\hline E02118-01 & $3.82 E-04$ & $-9.82 E-04$ & 0.1401 & 0.1415 & 156.98 & 0.97 \\
\hline E02118-02 & $1.59 E-03$ & $-1.42 E-03$ & 0.0926 & 0.0956 & -10.16 & 3.25 \\
\hline E02120-02 & $-9.84 E-04$ & $-8.72 E-04$ & 0.0869 & 0.0868 & -11.33 & -0.13 \\
\hline E02120-03 & $-1.74 E-03$ & $-7.14 \mathrm{E}-04$ & 0.0823 & 0.0813 & -58.88 & -1.24 \\
\hline E02120-04 & $-2.95 E-04$ & $-7.51 \mathrm{E}-04$ & 0.0831 & 0.0836 & 154.63 & 0.55 \\
\hline E02121-02 & $1.09 E-03$ & $-1.09 E-03$ & 0.0957 & 0.0979 & -0.07 & 2.28 \\
\hline E02121-03 & $1.68 E-03$ & $-9.17 \mathrm{E}-04$ & 0.0942 & 0.0968 & -45.36 & 2.75 \\
\hline E02121-04 & $-9.23 \mathrm{E}-06$ & $-8.67 \mathrm{E}-04$ & 0.0964 & 0.0973 & 9291.62 & 0.89 \\
\hline E02122-01 & $-3.96 \mathrm{E}-04$ & $-1.88 \mathrm{E}-03$ & 0.0832 & 0.0847 & 374.41 & 1.78 \\
\hline E02122-02 & $2.47 \mathrm{E}-04$ & $-1.02 \mathrm{E}-03$ & 0.0845 & 0.0857 & 313.83 & 1.50 \\
\hline E02122-03 & $-8.82 \mathrm{E}-04$ & $-3.90 \mathrm{E}-03$ & 0.0776 & 0.0806 & 342.13 & 3.89 \\
\hline E02124-01 & $-5.85 \mathrm{E}-04$ & $-1.27 \mathrm{E}-03$ & 0.0874 & 0.0881 & 117.40 & 0.79 \\
\hline E02124-02 & $-9.47 \mathrm{E}-05$ & $-1.19 \mathrm{E}-03$ & 0.0802 & 0.0813 & 1159.26 & 1.37 \\
\hline E02125-03 & $4.16 \mathrm{E}-04$ & $-9.44 \mathrm{E}-04$ & 0.0949 & 0.0962 & 127.02 & 1.43 \\
\hline E02126-01 & $6.47 \mathrm{E}-04$ & $-8.18 \mathrm{E}-04$ & 0.1019 & 0.1033 & 26.52 & 1.44 \\
\hline E02126-02 & $9.91 \mathrm{E}-04$ & $-8.23 \mathrm{E}-04$ & 0.0987 & 0.1005 & -17.00 & 1.84 \\
\hline E02127-01 & $1.22 \mathrm{E}-04$ & $-1.17 \mathrm{E}-03$ & 0.0827 & 0.0840 & 865.04 & 1.57 \\
\hline E02127-02 & $4.30 \mathrm{E}-04$ & $-1.44 \mathrm{E}-03$ & 0.0834 & 0.0852 & 233.74 & 2.24 \\
\hline Average & - & - & - & - & - & 1.51 \\
\hline SD & - & - & - & - & - & 1.15 \\
\hline
\end{tabular}


Table 8-17 Day to Day Variation in Methane Results from SAE J1151 GC for Diesel Blend FTP Exhaust Sample

\begin{tabular}{|c|c|c|c|c|c|c|c|c|c|c|c|c|c|c|}
\hline \multirow[t]{2}{*}{ SAMPLE \# } & \multicolumn{2}{|c|}{$\begin{array}{l}\text { SAE J1151 Methane } \\
\text { - First Analysis } \\
\text { (ppm) }\end{array}$} & \multicolumn{2}{|c|}{$\begin{array}{l}\text { SAE J1151 Methane } \\
\text { DAY } 1(\mathrm{ppm})\end{array}$} & \multicolumn{2}{|c|}{$\begin{array}{l}\text { SAE J1151 Methane } \\
\text { DAY } 2(\mathrm{ppm})\end{array}$} & \multicolumn{2}{|c|}{$\begin{array}{l}\text { SAE J1151 Methane } \\
\text { DAY } 3 \text { (ppm) }\end{array}$} & \multicolumn{3}{|c|}{$\begin{array}{l}\text { Dilute Bag Differece } \\
\text { (Day 1,2,3 - First } \\
\text { Analysis ) (\%) }\end{array}$} & \multicolumn{3}{|c|}{$\begin{array}{c}\text { Background Bag } \\
\text { Difference (Day } \\
\text { 1,2,3 - First } \\
\text { Analysis) (\%) } \\
\end{array}$} \\
\hline & Dilute & Background & Dilute & Background & Dilute & Background & Dilute & Background & $\begin{array}{c}\text { Day } \\
1\end{array}$ & Day 2 & $\begin{array}{c}\text { Day } \\
\mathbf{3}\end{array}$ & Day1 & $\begin{array}{c}\text { Day } \\
2\end{array}$ & $\begin{array}{c}\text { Day } \\
3\end{array}$ \\
\hline E02118-01 & 2.44 & 2.55 & 2.43 & 2.53 & 2.42 & 2.57 & 2.43 & 2.54 & -0.09 & -0.57 & -0.42 & -0.85 & 1.00 & -0.17 \\
\hline E02122-01 & 2.07 & 2.19 & 2.08 & 2.19 & 2.08 & 2.21 & 2.02 & 2.20 & 0.83 & 0.58 & -2.09 & 0.17 & 0.94 & 0.73 \\
\hline E02122-03 & 2.09 & 2.41 & 2.09 & 2.27 & 2.08 & 2.17 & 2.10 & 2.23 & -0.24 & -0.61 & 0.26 & -5.70 & -9.83 & -7.07 \\
\hline E02125-03 & 2.18 & 2.11 & 2.16 & 2.25 & 2.12 & 2.28 & 2.17 & 2.28 & -0.79 & -2.38 & -0.50 & 6.30 & 7.80 & 7.98 \\
\hline E02126-02 & 2.14 & 2.10 & 2.08 & 2.23 & 2.12 & 2.19 & 2.15 & 2.24 & -2.72 & -1.07 & 0.38 & 6.47 & 4.55 & 6.78 \\
\hline E02127-02 & 2.17 & 2.10 & 2.20 & 2.28 & 2.12 & 2.26 & 2.08 & 2.28 & 1.39 & -2.35 & -4.13 & 8.49 & 7.59 & 8.90 \\
\hline Maximum & - & - & - & - & - & - & - & - & 1.39 & 0.58 & 0.38 & 8.49 & 7.80 & 8.90 \\
\hline Minimum & - & - & - & - & - & - & - & - & -2.72 & -2.38 & -4.13 & -5.70 & -9.83 & -7.07 \\
\hline
\end{tabular}

Table 8-18 Day to Day Variation in Bag Integrated Concentrations from Horiba THC Analyzer for Tunnel Background Samples

\begin{tabular}{|c|c|c|c|c|c|c|c|c|}
\hline \multirow{2}{*}{ Run \# } & \multicolumn{2}{|l|}{ Horiba THC - Day $\mathbf{1}(\mathbf{p p m})$} & \multicolumn{2}{l|}{ Horiba THC - Day $\mathbf{2}(\mathbf{p p m})$} & \multicolumn{2}{l|}{ Horiba THC - Day 3 (ppm) } & \multicolumn{2}{l|}{ Horiba THC - Day 4 (ppm) } \\
\cline { 2 - 10 } & Dilute & Background & Dilute & Background & Dilute & Background & \multirow{2}{*}{ Dilute } & Background \\
\hline 1 & 2.6558 & 2.6374 & 5.6885 & 2.8307 & 3.9218 & 3.3009 & 2.8653 & 3.3268 \\
\hline 2 & 2.6558 & 2.6374 & 4.4022 & 2.8873 & 3.7514 & 2.8892 & 2.8765 & 2.9407 \\
\hline 3 & 2.6082 & 2.6554 & 4.2258 & 2.7221 & 3.7972 & 2.8056 & 2.8571 & 2.8739 \\
\hline 4 & 2.5975 & 2.6611 & Not Taken & Not Taken & 3.8466 & 2.8939 & -0.0015 & 2.8581 \\
\hline 5 & Not Taken & Not Taken & Not Taken & Not Taken & 3.8865 & 2.8355 & 2.8093 & 3.1721 \\
\hline MEAN & $\mathbf{2 . 6 3}$ & $\mathbf{2 . 6 5}$ & $\mathbf{4 . 7 7}$ & $\mathbf{2 . 8 1}$ & $\mathbf{3 . 8 3}$ & $\mathbf{2 . 9 7}$ & $\mathbf{2 . 1 5}$ & $\mathbf{3 . 0 0}$ \\
\hline SD & $\mathbf{0 . 0 3 1}$ & $\mathbf{0 . 0 1 2}$ & $\mathbf{0 . 7 9 8}$ & $\mathbf{0 . 0 8 4}$ & $\mathbf{0 . 0 7 3}$ & $\mathbf{0 . 2 2 3}$ & $\mathbf{1 . 4 3 4}$ & $\mathbf{0 . 2 2 1}$ \\
\hline COV (\%) & $\mathbf{1 . 1 7}$ & $\mathbf{0 . 4 6}$ & $\mathbf{1 6 . 7 3}$ & $\mathbf{2 . 9 8}$ & $\mathbf{1 . 9 0}$ & $\mathbf{7 . 4 9}$ & $\mathbf{6 6 . 7 1}$ & $\mathbf{7 . 3 6}$ \\
\hline
\end{tabular}


Table 8-19 Day to Day Variation in Bag Integrated Methane Results from CAI HFID Analyzer for Tunnel Background Samples

\begin{tabular}{|c|c|c|c|c|c|c|c|c|}
\hline \multirow{2}{*}{ Run \# } & \multicolumn{2}{|c|}{$\begin{array}{c}\text { CAI Methane - Day } 1 \\
(\text { ppm) }\end{array}$} & \multicolumn{2}{|c|}{$\begin{array}{c}\text { CAI Methane - Day } 2 \\
(p p m)\end{array}$} & \multicolumn{2}{|c|}{$\begin{array}{c}\text { CAI Methane - Day } 3 \\
(\text { ppm) }\end{array}$} & \multicolumn{2}{|c|}{$\begin{array}{c}\text { CAI Methane - Day } 4 \\
\text { (ppm) }\end{array}$} \\
\hline & Dilute & Background & Dilute & Background & Dilute & Background & Dilute & Background \\
\hline 1 & 1.9754 & 1.9967 & 1.8433 & 1.9095 & 1.9963 & 1.9729 & 2.0101 & 2.0337 \\
\hline 2 & 1.9754 & 1.9967 & 1.9006 & 1.9361 & 2.0262 & 1.9829 & 1.9666 & 1.9836 \\
\hline 3 & 1.9358 & 1.9751 & 1.9123 & 1.9233 & 1.9840 & 1.9740 & 1.9858 & 1.9797 \\
\hline 4 & 1.9168 & Not Taken* & $\begin{array}{c}\text { Not } \\
\text { Taken }\end{array}$ & Not Taken & 2.0135 & 1.9741 & 1.9196 & 1.9538 \\
\hline 5 & $\begin{array}{l}\text { Not } \\
\text { Taken }\end{array}$ & Not Taken & $\begin{array}{l}\text { Not } \\
\text { Taken }\end{array}$ & Not Taken & 2.0026 & 1.9738 & 1.9699 & 1.9679 \\
\hline MEAN & 1.95 & 1.99 & 1.89 & 1.92 & 2.00 & 1.98 & 1.97 & 1.99 \\
\hline SD & 0.029 & 0.012 & 0.037 & 0.013 & 0.019 & 0.005 & 0.038 & 0.033 \\
\hline $\begin{array}{l}\text { COV } \\
(\%)\end{array}$ & 1.51 & 0.63 & 1.96 & 0.69 & 0.93 & 0.24 & 1.95 & 1.68 \\
\hline
\end{tabular}

\footnotetext{
* Enough sample not available to collect bag integration data.
} 